\title{
DEVELOPMENT AND IDENTIFICATION OF CANDIDATE APTAMERS FOR GROWTH DIFFERENTIATION FACTOR 9
}

\section{Orin Lee Robb}

A thesis submitted to the Victoria University of Wellington in partial fulfilment of the requirements for the degree of Masters in Cell and Molecular Bioscience

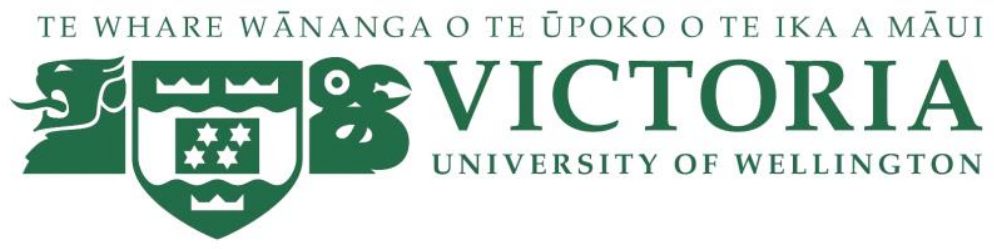

Victoria University of Wellington

Te Whare Wānanga o Te Ūpoko o Te Ika a Māui

2018 


\section{ABSTRACT}

Bone morphogenetic protein 15 (BMP15) and growth differentiation factor 9 (GDF9) are oocyte-secreted growth factors that are essential for fertility and ovarian development in many mammalian species. It is hypothesised that the ratios of these growth factors within ovarian follicles are unique to each species and determine litter size in mammals. The current detection method for these proteins is by Western blotting with monoclonal antibodies, however this methodology generates semi-quantitative results at best.

Systematic evolution via exponential enrichment (SELEX) is a method involving iterative rounds of affinity maturation. It has been used for generating synthetic DNA- and RNAbased sequences (aptamers) that are capable of recognising a target molecule with high sensitivity. To understand more about the biological functions of BMP15 and GDF9, reliable detection methods need to be developed so these proteins can be measured in biological samples. The generation of aptamers that recognise BMP15 and GDF9 of multiple species could enable a novel detection system to be developed to further explore the role of BMP15 and GDF9 in determining litter size in mammals.

In this study, recombinant BMP15 and GDF9 proteins from species that vary in litter size were produced and purified by IMAC and HPLC for aptamer validation. MembraneSELEX was used to generate candidate aptamers against recombinant human GDF9. After ten rounds of SELEX, seven candidate aptamers were identified and sequenced. Alignment of the sequences revealed a conserved region of $29 \mathrm{bp}$ in four of the seven candidate aptamers. These sequences also showed a high (85-90\%) guanine/thymine content consistent with G-quadruplex forming aptamers, a tertiary structure that increases specificity to the target molecule. These four sequences also showed homology with that of a previously published aptamer for BMP15. This is interesting as BMP15 and GDF9 are both members of the transforming growth factor beta superfamily and as such, share a high peptide homology suggesting convergent evolution occurred in two unrelated SELEX experiments against related proteins.

Whilst time constraints did not allow for characterisation of the resultant GDF9 aptamer candidates, nor their validation using recombinant ovine and mouse GDF9 produced herein, this study showed that GDF9 aptamer candidates were generated by SELEX that exhibited sequence similarities to an aptamer generated against a structurally-related protein. 


\section{AKNOWLEDGEMENTS}

Firstly, I would like to thank my co-supervisor's Dr Janet Pitman and Dr Shalen Kumar. Janet was the first staff member I spoke to when I was considering undertaking postgraduate research, she was very supportive and offered me several projects in which I found a place with her and, the newly-founded, AuramerBio team led by Shalen Kumar. Combined, both Janet and Shalen have counselled and supported me above and beyond what is required of them. I am equally proud and grateful for the opportunities provided to me through their expertise and kindness. Thank you.

Secondly, I would like to thank the extended network of staff and students within the School of Biological Sciences for assisting me in all matters. Within the Faculty of Science, Patricia Stein who has facilitated my MSc completion. Within AuramerBio, Dr Shiwei Li has always been there to answer questions and help me experimentally. Within the staff, Dr Derek Heath was of notable mention as my cell-culture mentor. Derek also was of great assistance with Western blotting and protein purification. Also, Sarah Sczelecki for her continual assistance with both laboratory, operational and scientific support. Within the laboratory; Abdul, Matire, Zak, William and Hamish for experimental help and the rest of the Reproductive and AuramerBio lab group for general support and friendship. Additionally, Dr Valérie Guieu and Université Grenoble Alpes for accommodating me during my research in France. Thank you all.

Additionally, I would like to acknowledge the funding provided from Royal Society of NZ Marsden Fund (VUW1301).

Lastly, I would like to thank my friends and family who have endured my struggles and supported my academic endeavours throughout the previous 6 years. You have helped me to develop myself during an important period of my life. To my girlfriend, Nina, for your unwavering support and help in accomplishing this milestone. To my family; Nona, Clive, Helen, Brian, Paul, Venice, Quinn, Blaze and Tai. This thesis is dedicated to you. 


\section{TABLE OF CONTENTS}

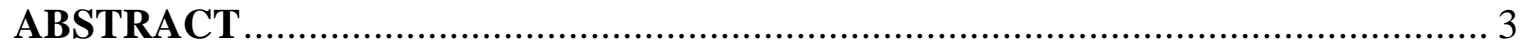

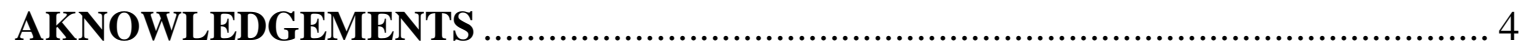

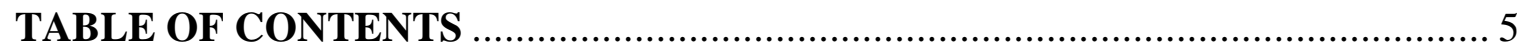

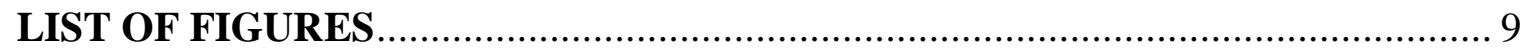

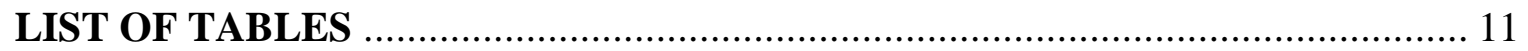

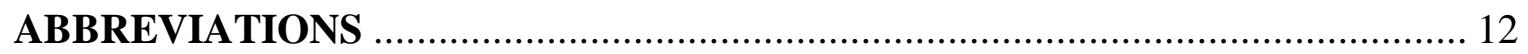

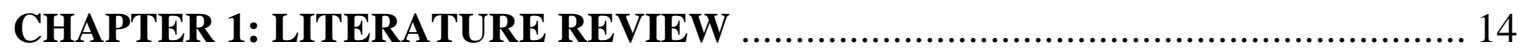

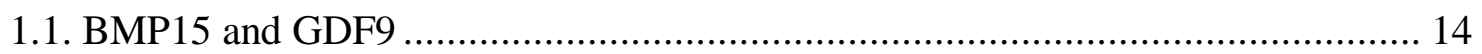

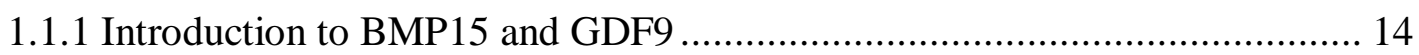

1.1.2 Effect of BMP15 and GDF9 mutations on fertility ............................... 14

1.1.3 Effect of immunisation against BMP15 and GDF9 ............................... 15

1.1.4 BMP15 and GDF9 structural characterisation .................................... 16

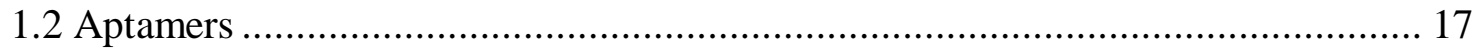

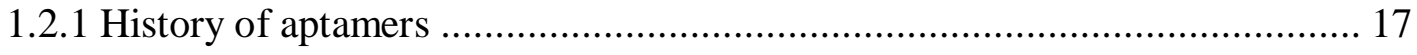

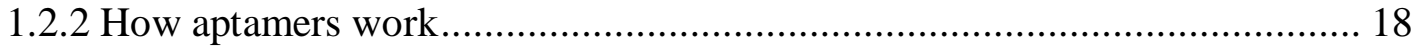

1.2.3 Systematic evolution of ligands by exponential enrichment ...................... 19

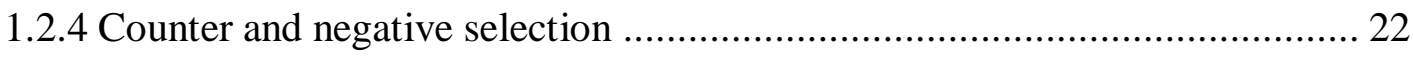

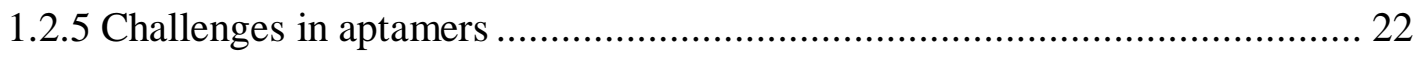

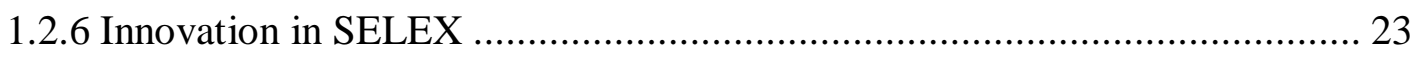

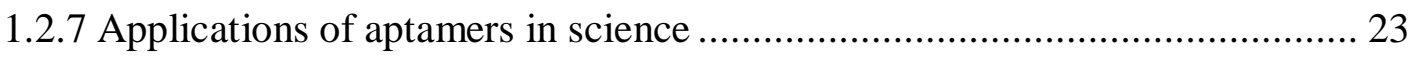

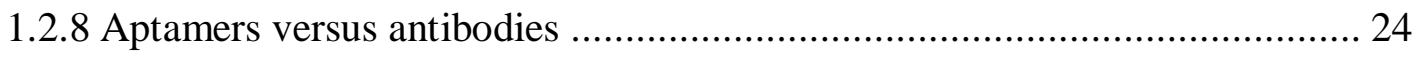

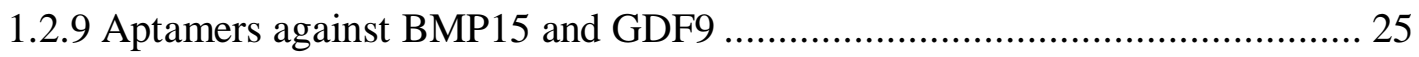

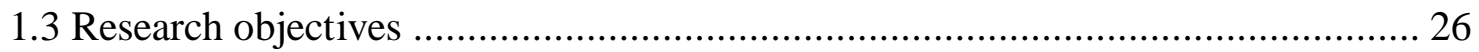

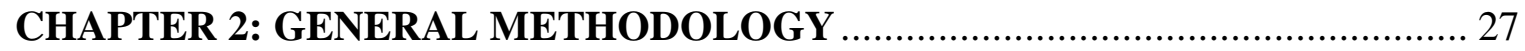

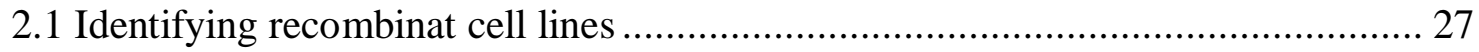

2.2 Production of recombinant proteins by modified HEK293 cells .......................... 28

2.3 Harvesting of recombinant proteins secreted by modified HEK293 cells............. 28

2.4 Purification of EM by immobilised metal ion affinity chromatography ............... 28

2.5 High performance liquid chromatrography of IMAC purified EM....................... 29 
2.6 Preparation of sodium dodecyl sulfate polyacrylamide gel (SDS-PAGE) for protein analysis

2.7 SDS-PAGE electrophoresis of EM, IMAC and HPLC purified protein samples....30

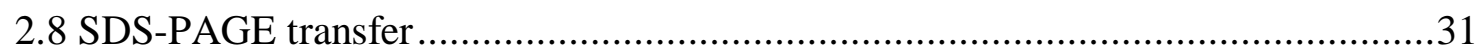

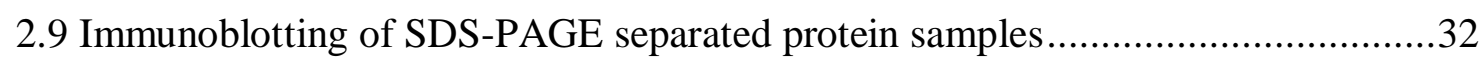

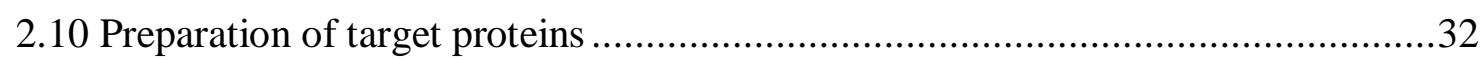

2.11 Preparation of nitrocellulose membrane-protein matrix .................................33

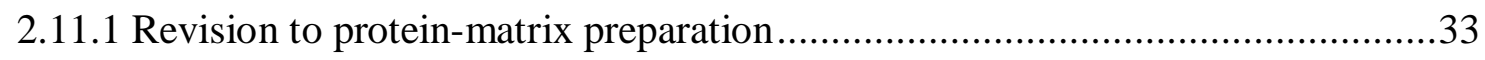

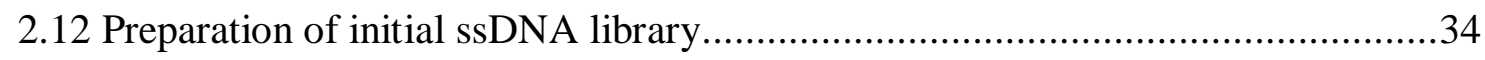

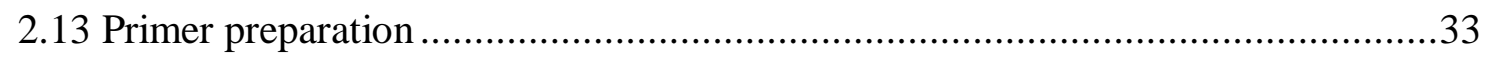

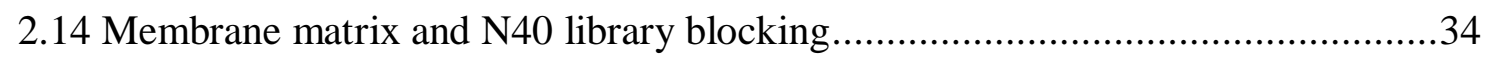

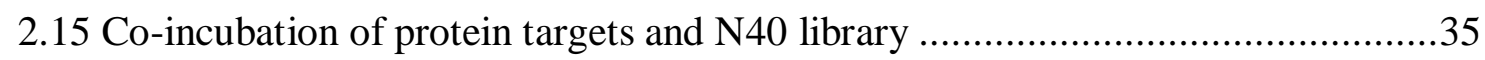

2.16 Washing of membrane-protein matrix following co-incubation..........................35

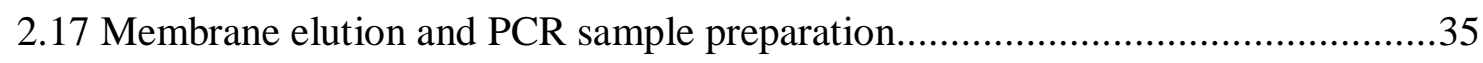

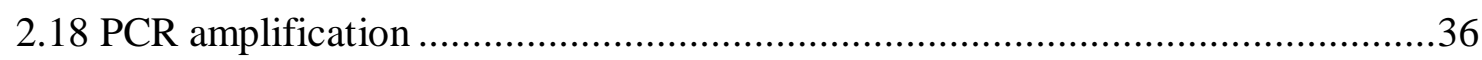

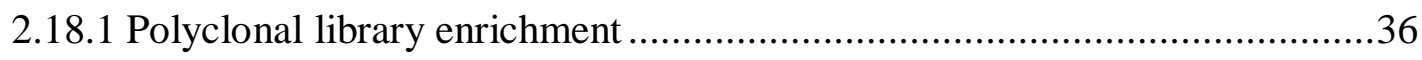

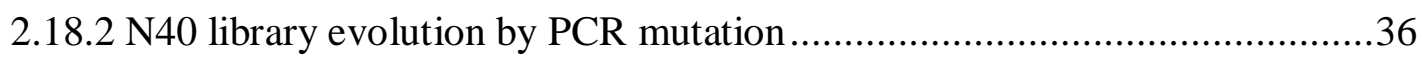

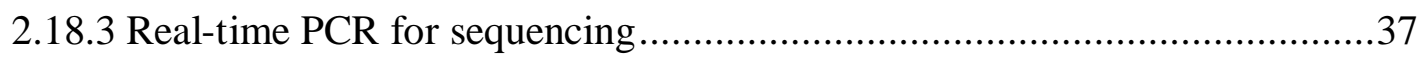

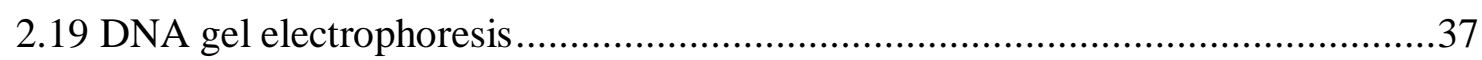

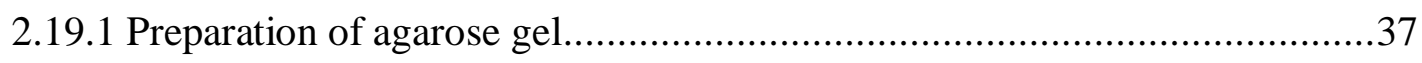

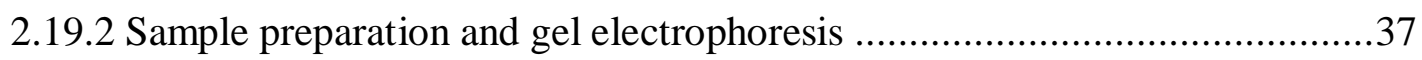

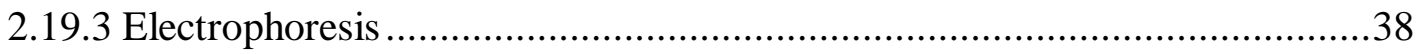

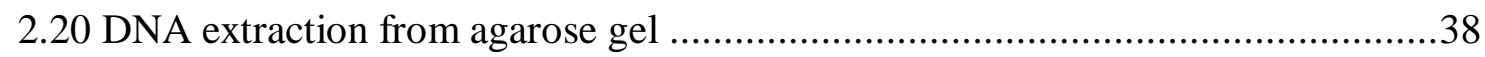

2.21 Generation of ssDNA for SELEX co-incubation via alkaline denaturation ..........39

2.22 Cloning and sequencing of N40 library from final SELEX round.......................39

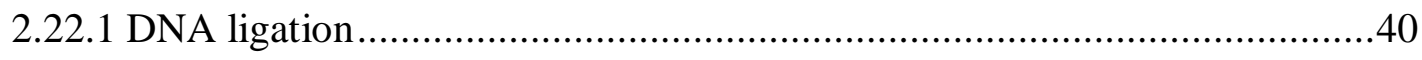

2.22.2 Transformation of ligated DNA .........................................................40

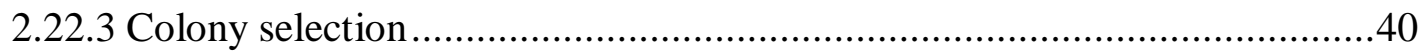

2.22.4 Isolation of plasmid DNA ...............................................................

2.22.5 Confirmation of ligation ….............................................................

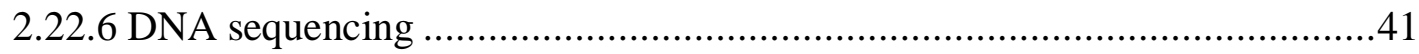

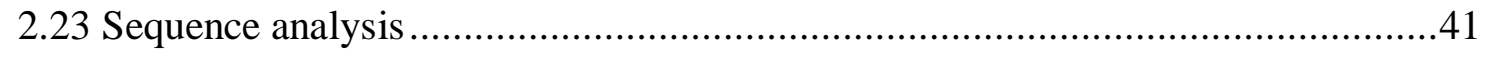


2.23.1 DNA and protein alignment 42

2.23.2 Generation of a phylogenetic tree. 42

2.23.3 Two-dimensional (2D) structure predictions 42

CHAPTER 3: RESULTS

3.1 Protein expression of recombinant ovine and murine BMP15 and GDF9 from modified HEK293 cell lines.

3.1.1 Ovine and murine BMP15 expression media.

3.1.2 Ovine and murine GDF9 expression media 44

3.2 Ion metal affinity chromatography purification of recombinant ovine and murine BMP15 and GDF9 from modified HEK293 cell lines

3.2.1 Ovine and murine BMP15 IMAC-purified expression media 45

3.2.2 Ovine and murine GDF9 IMAC-purified expression media 46

3.3 High performance liquid chromatography purification of IMAC purified recombinant BMP15 and GDF9 expression media

3.3.1 HPLC-purified murine GDF9 IMAC eluates. 49

3.3.2 HPLC-purification of ovine GDF9 IMAC eluates 50

3.4 Selection of aptamers for human recombinant GDF9 50

3.4.1 PCR products from all selection rounds and the generation of multiple sized PCR products from a $75 \mathrm{bp}$ template 52

3.4.2 Selection round 10 showing specificity for target over control membrane .... 52

3.4.3 DNA sequencing of multiple sized products 55

3.5 Nucleotide conservation of the random region of TGF- $\beta$ selected aptamers 56

3.6 Composition and two-dimensional structure predictions of candidate GDF9 aptamers

CHAPTER 4: DISCUSSION 60

4.1 General discussion 60

4.2 Initial design for generating recombinant BMP15 and GDF9 as aptamer targets .. 60

4.3 Characterisation of recombinant murine and ovine BMP15 and GDF9 ............... 61

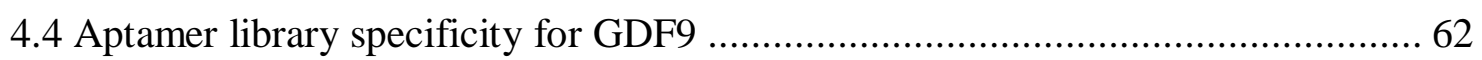

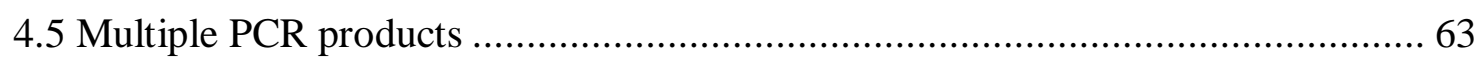

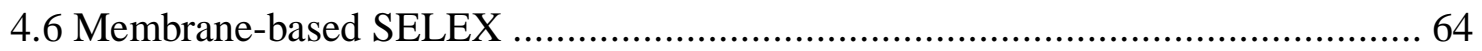

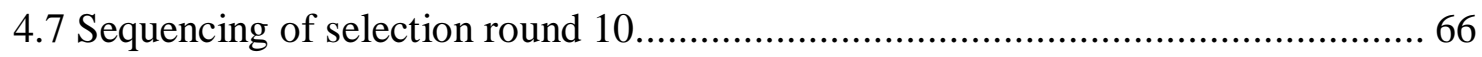


4.8 Candidate GDF9 aptamer homology and 29bp conserved region

4.9 Homology of GDF9 candidate aptamers with a previously characterised BMP15

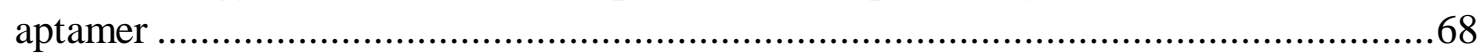

4.10 Predicted secondary structures of GDF9 candidate aptamers ..........................69

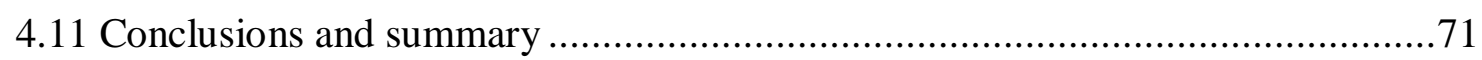

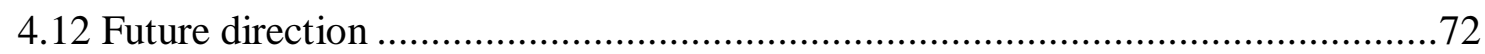

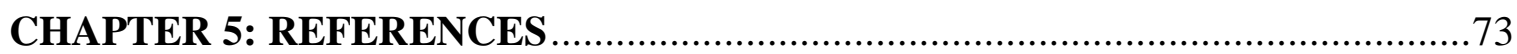

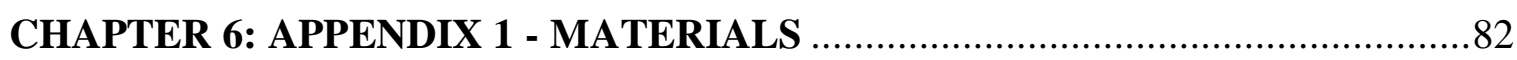

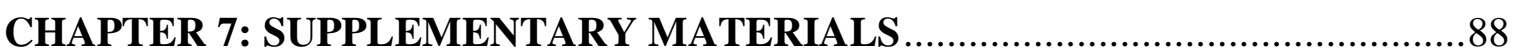




\section{LIST OF FIGURES}

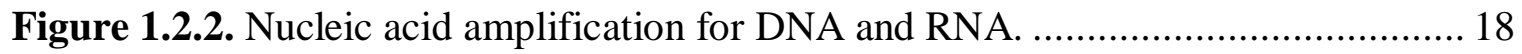

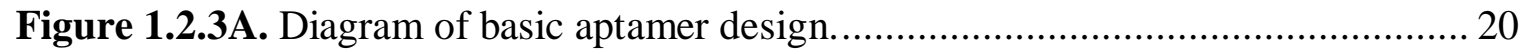

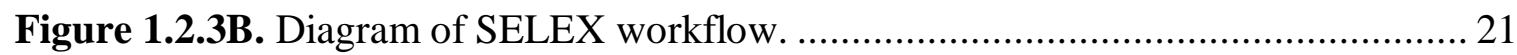

Figure 2.8. SDS-PAGE Transfer cassette assembly................................................ 31

Figure 3.1A. RecBMP15 protein expression test from HEK293 EM. ........................... 43

Figure 3.1B. RecGDF9 protein expression test from HEK293 EM............................. 44

Figure 3.2A. Purification of recmBMP15 HEK293 EM............................................ 45

Figure 3.2B. IMAC purification of recoBMP15 HEK293 EM. .................................... 46

Figure 3.2C. IMAC purification of recmGDF9 protein from HEK293 EM. .................. 47

Figure 3.2D. IMAC purification of recoGDF9 protein from HEK293 EM. .................. 48

Figure 3.3A. HPLC purification of recmGDF9 protein from IMAC purified EM.......... 49

Figure 3.3B. HPLC purification of recoGDF9 protein from IMAC purified EM. .......... 50

Figure 3.4A. Summary of post-PCR SELEX products following each co-incubation. ... 52

Figure 3.4B. PCR products following co-incubation of SR10 ................................ 53

Figure 3.4C. Mean densitometry measurements of SR10 PCR products. ..................... 54

Figure 3.4D. Real-time PCR products following co-incubation of SR 10 ...................... 54

Figure 3.4E. Mean densitometry measurements of SR10 real-time PCR products......... 55

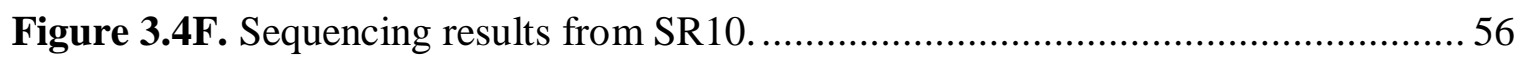

Figure 3.4G. Phylogenetic tree of full-length 75bp sequences from sequencing. ........... 56

Figure 3.5. Alignment of GDF9 selected sequences with conserved region against

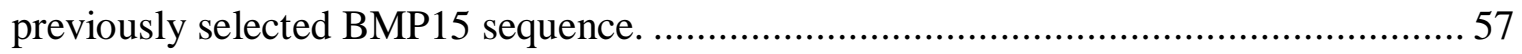

Supplementary Figure 1. Additional sequencing results from SR10 ....................... 88

Supplementary Figure 3. 2D structure predictions of BMP15 aptamer at $23^{\circ} \mathrm{C}$ (Lin et al., 2015).

Supplementary Figure 2. 2D structure predictions of BMP15 aptamer at $4^{\circ} \mathrm{C}$ (Lin et al., 2015)

Supplementary Figure 4. 2D structure predictions of GDF9-01 aptamer at $4{ }^{\circ} \mathrm{C} \ldots \ldots \ldots . . . .91$

Supplementary Figure 5. 2D structure predictions of GDF9-01 aptamer at $23^{\circ} \mathrm{C} \ldots \ldots . . .91$

Supplementary Figure 6. 2D structure predictions of GDF9-02 aptamer at $4{ }^{\circ} \mathrm{C} \ldots \ldots \ldots . . .92$

Supplementary Figure 7. 2D structure predictions of GDF9-02 aptamer at $23^{\circ} \mathrm{C} \ldots \ldots . . .92$

Supplementary Figure 8. 2D structure predictions of GDF9-03 aptamer at $4{ }^{\circ} \mathrm{C} \ldots \ldots \ldots . . .93$

Supplementary Figure 9. 2D structure predictions of GDF9-03 aptamer at $23^{\circ} \mathrm{C} \ldots \ldots . . .93$ 
Supplementary Figure 10. 2D structure predictions of GDF9-04 aptamer at $4^{\circ} \mathrm{C} \ldots \ldots \ldots .94$

Supplementary Figure 11. 2D structure predictions of GDF9-04 aptamer at $23^{\circ} \mathrm{C} \ldots \ldots .94$

Supplementary Figure 12. 2D structure predictions of GDF9-05 aptamer at $4{ }^{\circ} \mathrm{C} \ldots \ldots . .95$

Supplementary Figure 13. 2D structure predictions of GDF9-05 aptamer at $23^{\circ} \mathrm{C} \ldots \ldots .95$

Supplementary Figure 14. 2D structure predictions of GDF9-06 aptamer at $4^{\circ} \mathrm{C} \ldots \ldots . . .96$

Supplementary Figure 15. 2D structure predictions of GDF9-06 aptamer at $23^{\circ} \mathrm{C} \ldots \ldots .96$

Supplementary Figure 16. 2D structure predictions of GDF9-07 aptamer at $4{ }^{\circ} \mathrm{C} \ldots \ldots . . .97$

Supplementary Figure 17. 2D structure predictions of GDF9-07 aptamer at $23^{\circ} \mathrm{C} \ldots \ldots .97$

Supplementary Figure 18. Agar plated DH5- $\alpha$ cells for colony selection. ................... 98

Supplementary Figure 19. Restriction digest of SR10 plasmid miniprep samples....... 99 


\section{LIST OF TABLES}

Table 1.2.8. Comparative properties of aptamers and antibodies. ................................ 24

Table 2.6. Separating and Stacking gel recipes for SDS-PAGE experiments. ................ 30

Table 3.4. Summary of SELEX conditions used for each selection round....................... 51

Table 3.6. Nucleotide analysis and predicted Gibb's free energy calculation of secondary

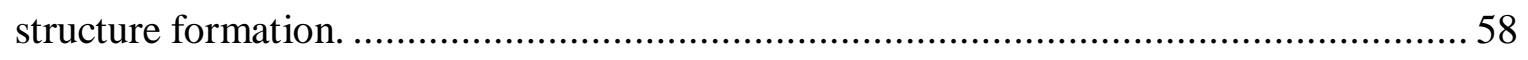

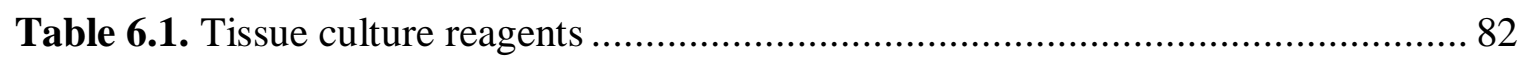

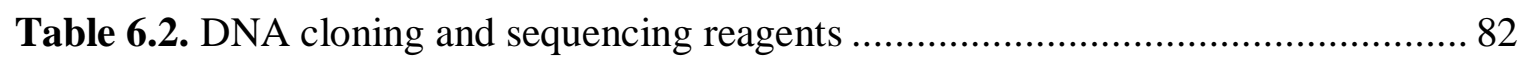

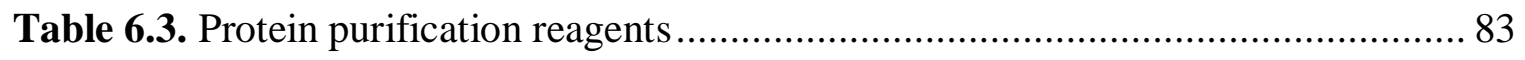

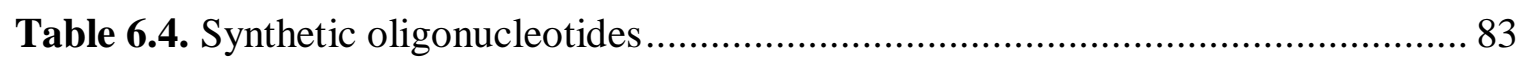

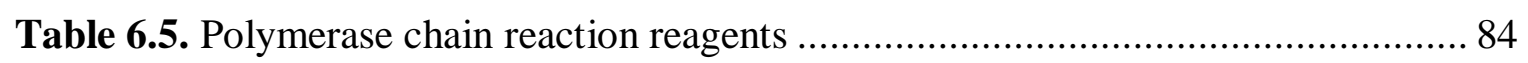

Table 6.6. Gel electrophoresis, gel extraction and strand separation reagents ................ 84

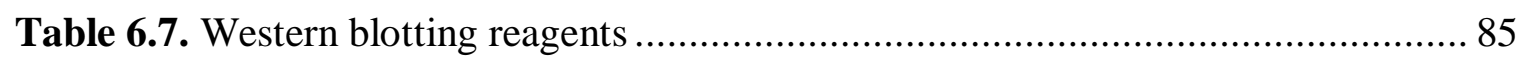

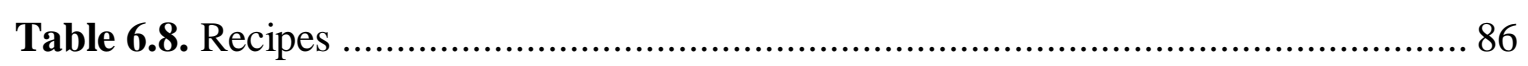

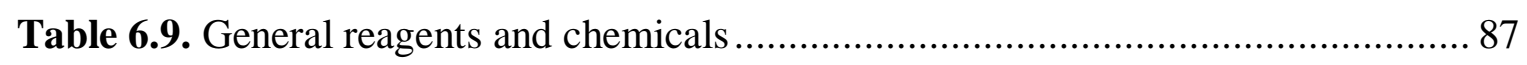

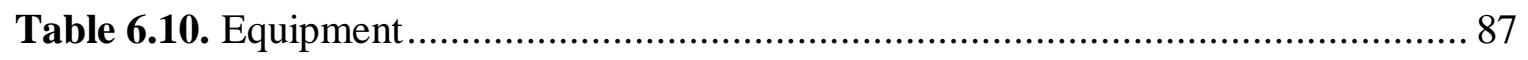

Supplementary Table 1. Nucleotide analysis and predicted Gibb's free energy

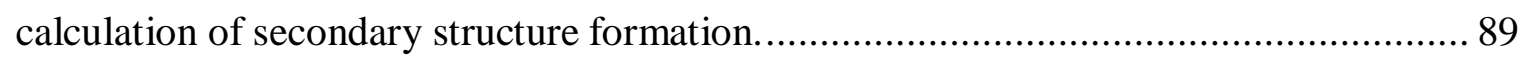

Supplementary Table 3. Step-by-step IMAC protocol with Buffers........................... 100

Supplementary Table 2. ACN concentration gradients over time for HPLC. ............. 100 


\section{ABBREVIATIONS}

2D

3D

A

aa

$\mathrm{ACN}$

BMP

BMP15

bp

BWB

C

cDNA

dATP

dCTP

dGTP

dNTP

dTTP

DMEM

DNA

dsDNA

EM

ERK 1/2

FDA

FSH

G

GC (Content)

GC

GDF

GDF9

HEK293

His
Two-dimensional

Three-dimensional

Adenosine

Amino acid

Acetonitrile

Bone morphogenetic protein

Bone morphogenetic protein 15

Base pair

Binding and washing buffer

Cytosine

Complementary DNA

Deoxyadenosine 5'-triphosphate

Deoxycytidine 5'-triphosphate

Deoxyguanine 5'-triphosphate

Deoxynucleotide 5'-triphosphate

Deoxythymidine 5'-triphosphate

Dulbecco’s Modified Eagle Medium

Deoxyribose nucleic acid

Double-stranded deoxyribose nucleic acid

Expression medium

extracellular signal-regulated kinases $1 / 2$

Food and Drug Administration

Follicle stimulating hormone

Guanine

Guanine/Cytosine

Granulosa cell

Growth differentiation factor

Growth differentiation factor 9

Human Embryonic Kidney 293 cell/s

Histidine 
His-tag 6x histidine tag

HPLC High performance liquid chromatography

IMAC Ion metal affinity chromatography

$\mathrm{kDa} \quad$ Kilodalton

$\mathrm{Kd}$

Dissociation constant

LB

Luria broth

MAPK

Mitogen-activated protein kinases

N40

Initial library/randomised library/starting library

o/o BMP15

Ovine/ovine BMP15 mature-dimer (Heath et al., 2017)

PCR

Polymerase chain reaction

Pf

Forward primer

$\operatorname{PrB}$

Reverse primer (Biotnylated)

RNA

Ribonucleic acid

SELEX

Systematic evolution of ligands by exponential enrichment

SDS-PAGE

sodium dodecyl sulfate - Polyacrylamide gel electrophoresis

SMAD

Small Mothers Against Decapentaplegic

SMB

Streptavidin magnetic bead

SR

Selection round

ssDNA

Single-stranded deoxyribose nucleic acid

Strep-HRP

Streptavidin - Horse radish peroxidase

$\mathrm{T}$

Thymine

TFA

Triflouroacetic acid

TGF- $\beta$

Transforming growth factor - beta

tRNA

Transfer ribonucleic acid

$\mathrm{v} / \mathrm{v}$

Volume per volume

$\mathrm{w} / \mathrm{v}$

Weight per volume 


\section{CHAPTER 1: LITERATURE REVIEW}

\subsection{BMP15 AND GDF9}

\subsubsection{INTRODUCTION TO BMP15 AND GDF9}

There was a long-held understanding that follicular growth in mammals was regulated wholly by the endocrine signalling pathway that exists between the pituitary gland and the ovary. It was not until 1970, that a role of the oocyte in this process was demonstrated, when the earliest research investigating the functional activity of the oocyte on their surrounding follicular cells was conducted. The study reported that ovectomy of mature follicles of rabbits resulted in spontaneous luteinisation and degradation of neighbouring granulosa cells (GC) (El-Fouly et al, 1970). The oocyte is now known to play an integral role in follicular development. Previous studies have identified an interaction between oocyte-derived growth factors and GC proliferation rate in rats, sheep and humans (McNatty et al., 2005; Huang et al., 2009; Otsuka et al., 2001). Specifically, the role of oocyte-derived bone morphogenetic protein-15 (BMP15) and growth differentiation factor9 (GDF9), have been assessed in vivo using sheep with natural mutations and mouse knockout models. These members of the transforming growth factor-beta (TGF- $\beta$ ) superfamily, have also been shown to act at the level of receptor as homodimers and heterodimers to regulate GC proliferation and differentiation in vitro (McNatty et al., 2005; Otsuka et al., 2001; Moore et al., 2003; Heath et al., 2017).

\subsubsection{EFFECT OF BMP15 AND GDF9 MUTATIONS ON FERTILITY}

The discovery of natural mutations in both BMP15 and GDF9 genes in sheep emphasised the importance of these growth factors on follicular development. The study of Belcare and Cambridge sheep utilised genotype analysis of both BMP15 (X chromosome) and GDF9 (chromosome 5) genes and observed associations in resulting fertility phenotypes (Hanrahan et al., 2004). Sheep that carried two copies of either BMP15 or GDF9 genes with an inactivating mutation resulted in sterility, whereas sheep that carried a single mutated allele for BMP15 or GDF9 showed an increased ovulation rate (Galloway et al., 2000, Hanrahan et al., 2004). This research demonstrated the critical role of BMP15 and GDF9 in follicular development by showing developmental arrest to occur at the primary follicle growth stage for both BMP15 or GDF9 homozygous mutant ewes and ewes immunised against BMP15 or GDF9. 
Similar to the studies conducted in sheep, a knockout-mouse model revealed some contrasting evidence to the sheep models which provided useful insight into how BMP15 and GDF9 differentially regulates ovulation in various species. A study conducted by Yan et al., 2001, utilised a Bmp15 null-mutant $\left(\left(^{--}\right)\right.$, heterozygous Bmp15 mutant $\left(\left(^{-/}\right)\right.$, Gdf9 nullmutant $\left({ }^{--}\right)$and heterozygous $G d f 9$ mutant $\left({ }^{-/+}\right)$mice to investigate gene dosage effects on follicular growth and fertility. Reduced levels of BMP15 in the Bmp15 $5^{-/+}$mice appeared to have no effect on fertility whereas reduced levels of GDF9 in the $G d f 9^{-/+}$genotype resulted in an increased ovulation rate in mice. Similar to that observed in sheep, follicular development was unable to progress past the primary follicle stage in $G d f 9^{-1-}$ mice (Dong

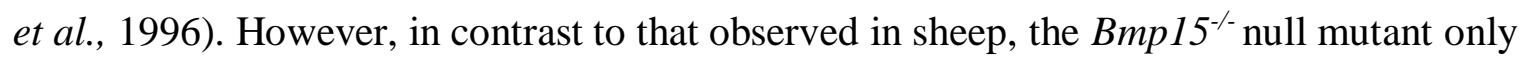
showed a partial reduction in fertility and was still otherwise considered fertile. Moreover, the combination of the $B m p 15^{-/}$and $G d f 9^{-/+}$genotypes resulted in early oocyte loss, formation of ovarian cysts and impaired cumulus cell expansion in mice (Yan et al., 2001; Su et al., 2004). Since these studies, it has been shown that the levels of BMP15 in rodents are much lower than that of humans (Hashimoto et al., 2005), sheep (Lin et al., 2012), pigs and red deer (Swinerd, 2016). This could possibility account for the differences observed in the BMP15 genotype/phenotype associations for poly-ovulatory mice and monoovulatory mammals (Hashimoto et al., 2005).

These results demonstrated that GDF9 has a functional effect on fertility in all species tested, whereas unlike non-rodent species, the role of BMP15 appears negligible but still necessary for normal fertility in mice (Yan et al., 2001; Su et al., 2004). Furthermore, the data from the $G d f 9^{-/+} / \mathrm{Bmp}^{-1} 5^{-}$mice supports the notion that BMP15 and GDF9 may somehow interact in a way that affects fertility, perhaps through the formation of a functional dimer at the level of the receptor (Otsuka et al., 2001; McNatty et al., 2005; Heath et al., 2017). Given the results from these genetic studies, it seems likely that the poly-ovulatory nature of mice and the low-ovulatory nature of sheep is an important difference to consider when we assess the biological function of BMP15 on ovulation-rate and fertility.

\subsubsection{EFFECT OF IMMUNISATION AGAINST BMP15 AND GDF9}

Research investigating the effects of immunising sheep against regions of both BMP15 and GDF9 peptides has delivered more evidence about the critical function of normal levels of BMP15 and GDF9 in folliculogenesis and puts forward the idea of vaccine-based therapies 
to induce either anovulation or an increased ovulation rate (Juengel et al., 2004; McNatty et al., 2007; Juengel et al., 2013). It was shown that a short-term immunisation against BMP15 or GDF9 resulted in an increased ovulation rate (Juengel et al., 2004), consistent with the phenotype observed in mutant ewes heterozygous for BMP15 or GDF9. Whereas a long-term immunisation protocol involving a primary immunisation followed by multiple booster immunisations against either BMP15 or GDF9 commonly resulted in anovulation (McNatty et al., 2007), similar with that observed in homozygous BMP15 or GDF9 mutant ewes. It also showed that immunisation against peptides corresponding to specific regions at the $\mathrm{N}$-terminus of the mature region was variable but generally more effective at producing an-ovulatory effects compared to other regions (McNatty et al., 2007). Consistent with the knockout mice models used to investigate the correlation between genetic dosage of BMP15 and GDF9 on fertility (Yan et al., 2001; Su et al., 2004), immunisation against BMP15 and GDF9 was also performed in mice. Mice immunised against the pro-region of BMP15 demonstrated decreased fertility, consistent with the $B m p 15^{-/}$and Bmp 15 ${ }^{-/+}$genotypes previously described (Yan et al., 2001; McIntosh et al., 2012).

\subsubsection{BMP15 AND GDF9 STRUCTURAL CHARACTERISATION}

The TGF- $\beta$ superfamily is comprised of over 30 structurally-similar, yet functionally diverse, proteins (Massagué J., 1998; Massagué et al., 2012). For simplicity, we can categorise the majority of the individual molecules into four subfamilies; activins/inhibins, TGF- $\beta$ molecules, nodals, bone morphogenetic proteins (BMPs) and growth differentiation factors (GDFs). The latter group constitute approximately half of the members of the TGF$\beta$ superfamily (Mueller \& Nickel., 2012). One characteristic of many TGF- $\beta$ family molecules is the ability to form dimeric, and in particular heterodimeric, structures via what is known as the cysteine-knot region common to most TGF- $\beta$ family molecules (Mueller \& Nickel., 2012; Monestier et al., 2014). It's the combinatorial nature of these TGF- $\beta$ monomers that gives rise to a multitude of cellular responses (Shi et al., 2003; Schmierer \& Hill 2007).

Characterisation of BMP15 shows a high structural and sequence homology to GDF9. The sequence of BMP15 was first described (Dube et al., 1998) as a 392-amino acid (aa) prepropeptide that consisted of three regions and two major subunits, the pre-region signal peptide, the pro-region and mature protein. The mouse and human orthologues of the 125- 
aa BMP15 mature protein were shown to have approximately $70 \%$ sequence homology (Dube et al., 1998). More recently, complete BMP15 and GDF9 gene sequencing of 24 different mammalian species was conducted, and the species were split into two groups classified as either mono- or poly-ovulating species. Many conserved regions exist for both mono- and poly-ovulating species, especially in the cysteine knot region, however fewer mutations were observed for mono-ovulating species, compared to poly-ovulating species (Monestier et al., 2014). This study gives evidence supporting the potential differences in BMP15 and GDF9 function between sheep and mice, which was previously discussed to explain contrasting results in the gene knockout and natural mutation models. As previously mentioned, high sequence homology was noted in the cysteine knot region (Monestier et al., 2014), this region is specifically conserved between species and ovulatory types because it is required for characteristic TGF- $\beta$ family functional dimerisation. Both mouse and human BMP15 showed identical point mutations to the fourth of the seven conserved cysteine residues within the mature protein (Dube et al., 1998). Since the identification and sequencing of human and mouse BMP15, it has been shown that despite lacking a conserved cysteine required for covalent bonding, BMP15 and GDF9 proteins could form non-covalent homo- and hetero-dimers between both the mature and pro-regions at the receptor level in vitro (Liao et al., 2003; McIntosh et al., 2008). This supports the previous notion of a potential biologically-active dimer and interaction between these two TGF- $\beta$ molecules in the mouse double knockout model that results in severe loss of fertility (Yan et al., 2001). It should be noted that these heterodimers have not yet been shown to exist in a free state (i.e. not bound to the receptor).

\subsection{APTAMERS}

\subsubsection{HISTORY OF APTAMERS}

In 1990, two laboratories independently reported a method for generating RNA molecules capable of binding to a specific target (Ellington and Szostak; Tuerk \& Gold, 1990). In August of 1990, Tuerk and Gold published the first experiments in this field, describing the isolation of two RNA molecules capable of binding to T4 DNA polymerase from a starting pool of more than 65,000 random sequences. Ellington and Sozstak's paper was published just three weeks later, reporting similar methods of identifying RNA "aptamers" that were capable of binding to various organic dyes. Thereafter in 1990, Blackwell and Weintraub also published a paper describing the Selection and amplification binding method, the first 
reported method capable of identifying specific DNA “oligomers" binding to MyoD and E2A proteins from an initial random library (Blackwell \& Weintraub, 1990). However, it was Ellington and Sozstak who coined the popular term 'aptamer' from the Latin word 'aptus' meaning 'to fit' and the Greek suffix 'mer' representing the polymer. More than two decades later, the term 'aptamer' is now widely accepted to refer to an oligonucleotide derived ligand that can specifically bind to a target molecule via the formation of three dimensional (3D) structures ( Song et al., 2012; Reverdatto et al., 2015). More specifically, linear single-stranded deoxyribose-nucleic acid (ssDNA) and ribonucleic acid (RNA) sequences are the most common type of aptamers. However, short poly-peptides that are specifically designed to bind to target molecules are also known as aptamers or 'peptide aptamers' (Reverdatto et al., 2015). The term 'target' is also universally considered to be any molecule that an aptamer is designed to bind to or interact with. So far in literature, aptamers have been generated against a diverse range of target molecules such as proteins (Lin and McNatty, 2009; Lin et al., 2015; Mondal et al., 2015), amino acids (Famulok, 1994), small molecules (Stojanovic et al., 2001), toxins (Cruz-Aguado \& Penner, 2008), viruses (Tang et al., 2009; Yamamoto et al., 2000) and whole cells including; bacteria (Bruno \& Kiel, 1999; Duan et al., 2012; Hamula et al., 2008), fungi (Low et al., 2009) and cancer cells (Chu et al., 2006; Lupold et al., 2002).

\subsubsection{HOW APTAMERS WORK}

Double-stranded DNA (dsDNA) is considered stable and resistant to degradation under buffering conditions. However, because aptamers are single-stranded nucleic acids, they are considered structurally unstable and prone to degradation by nucleases (Tsui et al.,

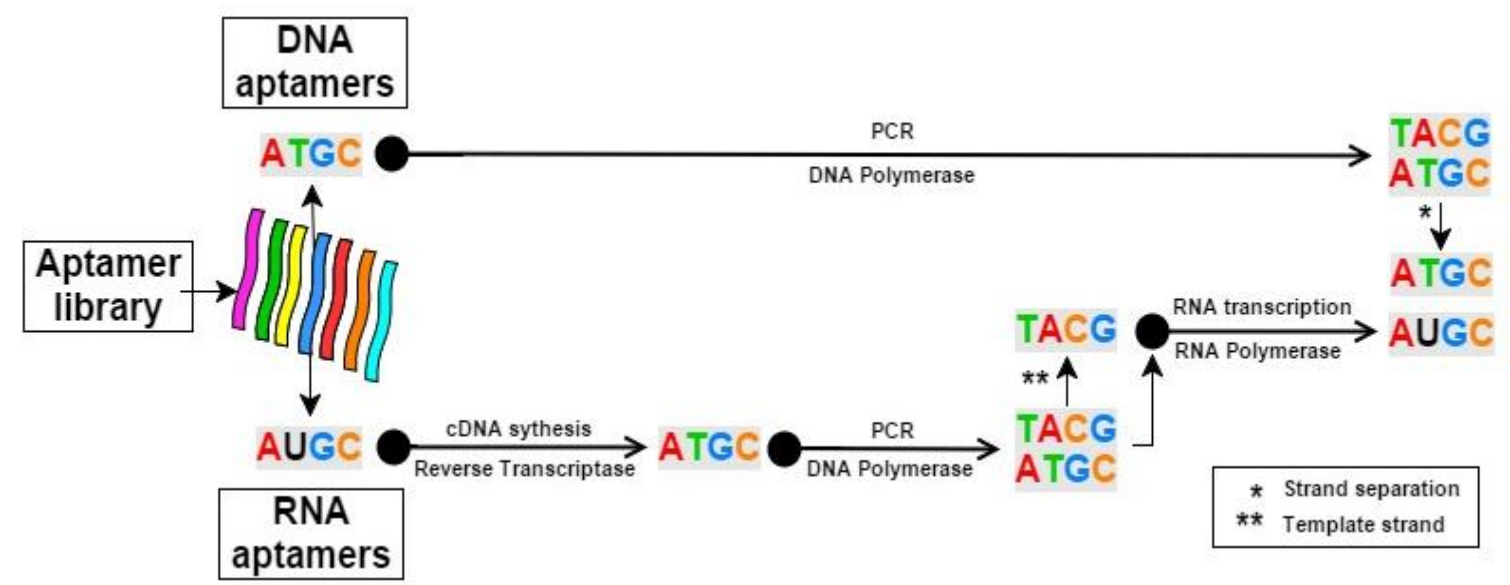

Figure 1.2.2. Nucleic acid amplification for DNA and RNA. The basic methodology of amplifying DNA and RNA is illustrated: starting from an initial DNA library; 1. DNA amplification via PCR. 2. RNA amplification via cDNA synthesis, PCR and RNA transcription. 
2002). Due to the structural instability, aptamer sequences commonly undergo a 'folding' process in which base pairing occurs and facilitates the formation of partial 2D and 3D secondary and tertiary structures such as; G-quadruplexes (Macaya et al., 1993), stems, hairpin loops, bulges and pseudoknots (Tuerk et al., 1992; Patel, 1997). The resulting secondary structures usually have a lower Gibb's free energy and are therefore considered more stable than their linear primary structure. The formation of secondary and tertiary structures is associated with an aptamers ability to bind with high affinity and specificity, via the formation of aptamer-target complexes. These complexes are primarily based on steric interactions between folded aptamer structures that is complimentary to that of the target molecule's (Ellington \& Szostak, 1990). In more detail, the intermolecular forces between the aptamer and target occur non-covalently via; Van Der-Waals forces, electrostatic interactions, pi-pi stacking and hydrogen bonding (Hermann \& Patel, 2000). When comparing RNA and DNA aptamers, RNA aptamers are renowned for having greater 3D conformational ability than DNA aptamers, however both DNA and RNA aptamers are capable of binding to the same targets (Song et al., 2012). Additionally, RNA aptamers are generally considered more difficult to generate because they are prone to degradation from RNases that are abundant in the environment and biological samples (Tsui et al., 2002). Generation of RNA aptamers also requires an additional enzymatic step required to convert RNA to complementary DNA (cDNA) prior to amplification after each round of SELEX (See Figure 1.2.2).

\subsubsection{SYSTEMATIC EVOLUTION OF LIGANDS BY EXPONENTIAL ENRICHMENT}

SELEX was originally described in detail by Tuerk and Gold (1990). However, because of advancements and innovation within aptamer research, the term SELEX now refers to a process rather than a specific method. As such, SELEX can be described in principal; SELEX is an affinity maturation method used to generate aptamers by separating targetbinding from non-target-binding nucleic acid sequences within an initial library of randomised sequences. SELEX can generally be defined further by two sub-processes; selection and enrichment. However, prior to beginning SELEX, an additional step is required in the design and preparation of the initial library which will be subsequently subjected to the SELEX process. Therefore, it is important to design an initial library that encompasses enough sequence diversity to isolate an aptamer for the desired target. It has previously been theorised that an initial library containing approximately $1 \times 10^{15}$ unique 
sequences is large enough provide sufficient population diversity to undertake the initial screening process for any target molecule (Ellington and Szostak 1990).

More specifically, an aptamer library is generally populated by sequences consisting of 20100 randomised nucleotides (referred also as base pairs (bp)), flanked by specific primer regions for amplification via polymerase chain reaction (PCR) (Figure 1.2.3A). Although randomised aptamer libraries are most commonly employed in SELEX, non-randomised aptamer libraries can also be used. Such libraries can be generated using in silico screening, where preliminary computational screening and modelling is performed to identify candidate sequences based on previously identified binding motifs (Duclair et al., 2015) or predicted 2D and 3D conformations that may positively interact with your target of interest (Ahirwar et al., 2016). Because of this, non-randomised aptamer libraries may often have sequence diversity much smaller than $1 \times 10^{15}$ and are often referred to as 'doped' libraries.

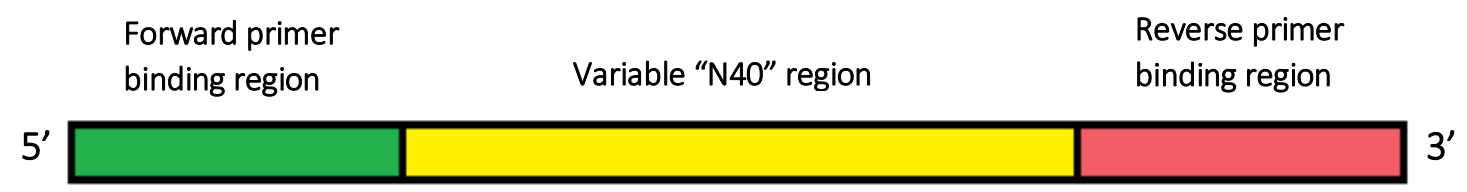

Figure 1.2.3A. Diagram of basic aptamer design. The basic design of an aptamer is illustrated: A total of $75 \mathrm{bp}$ in length with an $18 \mathrm{bp}$ forward and $17 \mathrm{bp}$ reverse primer regions flanking a 40bp variable N40 region comprising of randomised nucleotides.

The first step in SELEX is selection; Selection is the process in which the library is coincubated with the target molecule. During selection, sequences demonstrating the highest binding affinity for the target molecule are captured and/or isolated from those with little to no affinity. To achieve this, a 'matrix' can be used to separate bound DNA from unbound DNA. Matrices are structural supports in which the target is fixed to, assisting in conducting the aptamer library co-incubation and separation step. Examples of matrices include nitrocellulose membranes (Lin,et al., 2015), nickel ions $\left(\mathrm{Ni}^{2+}\right)$ (Murphy et al., 2003), carboxylic groups, amine groups or sulfhydryl groups (for protein conjugation via $\mathrm{N}$ terminus, C-terminus or cysteine residues) functionalised surfaces such as magnetic beads (Stoltenburg et al.,2005) and sepharose beads (Song et al., 2011). The same chemistry can be used to target various other small molecules, with each matrix type and chemistry often having a selective advantage over another depending on the application and target molecule. Other indirect methods could include streptavidin-biotin interactions such as the linking of a biotinylated target molecule with streptavidin coated matrix (Stoltenburg et al., 2015). Alternatively, the target molecule could be free in solution and the ssDNA library could be bound to a matrix. Surfaces such as salinised glass, graphene oxide and gold nano- 
particles (Sanghavi et al., 2016) can also interact with ssDNA and have been demonstrated as effective matrices used for generating aptamers. Although matrices are a powerful tool for selecting aptamers, it is suggested that potential aptamer binding-sites are blocked by fixing a target to a matrix. However, this may present a potential hindrance on the selection process by facilitating a steric interaction that may not be applicable for targets free in solution or in their native state.

The second SELEX step is 'enrichment'. Following selection, the oligo library has undergone a reduction in non-binding sequences. PCR amplification is then undertaken to increase the copy number of target-binding sequences, hereby replenishing and enriching the library's overall affinity for the target. Thereafter, the resulting dsDNA PCR product is subjected to molecular biology techniques such as alkaline denaturation or enzymatic digestion to generate ssDNA that can be used in a subsequent SELEX round (Tuerk \& Gold, 1990). The process of SELEX is iterative, by means of multiple rounds of selection and enrichment, with many papers reporting approximately 6-20 rounds of SELEX to generate high-affinity aptamers (see Figure 1.2.3B for summary). During each round, variation to the SELEX protocol and continual alteration of conditions such as the size and diversity of the initial library, target concentration, counter-selection steps, purification methods, PCR cycling and total number of SELEX rounds can influence the quality and sensitivity of the resultant aptamer library (Hamula et al., 2015). Therefore, it is important to carefully consider selection conditions and to design an intuitive aptamer selection strategy that will best suit the desired target and endpoint application for the aptamer.

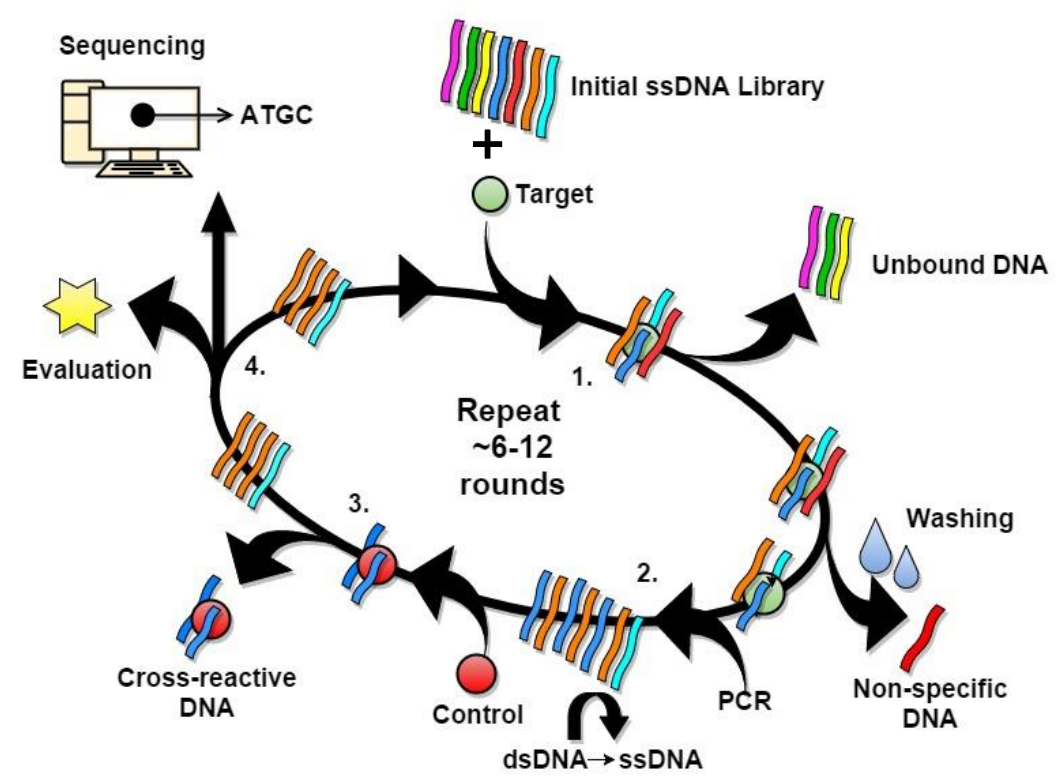

Figure 1.2.3B. Diagram of SELEX workflow. The basic SELEX methodology is illustrated: starting from an initial DNA library; 1. Co-incubation and selection. 2. Enrichment and conversion back to ssDNA. 3. Negative selection. 4. Analysis. 


\subsubsection{COUNTER AND NEGATIVE SELECTION}

During the SELEX process, aptamers can be matured to attain high affinity for a single target through the incorporation of additional processes such as negative (and/or counter) selection (White et al., 2001). This process involves alternating rounds of selection using compounds that are structurally similar or present in the same medium as the target molecule. The removal of aptamers from the selection pool that bind to these potentially interfering compounds will ensure the enrichment of aptamers with specificity to the target molecule. Similar to this, Toggle-SELEX, may be used as a counter selection method to generate aptamers that are able to recognise homologous proteins derived from either multiple or a single species (White et al., 2001).

\subsubsection{CHALLENGES IN APTAMERS}

A typical SELEX publication only reports the identification of several candidate aptamers from any given experiment. Assuming they began with $1 \times 10^{15}$ random sequences at the start of the SELEX process, there must be an accepted degree of non-reproducibility. For example, an experiment with replicated SELEX conditions is highly unlikely to yield the identical candidate aptamers for the same target due to several variables that exist within the SELEX methodology. These variables are primarily; diversity within the initial starting library, environmental conditions and variation within the PCR process. During PCR, mutations within the random region of the aptamer and amplification bias of nonfavourable sequences can be introduced. In theory, these effects could accumulate after multiple rounds of SELEX and possibly be detrimental to the success and reproducibility of the experiment and resultant aptamer library. However, in contrary to typical PCR methods, deliberate introduction of mutation during amplification may be beneficial for generating aptamers. Mutagenic PCR (or error-prone PCR) has been shown to be effective at diversifying aptamer libraries by introducing new point mutations that could increase aptamer binding affinity (Bittker et al., 2002). Lin et al (2015) describe the generation of an aptamer for BMP15 from a single ssDNA template which was subjected to mutagenic PCR, essentially adding diversity to the aptamer library which was missing within the initial library.

Furthermore, after SELEX is complete, aptamer sequencing is commonly performed using cloning vectors which are inserted into bacteria. This method is considered low-throughput, commonly used to screen between only 30-60 clones, which reduces the probability of 
identifying the best candidate-aptamers within the final library. Without high-resolution sequencing data, it is hard to define what the best methods for SELEX are. However, with modern techniques such as robotics and next-generation sequencing, aptamer research is achieving new levels of precision while providing a better understanding of how the aptamer library evolves during SELEX.

\subsubsection{INNOVATION IN SELEX}

Aptamer research is still evolving; new technologies and methods are constantly being implemented with improved results. Consequently, there is no universally-accepted method for generating and characterising aptamers, which was true from the very beginning in 1990. Two recent reviews (Mckeague \& Derosa, 2013; Darmostuk et al, 2015) cite more than 30 individual SELEX methodologies capable of producing aptamers from multiple publications. Some of the most common SELEX methods to be considered 'advanced', would include; Capillary-electrophoresis SELEX, Bead-based SELEX, Nanoparticle SELEX, Cell SELEX, In vivo SELEX, One-round SELEX and Automated SELEX. While many SELEX methods vary slightly, by means of matrices, buffers, experimental conditions or PCR methods, the advanced methods often vary by means of separating bound DNA from unbound DNA. For example, capillary electrophoresis can discriminate between bound and unbound complexes using small changes in electrical charge and mass, in solution, and can be functionalised to quantify the results. Moreover, advanced methods such as capillary electrophoresis can be performed much more rapidly than conventional SELEX methods. This is particularly true for a new-era of publications touting "one-round SELEX" methods capable of producing high affinity aptamers after only one round of selection (Liu et al., 2012). Furthermore, conventional SELEX methods requiring multiple rounds of SELEX are more laborious and henceforth require much more time compared with automated-SELEX, where multiple rounds of SELEX or can be performed by a robot in a single day for a multiplex of targets (Cox et al., 1998; Cox \& Ellington, 2001).

\subsubsection{APPLICATIONS OF APTAMERS IN SCIENCE}

The fundamental premise of aptamer technology relies on single-stranded nucleic acids binding to a specific target. However, it is the seemingly unparalleled ability of aptamers to target a diverse and potentially unlimited range of targets that makes them excellent candidates for use in diagnostics, therapeutic applications or as probing reagents for analytical assays. Although aptamers are ideal candidates for detection assays due to their 
relatively rapid in vitro generation process and high target diversity, aptamers can also be used therapeutically in vivo. Pegaptanib is an example of an RNA aptamer that was given Food and Drug Administration (FDA) approval in 2004 for clinical use in the treatment of age-related macular degeneration (Ruckman et al., 1998; Ng et al., 2006). At present, there are many aptamer-based therapies undergoing FDA approval for new therapies such as aptamer-targeted drug delivery and internal-imaging assays utilising functionalised aptamers.

\subsubsection{APTAMERS VERSUS ANTIBODIES}

Antibodies are the current industry standard for target capture in analytical or diagnostic assays and are often incorporation into micro-devices, such as pregnancy test kits, for biosensor applications. Polyclonal antibodies are generated by initiating an immune response in host-animal models before euthanising the host/s and subsequently purifying the antibodies. From a polyclonal library, monoclonal antibodies are most commonly generated by a process utilising an immortalised hybridoma cell line generated by fusion of a lymphocyte and myeloma cell (Little et al., 2000). Aptamers however, are generated via chemical synthesis and modified through molecular biology techniques, and it is the

Table 1.2.8. Comparative properties of aptamers and antibodies. Information for this table was derived from aptamer reviews (Nimjee et al., 2005; Bunka et al., 2006; Kefee et al., 2010).

\begin{tabular}{|c|c|c|}
\hline & Aptamers & Antibodies \\
\hline Generation & In vitro & In vivo \\
\hline Binding affinity & Low nanomolar to picomolar range & Low nanomolar to picomolar range \\
\hline Specificity & Theoretically unlimited target molecules & Limited to biological/immunogenic targets \\
\hline Synthesis & $\begin{array}{l}\text { SELEX, in vitro, increasing rounds of } \\
\text { selection with methodological differences } \\
\text { capable of increasing affinity rapidly }\end{array}$ & $\begin{array}{l}\text { Biological system, in vivo, limited range of } \\
\text { variations available, process comparably longer, } \\
\text { susceptible to contamination, difficult to select } \\
\text { against whole cells }\end{array}$ \\
\hline Modifications & $\begin{array}{l}\text { Large range of modifications available, } \\
\text { conjugates, chemical groups and binding to } \\
\text { gold nanoparticles directly }\end{array}$ & $\begin{array}{l}\text { Limited modifications available and often decrease } \\
\text { antibody activity }\end{array}$ \\
\hline Resilience & $\begin{array}{l}\text { Aptamers can withstand variable } \mathrm{pH} \text { and } \\
\text { temperature conditions, susceptible to } \\
\text { RNase and DNase degradation }\end{array}$ & $\begin{array}{l}\text { Limited to in vivo conditions and susceptible to } \\
\text { temperature denaturation }\end{array}$ \\
\hline Bioavailability & $\begin{array}{l}\text { Variable pharmacokinetic properties which } \\
\text { can be easily changed, small molecules } \\
\text { size increases tissue penetration }\end{array}$ & $\begin{array}{l}\text { Less variable pharmacokinetics, larger, } \\
\text { unreducible size limits the range of targets and } \\
\text { tissue penetration properties }\end{array}$ \\
\hline Immunogenicity & $\begin{array}{l}\text { RNA molecules are generally regarded as } \\
\text { non-immunogenic }\end{array}$ & $\begin{array}{l}\text { High immunogenicity, potential risks associated } \\
\text { with in vivo application }\end{array}$ \\
\hline Production & $\begin{array}{l}\text { Large scale chemical synthesis, scalable, } \\
\text { better cost efficiency }\end{array}$ & $\begin{array}{l}\text { Limited to in vivo production and not efficient to } \\
\text { scale, higher and variable price due to difficulty }\end{array}$ \\
\hline
\end{tabular}


physical properties of aptamers that lend them to an exciting and promising technology that could potentially replace antibodies in many circumstances. The advantages and limitations of aptamers, in comparison to antibodies, should be assessed carefully (see Table 1.2.8) when considering the application and development of aptamers.

\subsubsection{APTAMERS AGAINST BMP15 AND GDF9}

While there are no reported aptamers specific for GDF9, several aptamers with low nanomolar binding affinity and high specificity to recombinant mammalian BMP15 have already been identified and sequenced (Lin et al., 2015). These aptamers were generated using a membrane-based SELEX procedure that involved the application of mutagenic PCR on a single template to generate the initial library for the first round of SELEX. Interestingly, it was shown that error-prone PCR combined with nitrocellulose membrane separation methods (membrane-based SELEX) was able to generate several aptamers which converged on the same sequence, all showing conserved domains and binding affinity for BMP15 (Lin et al., 2015). It could be hypothesised that the highly conserved regions of BMP15 and GDF9 between species (Monestier et al., 2014) are essential for the binding of aptamers and could act as a novel target for aptamers raised against BMP15 or GDF9. The potential to use Toggle-SELEX and mutagenic PCR could prove effective at generating aptamers that not only have high affinity for BMP15 and GDF9, but also have reduced cross reactivity between species and facilitate the potential development of either BMP15 or GDF9 diagnostic assays.

The ability to accurately measure oocyte-secreted factors such as BMP15 and GDF9 concentrations in media used to culture oocytes (also known as oocyte-secreted media) or in a biological fluid such as follicular fluid will pave a pathway to investigate the different biological effects of BMP15 and GDF9 in different mammalian species. This information would be invaluable to the artificial reproductive technology industries in determining the prevalence of BMP15 and GDF9 perturbations on sub-fertility and potentially enable the refinement of in vitro maturation systems for human oocytes. The knowledge gained could also benefit conservation efforts through improvements in reproductive success for endangered species or reducing reproductive success for pest species. 


\subsection{RESEARCH OBJECTIVES}

The overall objectives of this study were to produce the tools required for measurement of native, oocyte-secreted BMP15 and GDF9 in a biological fluid sample through aptamer generation.

The specific aims of this study were to:

1) Produce recombinant BMP15 and GDF9 from two mammalian species that differ in litter size, namely the mouse and sheep;

2) Purify recombinant murine and ovine BMP15 and GDF9 using ion metal affinity chromatography (IMAC) and high performance liquid chromatography (HPLC) methodologies;

3) Validate recombinant murine, ovine and porcine BMP15 and GDF9 using immunoblotting, and;

4) Develop methods for the generation of aptamers capable of specifically binding to GDF9 across murine and ovine species.

It should be noted that the original plan of this research was to produce recombinant BMP15 and GDF9 from the mammalian species of mouse and sheep, before a two-step purification and subsequent aptamer selection process on said purified proteins. However, several key issues arose during this research which made the research aims unachievable in the remaining timeframe. Namely, the inability to IMAC purify BMP15 samples and the inability to quantify the purified GDF9 proteins. It is likely that the BMP15 proteins did not contain the histidine tag we expected and the concerns around the quantity of the recombinant GDF9 protein were worsened by the inability to ensure a purity that would be suitable for aptamer selection. Therefore, it was decided to use recombinant human GDF9 from a commercial source for the aptamer selection process performed after the initial protein experiments.

In addition, aim 4 was designed to include multiple target species of in-house recm/recoGDF9 for aptamer selection. However, it is theoretically possible to achieve this from a single source of target protein (commercial rechGDF9) but this was not able to be assessed due to the difficulties in protein characterisation and purification that hindered the research timeline. 


\section{CHAPTER 2: GENERAL METHODOLOGY}

The following chapter describes the general methodologies use to generate and purify recombinant murine (m) and ovine (o) BMP15 and GDF9 proteins by means of mammalian cell culture using a combination of standard purification techniques. In addition, the general methodologies will also cover the methods used which were designed for generating aptamers capable of binding to recombinant GDF9 proteins by means of nitrocellulose membrane-based SELEX. The methods described herein pertain to the specific steps involved in the preparation and co-incubation of nitrocellulose membrane matrix and protein targets, as well as the isolation and enrichment of the polyclonal ssDNA library. This library will serve to provide candidates for monoclonal aptamers that may be used in an enzyme-linked immunosorbent assay oligonucleotide assay (ELISA) for measuring GDF9, in media secretions. The information from which all chemicals, reagents, consumables and equipment are described by is listed in the Appendix.

\subsection{IDENTIFYING RECOMBINAT CELL LINES}

This research outlined the generation of both recombinant proteins from HEK 293 cells that had transfected several decades previously with the BMP15 and GDF9 genes of mouse and sheep origin. Given the age of the cell lines, it was anticipated HEK293 cells recently transfected in the Pitman laboratory with porcine (p) GDF9 and BMP15 would act as a positive control to assess recombinant $(\mathrm{rec})$ protein production and purification procedures but production of recpGDF9 and recpBM15 was unsuccessful. All recombinant cell lines used in this experiment were recombinant HEK293 immortalised cells lines stored in liquid nitrogen. The cell lines were previously established in our laboratory and were known to successfully produce biologically active recombinant proteins, detectable using immunoblotting with previously characterised monoclonal antibodies (Alhussini, 2016). Because of this; gene transcription, plasmid expression and transfections of the cell lines were not performed. The expression vector used to create these cell lines was pEFIRES-P which contains a resistance gene for the antibiotic, puromycin. This enables survival of only cells expressing the plasmid through increasing antibiotic selection conditions. Further immunoblotting was performed in conjunction with this to ensure the expression of recombinant GDF9 and BMP15 was taking place during cell culture. 


\subsection{PRODUCTION OF RECOMBINANT PROTEINS BY MODIFIED HEK293 CELLS}

HEK293 cells lines expressing pEFIRES-P-oBMP15 (ovine), pEFIRES-P-mBMP15 (murine), pEFIRES-P-oGDF9, pEFIRES-P-mGDF9 and pEFIRES-P (empty vector) were cultured in Gibco ${ }^{\mathrm{TM}}$ Dulbecco's Modified Eagle Medium (DMEM) (growth media) with added puromycin $(0-100 \mu \mathrm{g} / \mathrm{mL})$, penicillin $(100$ units $/ \mathrm{mL})$, streptomycin $(0.1 \mathrm{mg} / \mathrm{mL})$, GlutaMax (L-analine-L-glutamine, $2 \mathrm{mM}$ ) and foetal calf serum (10 \% v/v). The cells were cultured in gas-exchanging growth flasks at $37^{\circ} \mathrm{C}$ in $5 \% \mathrm{CO}_{2}$ atmosphere, until $70-90 \%$ confluency was reached with an increasing puromycin concentration (up to $100 \mu \mathrm{g} / \mathrm{mL}$ ) to a final surface area of $175 \mathrm{~cm}^{2}$.

\subsection{HARVESTING OF RECOMBINANT PROTEINS SECRETED BY MODIFIED HEK293 CELLS}

Each cell line was cultured in four growth flasks with a total surface area of $700 \mathrm{~cm}^{2}$ until $70-90 \%$ confluency was reached in growth media containing $100 \mu \mathrm{g} / \mathrm{mL}$ puromycin. After this, the growth media was removed and gently washed twice over with pre-warmed Gibco $^{\mathrm{TM}}$ Phosphate Buffered Saline, before being replaced by $50 \mathrm{~mL}$ of Gibco $^{\mathrm{TM}}$ DMEM:HamsF12 (1:1) protein expression media (EM) with added penicillin (100 units $/ \mathrm{mL}$ ), streptomycin $(0.1 \mathrm{mg} / \mathrm{mL})$, GlutaMax (L-alanine-L-glutamine, $2 \mathrm{mM})$, bovine serum albumin $(0.01 \% \mathrm{w} / \mathrm{v})$ and heparin $(100 \mu \mathrm{g} / \mathrm{mL})$. The cells were cultured in gasexchanging growth flasks at $37^{\circ} \mathrm{C}$ in $5 \% \mathrm{CO}_{2}$ atmosphere for $96 \pm 4$ hours until harvesting. The EM was removed and centrifuged at $200 \mathrm{~g}$ for 5 minutes to remove whole cells. The supernatant was removed and centrifuged again at $3200 \mathrm{~g}$ for 10 minutes to further remove cellular debris before being transferred to $50 \mathrm{~mL}$ Falcon tubes with the addition of $1 \mathrm{x}$ protease inhibitors (complete, EDTA-free protease inhibitor cocktail, Roche) as per the manufacturers guidelines before temporary storage at $-20^{\circ} \mathrm{C}$. Whole cells from the initial centrifugation step were suspended in $1 \mathrm{~mL}$ purified media with $1 \mathrm{x}$ protease inhibitors added, and subsequently stored at $-80^{\circ} \mathrm{C}$ for long term storage.

\subsection{PURIFICATION OF EM BY IMMOBILISED METAL ION AFFINITY CHROMATOGRAPHY}

The recombinant proteins as described in Sections 2.2 and 2.3 were modified to contain a 6xHis-tag which allowed for purification via the specific binding of free histidine (His) residues to immobilised $\mathrm{Ni}^{2+}$ ions. Ni-NTA agarose (Qiagen) was employed alongside an IMAC protocol supplied by Dr Derek Heath, Victoria University of Wellington, to purify 
the recombinant proteins from the harvested EM. The $200 \mathrm{~mL}$ of EM was pooled together and purified in batches, for each individual cell line; pEFIRES-P-oBMP15, pEFIRES-PmBMP15, pEFIRES-P-oGDF9, pEFIRES-P-mGDF9. The protocol was performed individually for each batch, (see Supplementary Material), and the supernatants from each step were stored at $-20^{\circ} \mathrm{C}$ for immunoblotting. Aside from the sample loading and binding, each step was performed at room temperature (RT) for 30seconds and supernatants were removed by centrifugation at $200 g$ for 5 minutes.

\subsection{HIGH PERFORMANCE LIQUID CHROMATROGRAPHY OF IMAC PURIFIED EM}

Following IMAC purification, the recombinant mGDF9 and oGDF9 ( $r e c$ mGDF9 and rec oGDF9) EM underwent further purification using HPLC. The protocol was supplied by Dr Derek Heath and was performed as previously described by Pukki et al 2012, with modifications to flow rate and acetonitrile (ACN) gradient. Elution from IMAC were pooled together and thereafter prepared to $5 \mathrm{~mL}$ using HPLC grade water with a final concentration of $\operatorname{ACN}(6 \%, v / v)$ and triflouroacetic acid (TFA, 0.1\%, v/v) as HPLC samples. The sample(s) were injected into the system through a $0.22 \mu \mathrm{m}$ syringe-filter and subsequently passed into a reverse phase HPLC column (Jupiter, $5 \mu \mathrm{m}, \mathrm{C} 4,300 \AA$; Phenomenix) fitted with an upstream security guard cartridge (Widepore, C4, Phenomenix) which had been previously equilibrated with $6 \%$ (v/v) ACN and $0.1 \%$ TFA in HPLC grade water. The solvent, ACN, was pushed through the column at a constant flow rate of 1 $\mathrm{mL} /$ minute with an increasing concentration of 6-95\% (v/v), while TFA concentration was fixed at $0.1 \%(\mathrm{v} / \mathrm{v})$. Fractions were collected every minute into Lo-Bind microcentrifuge tubes and the ACN was evaporated using an Eppendorf $®$ centrifugal vacuum concentrator (SIGMA, model 5301) at RT.

\subsection{PREPARATION OF SODIUM DODECYL SULFATE POLYACRYLAMIDE GEL (SDS PAGE) FOR PROTEIN ANALYSIS}

The SDS-PAGE gels were prepared as per the recipe (Table 2.5) in a glass beaker and set between two glass panels, $0.75 \mathrm{~mm}$ apart, using a casting kit (Bio-Rad). Approximately $2 \mathrm{~mL}$ of $13.5 \%$ stacking gel was pipetted in between the glass panels before a layer of MillQ water was added on top and left to polymerise at RT for 60 minutes. The layer of MillQ water was removed, and the stacking gel was pipetted on top of the separating gel, followed by the insertion of a 10 or 15 -well $0.75 \mathrm{~mm}$ gel comb (Bio-Rad) and left to 
polymerise at RT for 30 minutes. The gels were either used immediately or wrapped in damp paper towels and stored in a zip-lock bag at $4{ }^{\circ} \mathrm{C}$ for a maximum of one week.

Table 2.6. Separating and Stacking gel recipes for SDS-PAGE experiments. Gel recipe described as follows in the table.

\begin{tabular}{|l|c|c|}
\multicolumn{1}{|c|}{ Reagent } & $\begin{array}{c}\mathbf{1 3 . 5 \%} \\
\text { Separating gel }\end{array}$ & $\begin{array}{c}\mathbf{4} \% \\
\text { Stacking gel }\end{array}$ \\
\hline Milli Q water & $2.85 \mathrm{ml}$ & $3.05 \mathrm{ml}$ \\
\hline $\mathbf{1 . 5 M}$ Tris-HCl pH8.8 & $2.5 \mathrm{ml}$ & $1.25 \mathrm{ml}$ \\
\hline $\mathbf{1 0 \%}(w / v)$ SDS & $0.1 \mathrm{ml}$ & $50 \mu \mathrm{l}$ \\
\hline $\begin{array}{l}\text { Bis-acrylamide mix } \\
\mathbf{( 3 0} \%)\end{array}$ & $4.5 \mathrm{ml}$ & $0.65 \mathrm{ml}$ \\
\hline $\begin{array}{l}\mathbf{1 0} \%(w / v) \text { ammonium } \\
\text { persulphate }\end{array}$ & $50 \mathrm{ul}$ & $25 \mu \mathrm{l}$ \\
\hline TEMED & $5 \mathrm{ul}$ & $5 \mu \mathrm{l}$ \\
\hline
\end{tabular}

\subsection{SDS PAGE ELECTROPHORESIS OF EM, IMAC AND HPLC PURIFIED PROTEIN SAMPLES}

Protein samples for Western blotting were generally performed using freshly collected sample or stored short term at $-20^{\circ} \mathrm{C}$ prior to sample preparation. A purified sample of ovine pro-region conjugated to ovine mature BMP15 (o/oBMP15) was kindly gifted by Dr Derek Heath, and expression media containing recpGDF9 and recpBMP15 produced in-house, were included as positive controls in the Western blots. Samples were kept on ice and prepared under reducing conditions by adding $5 \mathrm{x}$ reducing buffer containing the reducing agents dithiothreitol and 2- $\beta$-mecarptoethanol. Using a water bath, the samples were heated to $95^{\circ} \mathrm{C}$ for 5 minutes in a sealed microcentrifuge tube. The samples were centrifuged for 5-10 seconds to allow the entire sample to collect at the bottom of the tube before loading. Thereafter, 500mL of Running Buffer was added into the Mini-PROTEAN Tetra II gel electrophoresis system (Bio-Rad), before the reduced samples were loaded into a 4\% SDSPAGE stacking gel, with empty lanes loaded with an equal volume of $2 \mathrm{x}$ reducing buffer. The samples were separated by size through the $13.5 \%$ separating gel, under a constant 150 volts for 60-70 minutes at RT. Precision Plus Protein ladder (Bio-Rad) was prepared under identical conditions, with the exception of no reducing agents, and ran alongside the 
reduced sample lanes to indicate apparent size of each of the molecular forms of BMP15 and GDF9, within a range of $10 \mathrm{kDa}$ to $250 \mathrm{kDa}$.

\subsection{SDS-PAGE TRANSFER}

After SDS-PAGE electrophoresis, the glass gel cast was disassembled carefully before the $4 \%$ stacking gel was discarded. The remaining separating gel was placed in excess of Transfer Buffer for 5 minutes at RT, in order to fix the proteins in the gel and to allow the gel to flatten before assembly in the transfer cassette. For each SDS-PAGE gel, one piece of nitrocellulose membrane (Hybond C, Amersham ${ }^{\mathrm{TM}}$ Protran $^{\mathrm{TM}}$ ) and four pieces of cellulose blotting paper were cut to match the size of the gel. All materials of the transfer cassette were pre-soaked in transfer buffer prior to assembly of the cassette. The transfer cassette was assembled from the negative electrode to the positive electrode (see Figure 2.8 , below), with the addition of each layer proceeded by gentle rolling using a hand-held roller in order to remove any air bubbles between the layers. The nitrocellulose membrane was placed onto the gel with precision, employing tweezers to reduce risk of the adsorption of surface contaminants onto the membrane. The assembled transfer cassette was placed in a Criterion ${ }^{\mathrm{TM}}$ transfer tank (Bio-Rad), before adding an ice pack, magnetic stirring bar and filling with pre-chilled Transfer-Buffer, ensuring the cassette is fully submerged. The transfer cassette was run at a constant 100 volts for 1 hour at $4^{\circ} \mathrm{C}$.

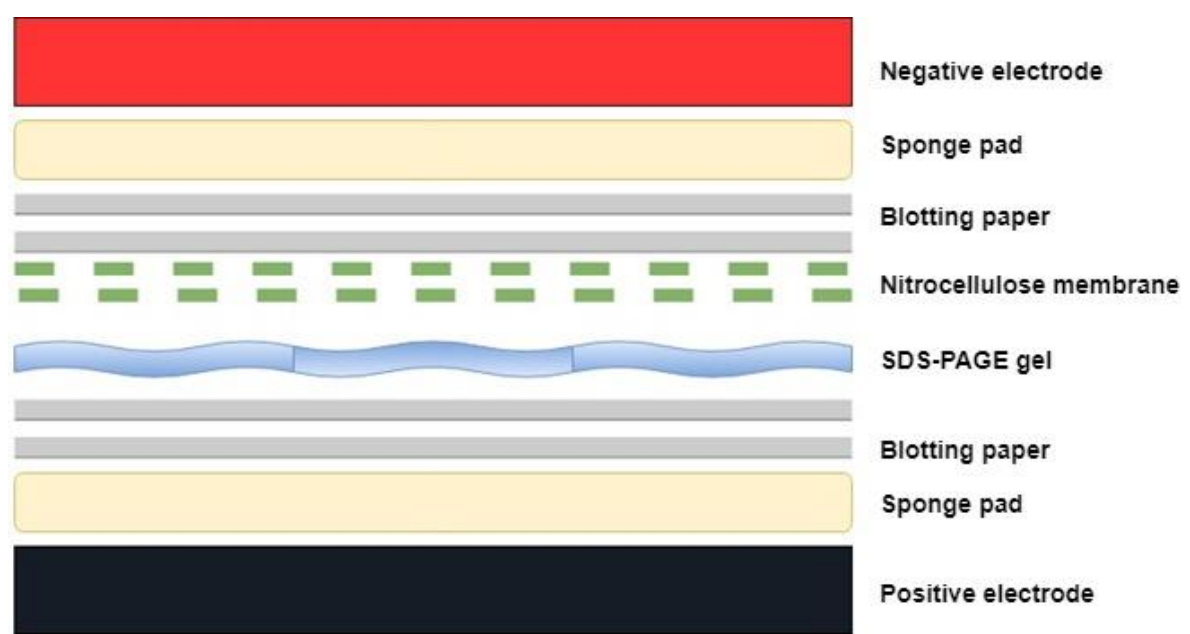

Figure 2.8. SDS-PAGE Transfer cassette assembly. The SDS-PAGE gels were transferred to nitrocellulose membranes using a transfer cassette assembled as follows. 


\subsection{IMMUNOBLOTTING OF SDS-PAGE SEPARATED PROTEIN SAMPLES}

Western blotting was employed throughout the protein expression and purification to characterise the forms of BMP15 and GDF9. All Western blots were performed under identical conditions except for specific antibodies and sample volumes, as stated in each figure. Unless otherwise stated, the incubations and washing steps were performed on a benchtop horizontal rocker at RT. Proteins were separated by SDS-PAGE, as outlined in Section 2.7, and transferred to nitrocellulose membrane, as outlined in Section 2.8. Thereafter, membranes were transferred to plastic containers and washed thrice for 10 minutes with an excess of Tris-buffered Saline with Tween-20 (0.1\%, v/v) (TBS-T). Thereafter, the washed membranes were blocked for 2 hours using an excess of $5 \%(\mathrm{w} / \mathrm{v})$ skim milk powder in TBS-T. Directly after blocking, the primary incubation was performed by replacing the blocking solution with mouse-monoclonal antibody (mAb), specific for either BMP15 or GDF9, at a fixed concentration in $5 \mathrm{~mL}$ of TBS-T containing $5 \%(\mathrm{w} / \mathrm{v})$ skim-milk powder and subsequently incubated overnight at $4^{\circ} \mathrm{C}$. Following the primary incubation, 3 more washing steps were employed before the secondary antibody, Horse radish peroxidase (HRP) conjugated goat-anti-mouse IgG (Jackson Laboratories Inc) was added in a 1:2000 dilution in 5mL of TBS-T containing 5\% (w/v) skim-milk powder and incubated for 2 hours. Thereafter, the membranes were washed thrice again prior to the addition of 4-5 sprays of HRP substrate, WesternBright ${ }^{\mathrm{TM}}$ Electrochemiluminescence spray (Advansta) was applied directly to the membrane from a distance ensuring the membrane is sufficiently covered before incubation for 2 minutes. Following this, the membrane was blotted dry of excess substrate, secured with plastic film, and imaged using a benchtop trans-illuminator to detect chemi-illuminescence from the HRP, Omega Lum G (Applegen). The images were saved as raw.tiff format and analysed later using ImageJ and Microsoft PowerPoint software. The immunoblotting images presented herein the Results section have been digitally enhanced using this software. For any such results, the raw image captured, and subsequent digital enhancements were performed equally across each entire blot. To say, each sample in the same blot is representative of the entire blot.

\subsection{PREPARATION OF TARGET PROTEINS}

The target protein used for the positive selection rounds (SR) in this project was rechGDF9, which had been expressed in HEK293 cells (R\&D Systems). The protein was supplied as $10 \mu \mathrm{g}$ lyophilised powder and reconstituted as per manufacturer instructions, to $100 \mu \mathrm{g} / \mathrm{mL}$ 
in $4 \mathrm{mM} \mathrm{HCl}(0.22 \mu \mathrm{m}$ filter-sterilised $)$. The reconstituted proteins were stored at $-20^{\circ} \mathrm{C}$ until use as outlined in Sections 2.11 and 2.11.1.

\subsection{PREPARATION OF NITROCELLULOSE MEMBRANE-PROTEIN MATRIX}

Nitrocellulose membranes $\left(0.45 \mu \mathrm{m}\right.$, Hybond $\mathrm{C}^{\mathrm{TM}}$, Amersham Protran) were cut into small squares approximately $1.5 \mathrm{~mm}^{2}$ in size, these membranes were strictly handled on clean surfaces with the use of latex gloves to prevent the absorption of surface contaminants onto the membrane surface. Three individual $1.5 \mathrm{~mL}$ micro centrifuge tubes were prepared by inserting 10 pieces of the nitrocellulose membrane and immersing in $80 \mathrm{uL}$ of protein solution in $1 \mathrm{x}$ Binding and Washing Buffer (BWB) containing either $5 \mu \mathrm{g}, 3 \mu \mathrm{g}$ and $1 \mu \mathrm{g}$ total of recmGDF9. Control membranes were also prepared by adding the equivalent membranes into a micro centrifuge tube containing $80 \mathrm{uL}$ of $1 \mathrm{xBWB}$ without protein. The control membranes are designed to evaluate and reduce non-specific surface adsorption of ssDNA molecules that may preferentially bind to nitrocellulose rather than the protein target. The target and control membranes were placed on an orbital shaker overnight at $4^{\circ} \mathrm{C}$ to ensure maximum adsorption of the target protein to the membrane. They were then stored at $4^{\circ} \mathrm{C}$ for no longer than 4 weeks.

\subsubsection{REVISION TO PROTEIN-MATRIX PREPARATION}

After 10 rounds of SELEX, the method for preparing the target protein onto the nitrocellulose membrane was modified. All co-incubations after SR9 used membranes prepared as followed. A new vial containing rec human(h)GDF9 (R\&D Systems) was prepared (as per 2.10) and $10 \mu \mathrm{L}$ aliquots were stored at $-20^{\circ} \mathrm{C}$. A new aliquot was defrosted on ice prior to each co-incubation, and two freshly-prepared pieces of nitrocellulose were added into the tube and left to incubate with the protein for 4 hours on an orbital shaker at $4^{\circ} \mathrm{C}$ before proceeding with the co-incubation.

\subsection{PREPARATION OF INITIAL SSDNA LIBRARY}

The initial library (N40 library) (see Table 6.4) was supplied as a lyophilised powder and prepared to a working stock solution of $400 \mu \mathrm{M}$ using Ultra-pure DNase-free water (Invitrogen). The N40 library contained chemically-synthesised ssDNA oligonucleotides that are comprised of a 40-nucleotide randomised region with forward and reverse primer flanking regions for PCR (see Table 6.4). Prior to the initial SELEX round, $5 \mu \mathrm{L}$ of the $400 \mu \mathrm{M}$ stock solution was added to $45 \mu \mathrm{L}$ of ultra-pure DNase-free water (Invitrogen) in a 
$1.5 \mathrm{~mL}$ microcentrifuge tube. Following this, the N40 library was denatured at $95^{\circ} \mathrm{C}$ for 7 minutes in a water-bath, briefly vortexed and centrifuged for several seconds before being placed on ice for 10 minutes. The purpose of this was to allow the oligonucleotides to denature and linearise before allowing them to anneal and reform any potential secondary structures prior to the first co-incubation.

\subsection{PRIMER PREPARATION}

The primers were supplied as lyophilised powder and were prepared as per the N40 library. A $100 \mu \mathrm{M}$ stock solution was prepared using Ultra-pure DNase-free water (Invitrogen). And $10 \mu \mathrm{M}$ working aliquots were prepared using Ultra-pure DNase-free water (Invitrogen) in $1.5 \mathrm{~mL}$ micro centrifuge tubes and stored at $-20^{\circ} \mathrm{C}$. The forward $(\mathrm{Pf})$ and reverse $(\mathrm{Pr})$ primers were chemically synthesised and designed to match identically with the flanking regions of the N40 library. The primers used for PCR amplification during SELEX consisted of non-modified forward primer $(\mathrm{Pf})$ and $5^{\prime}$ biotin-labelled reverse primer $(\mathrm{PrB})$. The biotin label was employed during the strand separation process and does not inhibit the PCR reaction.

\subsection{MEMBRANE MATRIX AND N40 LIBRARY BLOCKING}

The blocking solution was prepared fresh, as 10\% (w/v) skim-milk powder in 1x BWB with $0.1 \%$ IGEPAL (v/v) and stored temporarily at $4{ }^{\circ} \mathrm{C}$ to allow for solids to dissolve. Additionally, $5 \%$ blocking solution was prepared by diluting 2 -fold with equal parts $1 \mathrm{x}$ BWB containing $0.1 \%$ IGEPAL (v/v). Before blocking, the ssDNA library would be prepared by denaturation for the initial round or via strand separation (see 2.21) for subsequent SELEX rounds, before adding equal volumes of $10 \%$ blocking solution for 30 minutes at RT. Similarly, target and control membranes (as described in Sections 2.9 and 2.9.1) would be removed carefully using a sterile pipette tip, transferred to a $1.5 \mathrm{~mL}$ micro centrifuge tube, and gently washed thrice by pipetting with $500 \mu \mathrm{L}$ of $1 \mathrm{x}$ BWB containing $0.1 \%$ IGEPAL $(\mathrm{v} / \mathrm{v})$ to remove any protein solution or weakly bound protein that may interfere with the co-incubation. After this, the membranes would be transferred again into $1.5 \mathrm{~mL}$ micro-centrifuge tubes containing $50 \mathrm{uL}$ of $5 \%$ blocking solution for 1 hour at RT. Typically, two target membranes and one control membrane were used in each SELEX round and the control and target membranes were strictly washed and blocked separately before co-incubation, reducing the chance of contaminating the unblocked-control membrane with target protein. 


\subsection{CO-INCUBATION OF PROTEIN TARGETS AND N40 LIBRARY}

Following the blocking step, a co-incubation step was performed. For this, the blocked control and target membranes were transferred into a $1.7 \mathrm{~mL}$ micro-centrifuge tube, before adding the blocked N40 library. The co-incubation was mixed gently by pipetting several times before being placed on an orbital shaker at 500rpm for $12-16$ hours at $4{ }^{\circ} \mathrm{C}$, usually overnight. It is important to note that the co-incubation step is performed at $4{ }^{\circ} \mathrm{C}$ to prevent degradation of the protein.

\subsection{WASHING OF MEMBRANE-PROTEIN MATRIX FOLLOWING CO- INCUBATION}

Following the co-incubation step and prior to PCR amplification, the membranes were washed to remove both excess blocking solution and non-specific sequences bound weakly to the surface of the membrane. To achieve this, the co-incubation media was discarded and $500 \mu \mathrm{L}$ of $1 \mathrm{x}$ BWB containing $0.1 \%(\mathrm{v} / \mathrm{v})$ IGEPAL was added to each tube and gently pipette mixed to wash the membranes. This step was repeated for a total of 3 times, before transferring each membrane to a separate $200 \mu \mathrm{L}$ PCR tube containing $15 \mu \mathrm{L}$ of Ultra-pure DNase-free water prior to elution and PCR.

\subsection{MEMBRANE ELUTION AND PCR SAMPLE PREPARATION}

The membrane-bound N40 library was denatured from each membrane prior to PCR amplification. The PCR tubes containing washed and individual membranes from the coincubation (see Sections 2.15 and 2.16), were heat denatured at $95^{\circ} \mathrm{C}$ for 10 minutes, using a thermocycler (Eppendorf). Immediately after denaturation, the membranes were removed and transferred into individual $200 \mu \mathrm{L}$ PCR tubes and washed thrice with $100 \mu \mathrm{L}$ of Ultrapure DNase-free water and kept for PCR. Resulting in $15 \mu \mathrm{L}$ of ssDNA 'elution' and whole nitrocellulose membranes, to be used as PCR templates. The control-membrane elution, and all membrane samples, were considered as controls to visualise the non-specific binding to the membrane and the elution efficiency, respectively. Whereas, the targetmembrane elution was considered as the molecules of interest and be regenerated for the following SELEX round. 


\subsection{PCR AMPLIFICATION}

\subsubsection{POLYCLONAL LIBRARY ENRICHMENT}

The PCR reactions were prepared using the Taq Polymerase kit (Qiagen) following manufacturer's instructions. A master mix (MM) was prepared for all the samples, based on $50 \mu \mathrm{L}$ total reaction volume per sample, comprising; 2 units of Taq, Polymerase, $5 \mu \mathrm{L}$ of 10x PCR buffer, $1.2 \mu \mathrm{L}$ of dNTPs $(10 \mathrm{mM}, 1: 1: 1: 1$, deoxyadenosine 5'-triphosphate (dATP): deoxycytidine 5'-triphosphate(dCTP): deoxyguanine 5'-triphosphate (dGTP): deoxythymidine 5'-triphosphate (dTTP)), $1.1 \mu \mathrm{L}$ of both biotinylated reverse Primer (PrB, $50 \mathrm{mM})$ (see appendix) and forward primer (Pr, $50 \mathrm{mM}), 34.2 \mu \mathrm{L}$ of ultra-pure DNase-free water, then vortexed and centrifuged to mix. After this, $43 \mu \mathrm{L}$ of MM per sample was added to individual $200 \mu \mathrm{L}$ PCR tubes before addition of either; $7 \mu \mathrm{L}$ of Ultra-pure DNase-free water (negative control), $7 \mu \mathrm{L}$ of $75 \mathrm{bp}$ monoclonal oligonucleotide $(28.5 \mathrm{mM})$ (positive control), $7 \mu \mathrm{L}$ of elution or $7 \mu \mathrm{L}$ of Ultra-pure DNase-free water with an individual membrane (see 2.17). Using a thermocycler (Eppendorf), an initial $95^{\circ} \mathrm{C}$ denaturation step was performed to activate the Taq Polymerase, followed by $35 \mathrm{x}$ cycles of; $94^{\circ} \mathrm{C}$ for 40 seconds (denaturation), $52^{\circ} \mathrm{C}$ for 20 seconds (annealing) and a $72^{\circ} \mathrm{C}$ for 10 seconds (extension). Finally, a $72^{\circ} \mathrm{C}$ extension step for 60 seconds was performed in order to allow the full extension of any products present in the final thermal cycle. To prevent contamination, it is important to note that the negative sample was pipetted first, prior to the introduction of any samples. All samples were prepared in a sterile laminar flow safety hood, using aseptic technique, to further avoid contamination.

\subsubsection{N40 LIBRARY EVOLUTION BY PCR MUTATION}

During several rounds of SELEX, PCR mutation was encouraged to introduce new, potentially beneficial, point mutations to the SELEX library. This was achieved as per 2.18.1, with the addition of $0.3 \mu \mathrm{L}$ of $50 \mathrm{mM}$ of $\mathrm{MgCl}_{2}\left(\mathrm{Mg}^{2+}\right)$ to the $\mathrm{MM}$ in place of the equivalent volume of ultra-pure DNase-free water. It is important to note that $\mathrm{Mg}^{2+}$ is a vital cofactor for Taq polymerase, and the 10x PCR buffer already contains $2.5 \mathrm{mM}$ of $\mathrm{Mg}^{2+}$ (as $\mathrm{MgCl}_{2}$ ). However, the addition of $\mathrm{MgCl}_{2}$ acts to increase the error-rate of the Taq polymerase enzyme, facilitating single point mutations within the variable region of the N40 library sequences via wrongful dNTP incorporation. 


\subsubsection{REAL-TIME PCR FOR SEQUENCING}

For the final round of SELEX, real-time PCR was employed to amplify the N40 library in order to monitor the PCR efficiency. The benefit of real-time PCR over end-point PCR (see Sections 2.18.1 and 2.18.2) is that, by stopping the reaction at peak amplification efficiency, the formation of PCR by-products is not favoured and therefore produces a sample more representative of the N40 library from the previous SELEX round prior to DNA sequencing. The reagents and volumes were as stated in section 2.18.1 with the following exceptions: $31.3 \mu \mathrm{L}$ of ultra-pure DNase-free water, $1.0 \mu \mathrm{L}$ of dNTPs, 1.5 units of Taq polymerase and $0.2 \mu \mathrm{L}$ of SYBR Safe II (Life Technologies) to a final MM volume of $40 \mu \mathrm{L}$. $10 \mu \mathrm{L}$ of sample template was added for a final reaction volume of $50 \mu \mathrm{L}$. The PCR mixture was split evenly into two strip-tubes (Qiagen) and placed into a 72-Gene-Disc rotor (Qiagen) with locking ring, then placed into a Corbett Rotogene Q (Qiagen) real-time PCR machine for a total of 33 cycles.

\subsection{DNA GEL ELECTROPHORESIS}

\subsubsection{PREPARATION OF AGAROSE GEL}

Horizontal gel electrophoresis was used to separate and visualise the dsDNA products following PCR (see Section 2.18). Using a glass conical flask, gels were made by adding $2.5 \%$ or $4 \%(\mathrm{w} / \mathrm{v})$ of LE (SeaKem ${ }^{\circledR}$, Lonza) or GTG agarose powder (NuSieve ${ }^{\mathrm{TM}}$, Lonza) in $1 \mathrm{x}$ Tris-Acetate-EDTA (TAE) buffer, to either $40 \mathrm{~mL}$ or $100 \mathrm{~mL}$, depending on the number of samples. Thereafter, a stirring bar was added to the flask and the flask was placed on a heated magnetic-stirrer. The mixture was heated for several minutes until boiling, and then briefly until all the agarose powder was visibly dissolved. At this point, the flask was removed from the hot plate and cooled for several minutes, before carefully pouring the gel into the gel cast and inserting the gel comb. Air bubbles were removed from the gel immediately after pouring, before being left to polymerise at RT for 30-60 minutes. Gels made in advance were set and wrapped in cling-film, then kept at $4^{\circ} \mathrm{C}$ for no longer than 12 hours before use. All samples after SR4 were resolved on 4\% GTG gels, apart from DNA plasmid digestions, which were ran on $2.5 \%$ LE agarose gels.

\subsubsection{SAMPLE PREPARATION AND GEL ELECTROPHORESIS}

A DNA intercalating dye, SYBR Safe II (Life Technologies), was used to visualise the dsPCR products after each round of SELEX. The samples were prepared at RT in individual micro-centrifuge tubes as follows; $2 \mu \mathrm{L}$ of $100 x$ SYBR Safe II dye, $20 \mu \mathrm{L}$ of PCR reaction, 
$5 \mu \mathrm{L}$ of $6 \mathrm{x}$ DNA loading dye (Glycerol and TAE, 1:1, v/v, with bromophenol blue) to a final volume of $27 \mu \mathrm{L}$. The samples were pipette mixed, before being left to incubate for 8 minutes at RT. Thereafter, the samples were vortexed and centrifuged for several seconds before gel electrophoresis. A low-range DNA ladder (Gene-Ruler LR, Thermo Fischer) was used to align PCR products by size, and was prepared as per the other samples, however adding $2 \mu \mathrm{L}$ of the ladder in place of the PCR reaction. The remaining PCR reaction was stored temporarily at $4^{\circ} \mathrm{C}$ before being transferred to $-20^{\circ} \mathrm{C}$ for long term storage.

\subsubsection{ELECTROPHORESIS}

The agarose gel was submerged in an electrophoresis tank (Bio-Rad) filled with $1 \mathrm{x}$ TAE buffer, approximately $5 \mathrm{~mm}$ above the surface of the gel. The entire volume from each sample was loaded into separate wells of the agarose gel (see 2.19.1). The samples were electrophoresed for 60-90 minutes at wither 75V (for 4\% GTG agarose gels) or 95V (for 2.5\% LE agarose gels) depending on the size of the gel and the migration of the bromophenol blue dye. The PCR products were analysed using an Omega Lum G Imaging System (Aplegen), exposing the gel for up to several seconds using 325nM ultraviolet light (UV). The presence of the desired 75bp products was confirmed via by alignment with the ladder and a monoclonal 75bp positive control sequence, as equivalent to the N40 library. The $75 \mathrm{mer}$ bands were excised from the gel using a razor blade and placed into $15 \mathrm{~mL}$ falcon tubes prior to gel extraction (see Section 2.20) or stored at $-20^{\circ} \mathrm{C}$ until use.

\subsection{DNA EXTRACTION FROM AGAROSE GEL}

The DNA products were extracted from the gel sections using a MinElute ${ }^{\mathrm{TM}}$ gel extraction kit (Qiagen) following manufacturer's instructions. The gel piece was weighed, before the addition of 3x (w/v) of Buffer QG (Qiagen) to the gel in a $15 \mathrm{~mL}$ Falcon tube. The falcon tube was placed into a $55^{\circ} \mathrm{C}$ water bath until gel sample was melted and then vortexed to ensure complete mixing. Following this, $1 \mathrm{x}(\mathrm{w} / \mathrm{v})$ of the original gel weight isopropanol was added, then vortexed, in order to linearise the DNA. The gel mixture was passed through a MinElute ${ }^{\mathrm{TM}}$ column, $700 \mu \mathrm{L}$ at a time, by centrifugation at $6 g$ for 60 seconds. The flow-through was repassed through the column three times in order to maximise the capture of the DNA product, as the 75bp sequences may have low binding efficiency to the column. Thereafter, the column was washed of salts and proteins using $500 \mu \mathrm{L}$ of buffer QG for $60 \mathrm{sec}$ at $6000 \mathrm{~g}$. Following the buffer PB wash, $750 \mu \mathrm{L}$ of buffer PE (Qiagen) was added to column to precipitate the DNA on the membrane, then centrifuged for 60 secs at 13,000g. This centrifugation step was repeated twice, in order to remove any residual ethanol 
(contained in Buffer PE) left from buffer PE that may interfere with following elution step. To elute the DNA from the column, the column was transferred in a $1.7 \mathrm{~mL}$ micro centrifuge tube before the addition of 30 $\mu \mathrm{L}$ of 1:50 EB buffer (Qiagen, diluted in Ultra-pure DNasefree water) directly to the column membrane. The buffer EB was incubated with the membrane for 2 minutes at RT, before the DNA was eluted by centrifugation for $60 \mathrm{sec}$ at $13 g$. This step was repeated a second time, with $20 \mu \mathrm{L}$ of Buffer EB (1:50), in order to elute any DNA still bound to the column following the initial elution. The eluted DNA was kept at $4{ }^{\circ} \mathrm{C}$ prior to immediate use or stored at $-20^{\circ} \mathrm{C}$ for future use.

\subsection{GENERATION OF SSDNA FOR SELEX CO-INCUBATION VIA ALKALINE DENATURATION}

Since the co-incubation requires the N40 library to be ssDNA, the positive strands of the N40 library need to be isolated from the negative strand. A biotin tag was use to label the dsDNA molecules, which was incorporated into the dsDNA product during PCR using biotin labelled reverse primer ( $\operatorname{PrB})$. To capture the dsDNA molecules, streptavidin coated magnetic beads (SMB, New England BioScience) were used to bind the dsDNA via the free-biotin labels of the reverse strands. In detail, $50 \mu \mathrm{L}$ of SMBs were added to a $1.7 \mu \mathrm{L}$ micro centrifuge tube, before being collected using a magnetic pipette (PickPen ${ }^{\mathrm{TM}}$ ) and washed thrice, each wash completed by transferring the SMBs to a new $1.7 \mathrm{~mL}$ micro centrifuge tube containing $50 \mu \mathrm{L}$ of $1 \mathrm{x}$ BWB $(0.1 \%(\mathrm{v} / \mathrm{v})$ IGEPAL). The washed SMBs were then added to the dsDNA elute (see Section 2.20) and incubated at RT for 30 minutes. Thereafter, the dsDNA-SMB complexes were washed twice as per previously described, before a final wash in $50 \mu \mathrm{L}$ Ultra-Pure DNase-free water. Using the magnetic pipette, the dsDNA-SMB complexes were transferred into a sterile $1.7 \mu$ Lmicro centrifuge tube containing $30 \mu \mathrm{L}$ of $0.3 \mathrm{M} \mathrm{NaOH}$ and incubated for 2 minutes at RT to allow the forward strand to denture from the SMB-bound reverse strand. After incubation, the SMBs were removed using the magnetic pipette, leaving the forward strand in solution. Immediately following removal of the SMBs, approximately $8 \mu \mathrm{L}$ of $1 \mathrm{M} \mathrm{HCl}$ was added to neutralise the solution to between $\mathrm{pH}$ 7.0-7.5 (determined by $\mathrm{pH}$ test strip kit). The resulting ssDNA solution was prepared for co-incubation of subsequent SELEX rounds (as per 2.14, 2.15).

\subsection{CLONING AND SEQUENCING OF N40 LIBRARY FROM FINAL SELEX ROUND}

After 10 rounds of SELEX, the N40 library was prepared for Sanger sequencing and subsequent analysis and screening for candidate aptamers for the target protein, GDF9. In 
summary, the ssDNA template from SR10 was amplified using RT-PCR (see Section 2.18.3) and ran a 4\% GTG gel (see Sections 2.19.2 and 2.19.3) before being subject to DNA gel extraction as per Section 2.18, however with a smaller elution volume of $10 \mu \mathrm{L}$ to concentrate the sample prior to ligation and subsequent cloning techniques as described below.

\subsubsection{DNA LIGATION}

A $10 \mu \mathrm{L}$ ligation mixture was created for each sample using the pGEM®-T-Easy Vector Cloning Kit System I cloning kit as follows; $3 \mu \mathrm{L}$ of purified PCR product (see Methods 2.20), $5 \mu \mathrm{L}$ of ligation buffer $(2 \mathrm{x}), 1 \mu \mathrm{L}$ pGEM-T Easy cloning vector (50ng), $1 \mu \mathrm{L}$ T4-DNA ligase (3units). Thereafter, the ligation mixture was pipette mixed and incubated overnight at $4^{\circ} \mathrm{C}$.

\subsubsection{TRANSFORMATION OF LIGATED DNA}

Ligated plasmids were transformed into competent DH5- $\alpha$ Escherichia coli (E. Coli) cells by the addition of $5 \mu \mathrm{L}$ of ligation mixture to $50 \mu \mathrm{L}$ of DH5- $\alpha$ cells followed by a 30 minute co-incubation on ice. After co-incubation, the uptake of plasmid DNA into the cells was performed using a 2 minute heat shock at $37{ }^{\circ} \mathrm{C}$ followed immediately by a 2 minute incubation on ice. After transformation, cells were grown in $950 \mu \mathrm{L}$ of Luria broth (LB; see Appendix 1) for 2 hours at $37^{\circ} \mathrm{C}$ on a shaking incubator at $250 \mathrm{rpm}$ before centrifugation at $3000 \mathrm{~g}$ for 5 minutes. Supernatant was discarded, and the bacterial pellet resuspended using $100 \mu \mathrm{L}$ of LB broth. Following this, the entire resuspended bacterial pellet was pipetted onto LB agar plates containing $50 \mu \mathrm{L} X-\mathrm{gal}(2 \%$ solution) and $50 \mu \mathrm{g} / \mathrm{mL}$ ampicillin before aseptically spreading using a glass rod. Thereafter, bacterial colonies were grown by incubating the agar plates upside down for 2 hours at RT before transferring to a $37^{\circ} \mathrm{C}$ incubator overnight.

\subsubsection{COLONY SELECTION}

Following overnight incubation, white bacterial colonies presumably containing the plasmid DNA were aseptically selected and transferred into individual glass vials containing $10 \mathrm{~mL} \mathrm{LB}$ broth (see Appendix 1) with $50 \mu \mathrm{g} / \mathrm{mL}$ ampicillin. Thereafter, the glass vials were incubated at $37^{\circ} \mathrm{C}$ overnight on a shaking incubator at $250 \mathrm{rpm}$. See Supplementary Figure 18 for examples of colony selection and agar plating. 


\subsubsection{ISOLATION OF PLASMID DNA}

After the overnight incubation (see 2.22.3), the bacteria was pelleted by centrifuging the glass vials were at $3,000 \mathrm{~g}$ for 10 minutes. The supernatant was poured off before resuspending and purifying the plasmid DNA from the bacterial pellet using the QIAprep Spin Miniprep Kit (Qiagen) following the manufactures instructions. Following elution, the concentration of the plasmid DNA containing the candidate aptamer sequences was measuring using 260/280nm wavelength (Nano-drop ${ }^{\mathrm{TM}}$, NDV-1000) before storage at $4^{\circ} \mathrm{C}$ or $-20^{\circ} \mathrm{C}$ for long-term storage.

\subsubsection{CONFIRMATION OF LIGATION}

Prior to sequencing, restriction digestion of the plasmid DNA was used to confirm the $75 \mathrm{bp}$ insert was present. A $15 \mu \mathrm{L}$ digestion reaction for each plasmid was prepared as follows; $10 \mu \mathrm{L}$ purified plasmid DNA (see methods 2.22.4), 1.5 $\mu \mathrm{L}$ Buffer $\mathrm{H}$ (digestion buffer, 10x), $1 \mu \mathrm{L}$ EcoRI (units $/ \mu \mathrm{L}$ ) and $2.5 \mu \mathrm{L}$ Ultra-pure DNase-free water. The samples were incubated at $37^{\circ} \mathrm{C}$ for 2 hours before inactivation at $65^{\circ} \mathrm{C}$ for 5 minutes. The digested DNA was separated using gel electrophoresis by adding $2 \mu \mathrm{L}$ pf 100x SYBR Safe II dye to the ligation mixture and continuing as described in section 2.19.2 and 2.19.3. The gel separated products were visualised using an Omega Lum G imaging system (Aplegen) and the 75bp insert was confirmed by alignment with a 75 DNA ladder maker. See Supplementary Figure 19 for example of restriction digestion.

\subsubsection{DNA SEQUENCING}

All sequencing was performed externally, at the DNA sequencing facility of Waikato University (Hamilton, NZ). Sanger Sequencing was used and sequencing files were generated as .ab1 and .seq formats.

\subsection{SEQUENCE ANALYSIS}

Analysis was performed on sequence files to determine nucleotide composition, conserved regions and homology of candidate GDF9 aptamers with each other and a published BMP15 aptamer (Lin et al., 2015). Sequence lists were saved as FASTA files for further analysis. 


\subsubsection{DNA AND PROTEIN ALIGNMENT}

DNA nucleotide alignment was performed using Geneious software version 8.1.8 (https://www.geneious.com). Flanking sequences were identified, and the sequences were trimmed and aligned using the "de novo assembly" feature with default Clustal W settings (Larkin et al., 2007). Protein alignment was performed using the software, Clustal Omega (Sievers et al., 2014), as part of the EMBL-EBI suite, (accessed: https://www.ebi.ac.uk/Tools/msa/clustalo/) with default settings and parameters used. Alignment of the mature proteins was performed for residues 315-453 for hGDF9 and 264393 for oBMP15 (Accession numbers: Q9MZE2 and O60383, respectively). Sequence files were obtained from the UniProt Database (The UniProt Consortium, 2016).

\subsubsection{GENERATION OF A PHYLOGENETIC TREE}

To investigate the evolutionary relatedness of the candidate GDF9 aptamers, the Neighbour-Joining method was used to generate a phylogenetic tree. The software, Simple Phylogeny (Larkin et al., 2007), as part of the EMBL-EBI suite (accessed: https://www.ebi.ac.uk/Tools/phylogeny/simple_phylogeny/), was used with the default settings and parameters. FASTA files generated from Geneious (see 2.21.1) were used as the file source.

\subsubsection{TWO-DIMENSIONAL (2D) STRUCTURE PREDICTIONS}

The mFold Web server (accessed: http://mfold.rna.albany.edu/?q=mfold/DNA-FoldingForm) (Zuker, 2003) was used to perform 2D structure analysis of candidate GDF9 aptamers. Within mFold, the 'DNA folding form' was used under default parameters with the exceptions of ionic conditions of $100 \mathrm{nM} \mathrm{Na}^{+}, 2 \mathrm{mM} \mathrm{Mg} 2^{+}$and temperature of $4{ }^{\circ} \mathrm{C}$ and 23. Predicted structures and calculated Gibb's free energy was presented as .JPEG files and tables, respectively. 


\section{CHAPTER 3: RESULTS}

\subsection{PROTEIN EXPRESSION OF RECOMBINANT OVINE AND MURINE BMP15 AND GDF9 FROM MODIFIED HEK293 CELL LINES}

The first aim of this project was to produce recombinant BMP15 and GDF9 proteins using previously transfected HEK293 cell lines modified with the p-EFIRES-P vector containing genes for BMP15 or GDF9 of mouse, sheep and pig origin. To determine if these cells lines were actively expressing these recombinant proteins, immunoblotting tests against BMP15 and GDF9 were performed under reducing conditions using previously characterised monoclonal antibodies, mAb61A (Swinerd, 2016) and mAb37A (Alhussini, 2016), respectively.

\subsubsection{OVINE AND MURINE BMP15 EXPRESSION MEDIA}

The presence of recombinant BMP15 in active cell culture medium was confirmed using a Western blot (Figure 3.1A), where an abundance of recmBMP15 and recoBMP15 that was $\sim 55 \mathrm{kDa}$ in size was detected, corresponding to the molecular weight of the pro-mature complex of BMP15. However, no bands equivalent to the size of mature BMP15 were detected in either EM sample, as compared to the o/oBMP15 positive control which in addition to the band equivalent to pro-mature BMP15, has a less abundant band equivalent to the size of mature BMP15 ( 15kDa) (Figure 3.1A).

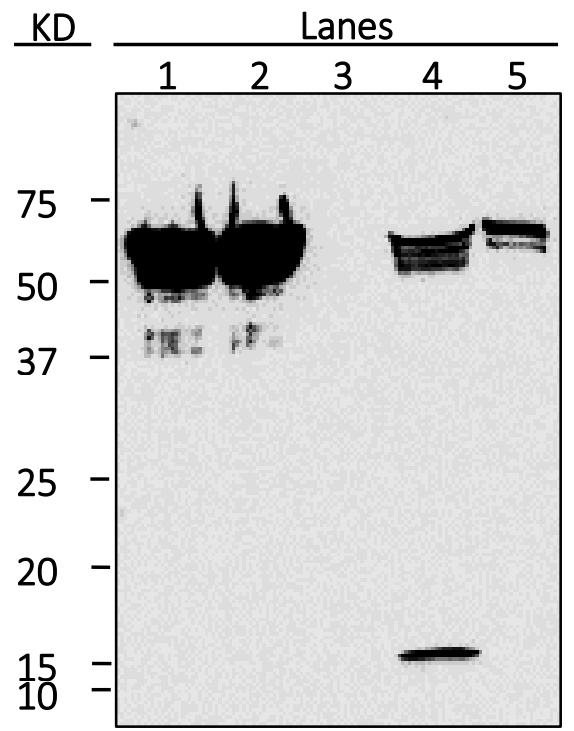

Figure 3.1A. RecBMP15 protein expression test from HEK293 EM. Western immunoblot 13.5\% SDS-PAGE ran under reducing conditions. Lane 1; mBMP15 EM $(5 \mu \mathrm{L})$, Lane 2;

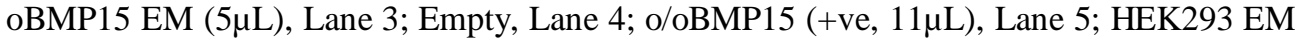
(no protein vector) $(-\mathrm{ve}, 11 \mu \mathrm{L})$. 


\subsubsection{OVINE AND MURINE GDF9 EXPRESSION MEDIA}

An expression test for recombinant GDF9 production was also performed on culture medium using immunoblotting with the antibody mAb37A. The Western blot (Figure 3.1B) shows the presence of a pro-mature complex at $\sim 55 \mathrm{kDa}$ for pGDF9 and oGDF9, although the band is less dense for oGDF9. Expression media containing porcine, ovine and murine GDF9 have detectable mature monomers of $\sim 17 \mathrm{kDa}$ (Figure 3.1B). Expression media containing pGDF9 and oGDF9 also showed the presence of a low-molecular weight band around $\sim 12 \mathrm{kDa}$ (Figure 3.1B). The faint band detected for mGDF9 mature protein may been due to a lack of antibody specificity, as it was generated against oGDF9.

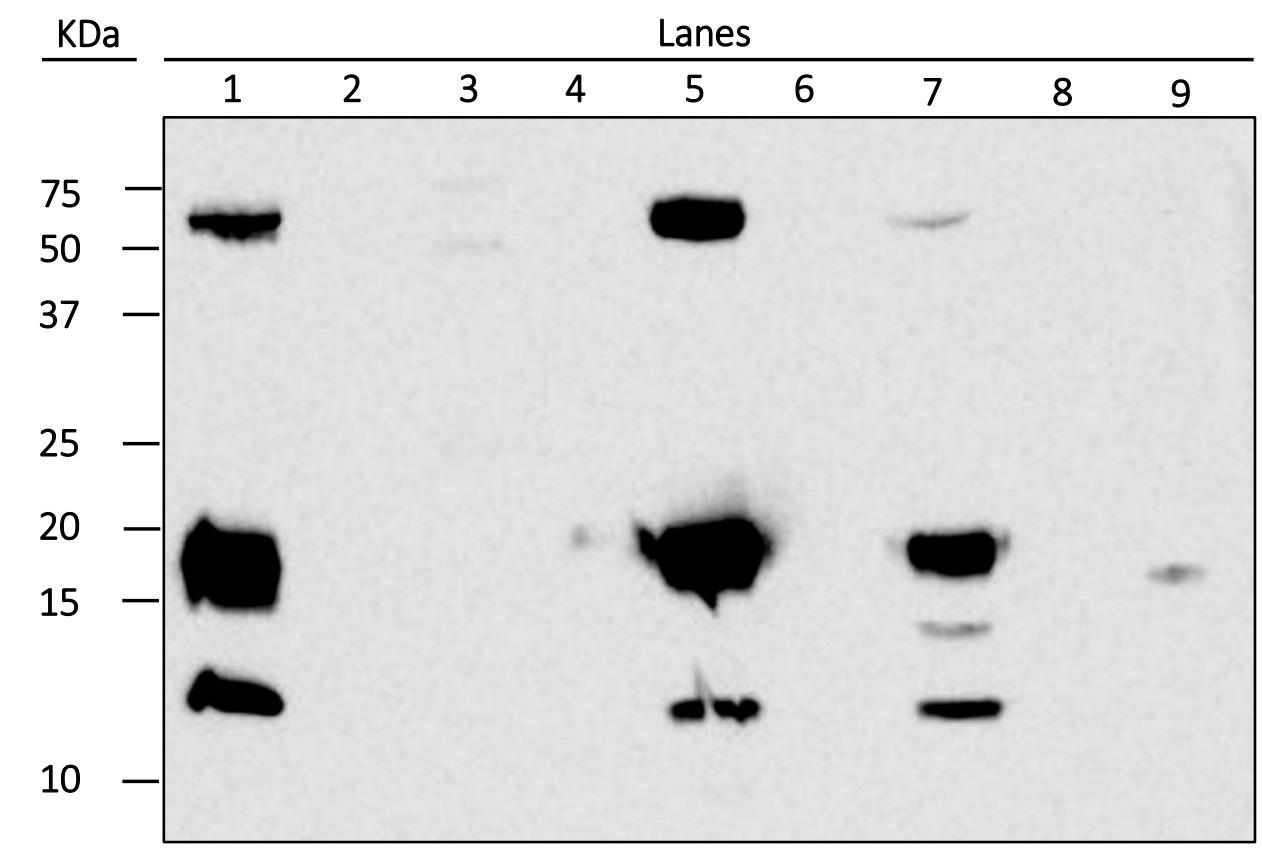

Figure 3.1B. RecGDF9 protein expression test from HEK293 EM. Western immuno-blot $13.5 \%$ SDS-PAGE ran under reducing conditions. Lanes 4, 6, 8; Empty lanes, Lane 1; pGDF9 EM (+ve, $2 \mu \mathrm{L})$,

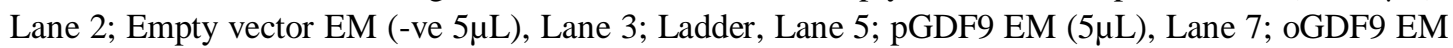
$(5 \mu \mathrm{L})$, Lane 9; mGDF9 (5uL).

\subsection{ION METAL AFFINITY CHROMATOGRAPHY PURIFICATION OF RECOMBINANT OVINE AND MURINE BMP15 AND GDF9 FROM MODIFIED HEK293 CELL LINES}

The second aim of this project was to purify the HEK293-produced recombinant BMP15 and GDF9 proteins, previously confirmed to be present in the expression media (Figures 3.1A and 3.1B). IMAC was employed to separate the proteins by $6 \mathrm{xHis-tags}$ present in the protein vector originally used to generate the genetically-modified cell lines. Immunoblotting for BMP15 and GDF9 was performed under reducing conditions using 
previously characterised monoclonal antibodies, mAb61A (Swinerd, 2016) and mAb37A (Alhussini, 2016), respectively.

\subsubsection{OVINE AND MURINE BMP15 IMAC-PURIFIED EXPRESSION MEDIA}

To track the abundance and molecular forms of BMP15 during IMAC purification, western blotting with mAB61A was performed for under reducing conditions with one sample from each step within the IMAC protocol. The expression media containing mBMP15 did not yield any protein following IMAC purification as illustrated in Figure 3.2A. An unknown $\sim 75 \mathrm{kDa}$ band was however detected in the expression media prior to IMAC purification, possibly representing a mature/pro-mature complex and a band at $\sim 17 \mathrm{kDa}$, corresponding to the mature BMP15 monomer as consistent with that illustrated in Figure 3.1.A. Ovine BMP15 was also not detected following IMAC purification. The EM prior to, and the wash solutions during, IMAC purifications contained bands similar to a pro-mature complex $(\sim 50 \mathrm{kDa})$ and mature BMP15 monomer $(\sim 17 \mathrm{kDa})$, respectively (Figure 3.2.B). Interestingly, no eluates contained any molecular forms of BMP15. An unknown band of $\sim 25 \mathrm{kDa}$ size was also present in these expression media and wash solution samples (Figure 3.2.B).

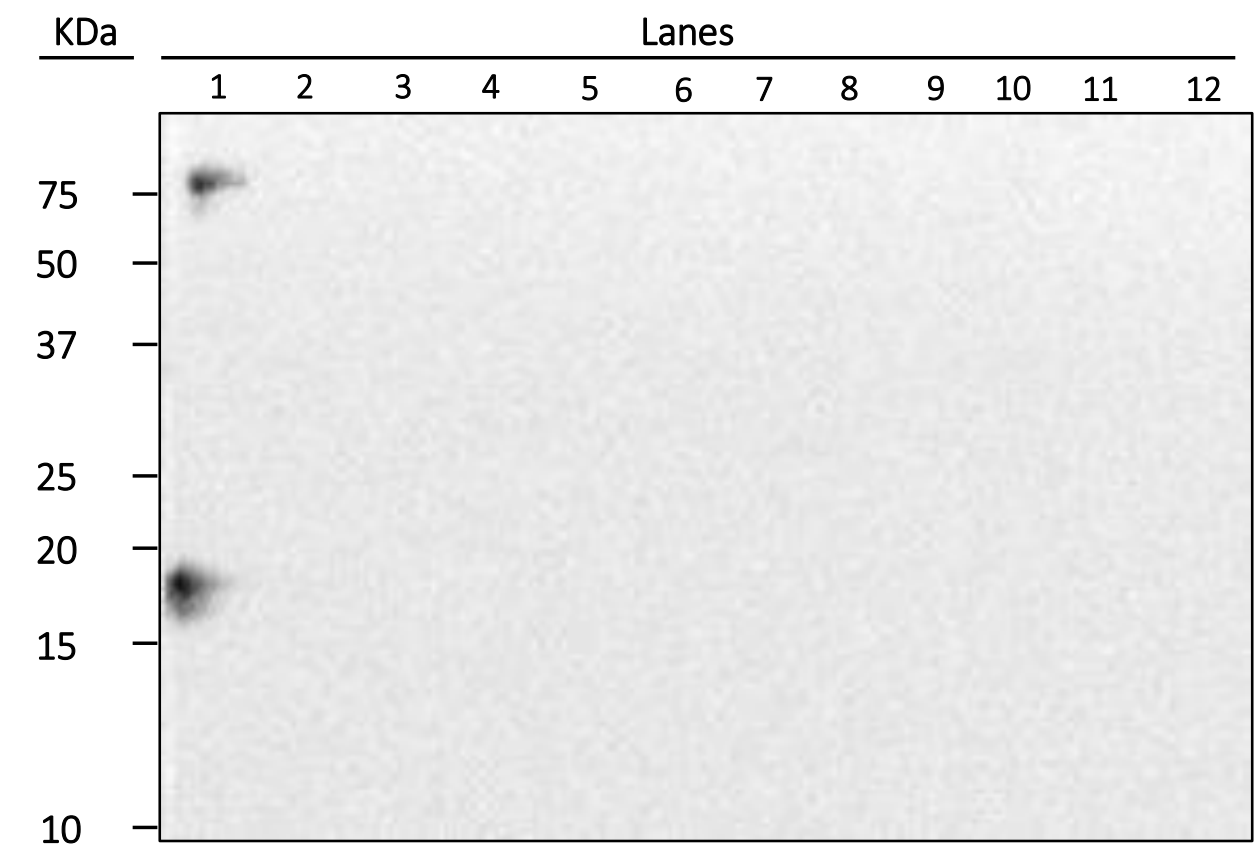

Figure 3.2A. Purification of recmBMP15 HEK293 EM. Western immuno-blot 13.5\% SDS-PAGE ran

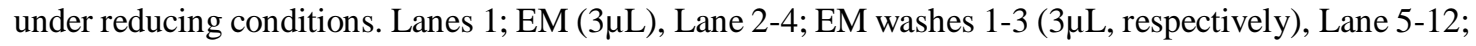

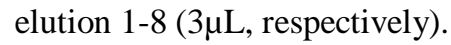




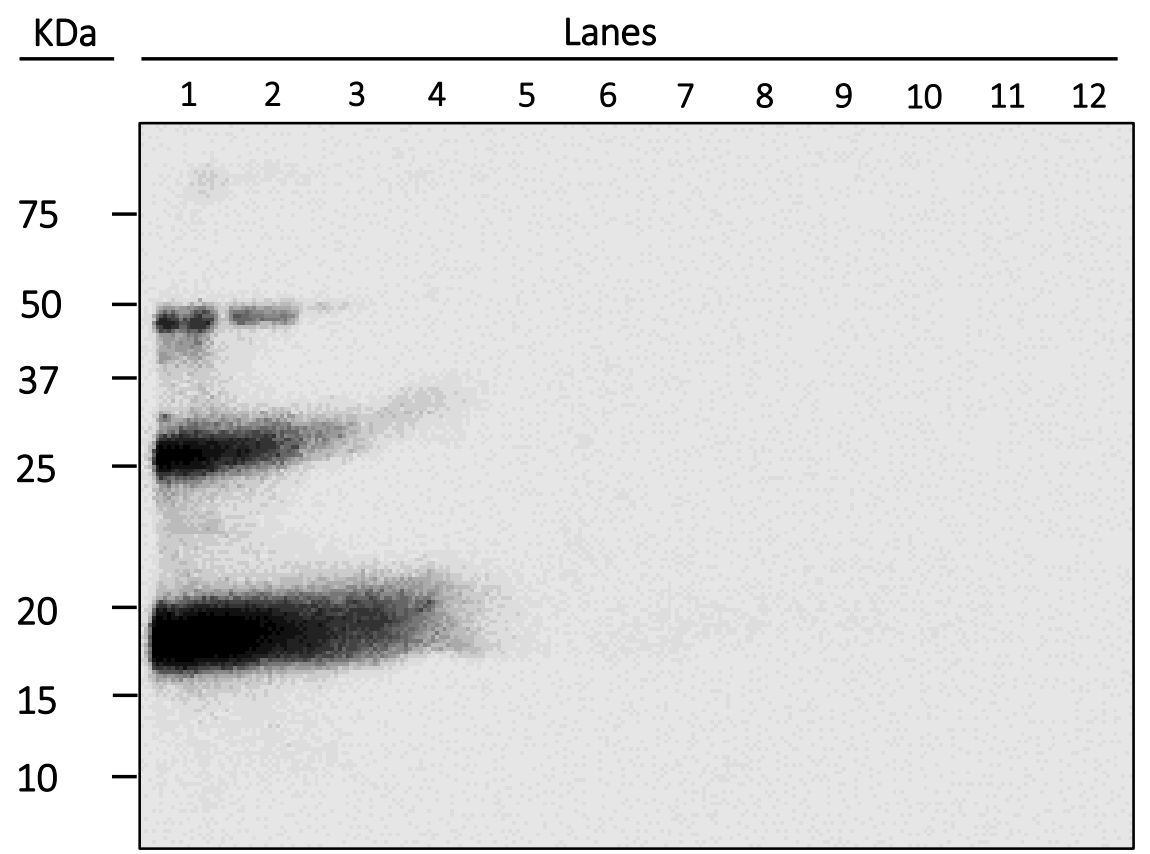

Figure 3.2B. IMAC purification of recoBMP15 HEK293 EM. Western immuno-blot 13.5\% SDS-PAGE

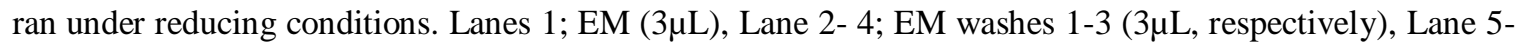
12 ; elution 1-8 $(3 \mu \mathrm{L}$, respectively).

\subsubsection{OVINE AND MURINE GDF9 IMAC-PURIFIED EXPRESSION MEDIA}

To track the abundance and molecular forms of GDF9 following IMAC purification, western blotting with mAB37A was performed for under reducing conditions with one sample from each step within the IMAC protocol (as in Section 3.2.1). In expression media containing mGDF9, a faint band corresponding to the mature GDF9 monomer ( 15kDa) was detected prior to IMAC purification (Figure 3.2C) and no bands were detected in the wash solutions. Strong bands representing mature GDF9 monomer were detected in the first six eluates and a $\sim 60 \mathrm{kDa}$ band corresponding to pro-mature GDF9 was present in all eluates (Figure 3.2C).

In expression media containing oGDF9, faint bands representing the pro-mature complex and mature monomer were detected in the expression media prior to IMAC-purification (Figure 3.2.D). Similar to mGDF9, strong bands representing mature oGDF9 monomer $(\sim 17 \mathrm{kDa})$ were detected in all 15 eluates with band density decreasing gradually. Two prominent, low molecular mass bands $(\sim 12$ and $\sim 14 \mathrm{kDa})$ of unknown identity were detected in most eluates, consistent with previous blots of expression media (c.f. Figure 3.1B). Less pro-mature complex was observed in the oGDF9, compared with mGDF9, eluates, although the former increased during the second-round eluates using $7 \mathrm{M}$ urea solution. 


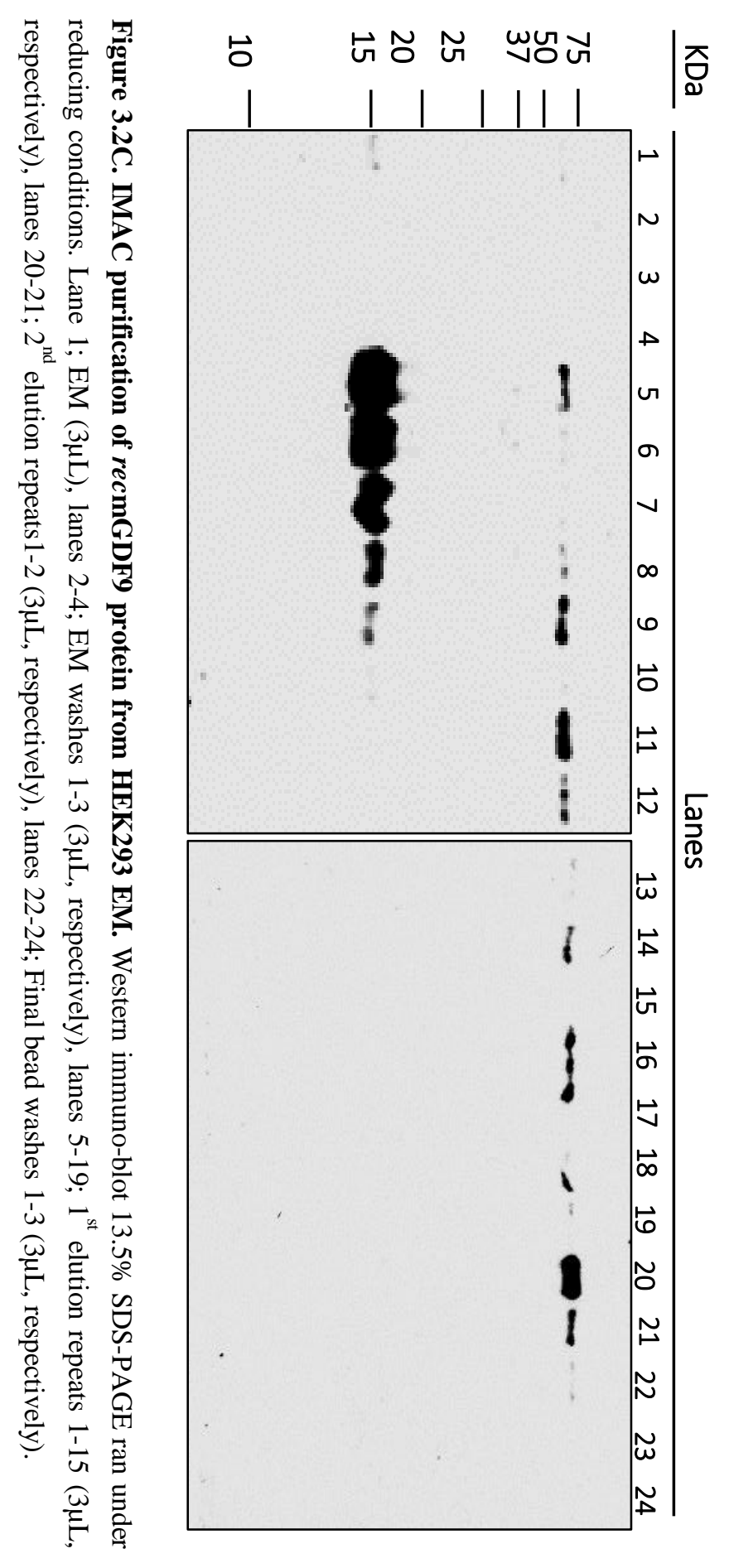




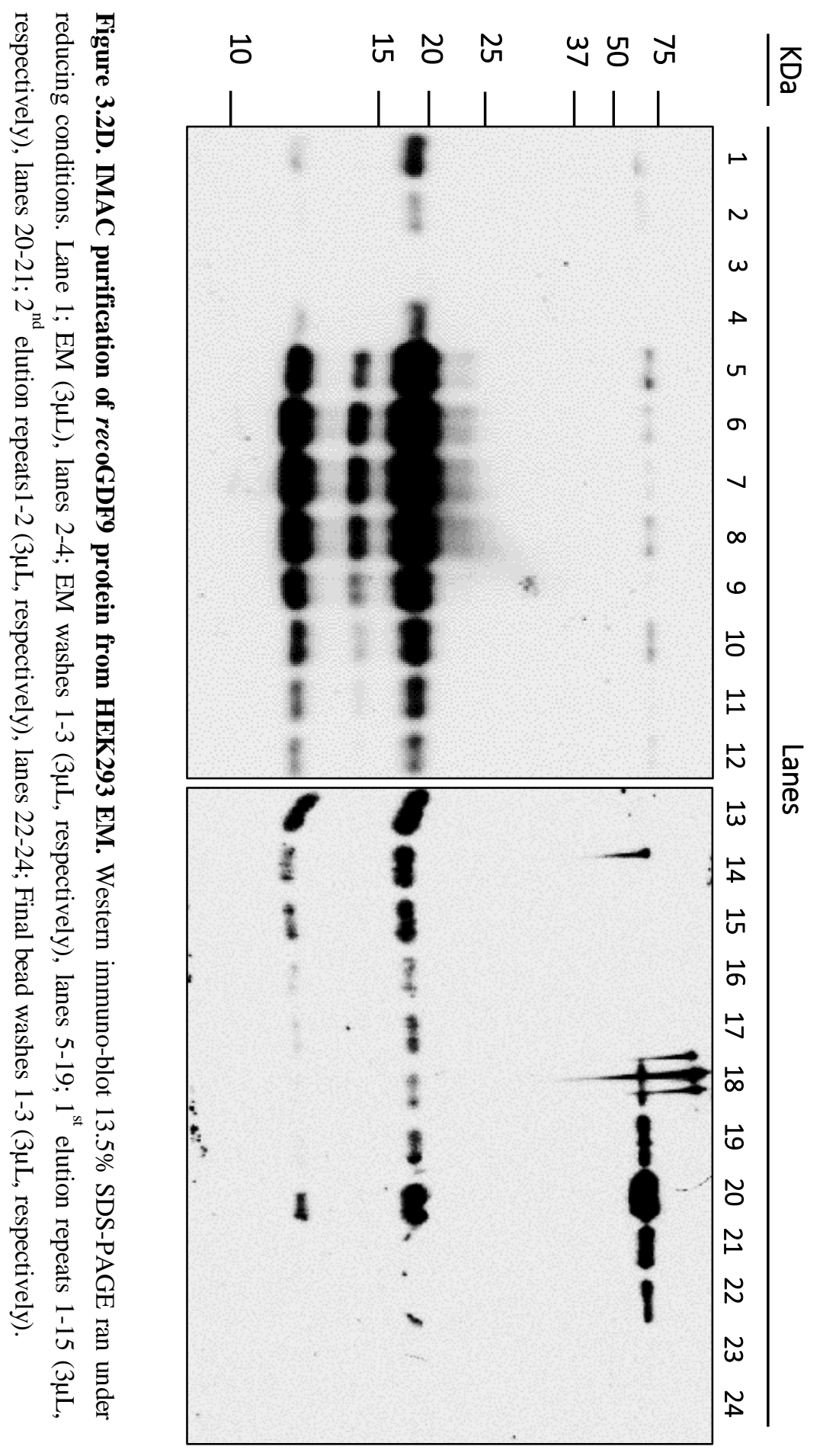




\subsection{HIGH PERFORMANCE LIQUID CHROMATOGRAPHY PURIFICATION OF IMAC PURIFIED RECOMBINANT BMP15 AND GDF9 EXPRESSION MEDIA}

High performance liquid chromatography (HPLC) using a reverse phase column and solvent gradient was employed to further purify the IMAC-purified mGDF9 (Fractions 1 to 5) and oGDF9 (Fractions 1 to 15) eluates (Figures 3.2C and D, respectively) to separate the molecular forms by mass. Immunoblotting for GDF9 was performed under reducing conditions as described above (Section 3.1.1 to 3.2.2) except for samples and sample volumes (stated for each figure).

\subsubsection{HPLC-PURIFIED MURINE GDF9 IMAC ELUATES}

To track the abundance and molecular forms of mGDF9 following HPLC purification, one sample was collected after each minute of HPLC elution as the solvent gradient increased. Eluates for mGDF9 were positive for mature GDF9 monomer ( 20kDa) from Fractions 29 to 32 (Figure 3.3A, lanes 9-12). No bands corresponding to a pro-mature complex, or otherwise, were detected in any samples following Fraction 8 (data not shown). For some eluates (Fractions 6-8) where a mature GDF9 monomer was detected, an additional $\sim 15 \mathrm{kDa}$ band was also detected and may possibly be due to denaturation following HPLC treatment and purification.

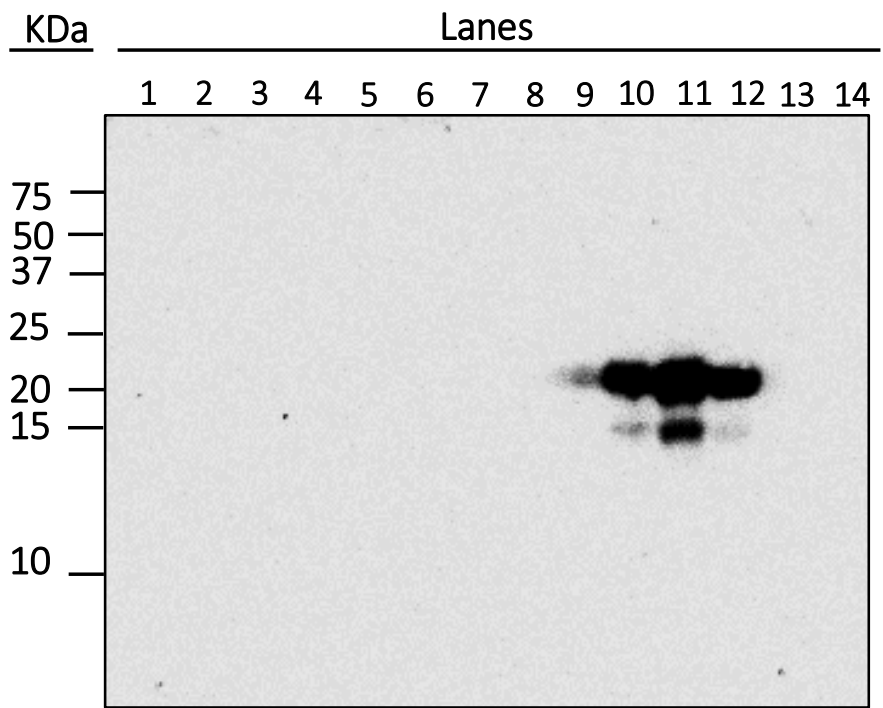

Figure 3.3A. HPLC purification of recmGDF9 protein from IMAC purified EM. Western immuno-blot 13.5\% SDS-PAGE ran under reducing conditions. Lanes 1-14: HPLC fraction 21$34(7.5 \mu \mathrm{L}$ each $)$. 


\subsubsection{HPLC-PURIFICATION OF OVINE GDF9 IMAC ELUATES}

To track the abundance and molecular forms of oGDF9 following HPLC purification, samples were collected throughout the HPLC procedure as described above. Consistent with the HPLC eluates for mGDF9, eluates containing mature monomers of oGDF9 were collected in Fractions 27 to 31 (Figure 3.3B, lanes 7-11), the molecular weight consistent with pervious results (Figures 3.1B and D). Multiple low-molecular bands ( 10-15kDa) were also detected. The most prominent of these bands were of $\sim 12$ and $\sim 14 \mathrm{kDa}$ in size and were previously detected in the IMAC eluates for oGDF9 (Figure 3.2D). Additionally, several very low-molecular weight bands $(<10 \mathrm{kDa})$ were detected and possibly correlate to denaturation or fragmentation of the protein resulting from HPLC treatment and purification.

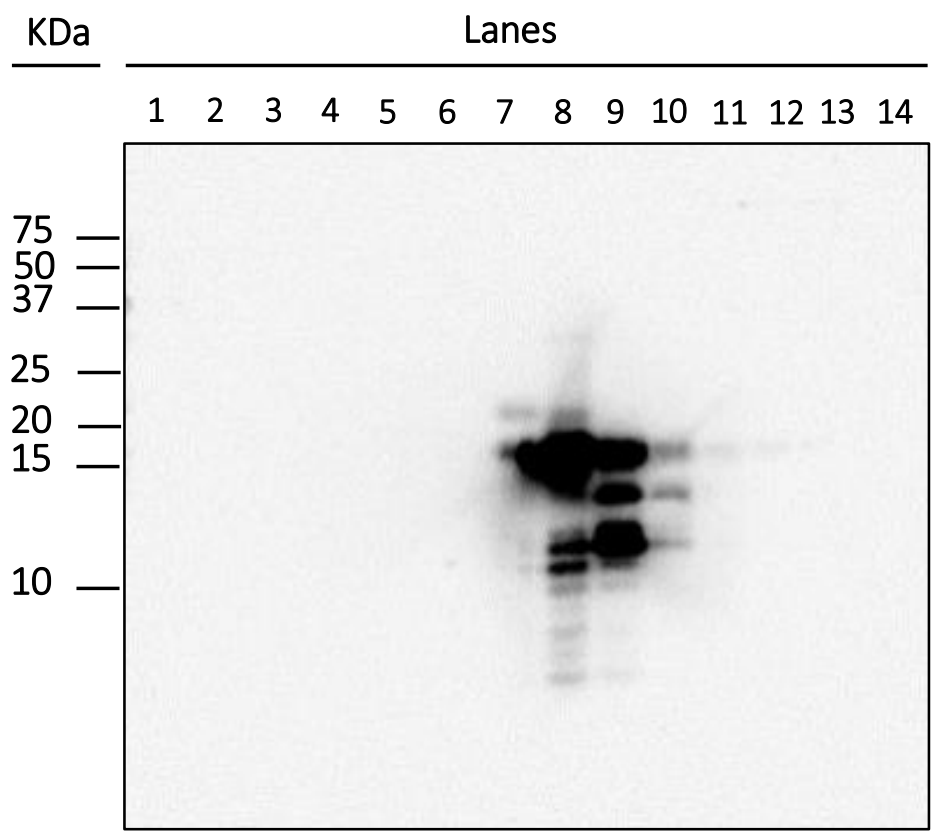

Figure 3.3B. HPLC purification of recoGDF9 protein from IMAC purified EM. Western immuno-blot 13.5\% SDS-PAGE ran under reducing conditions. Lanes 1-14: HPLC fraction 21-34 $(7.5 \mu \mathrm{L}$ each $)$.

\subsection{SELECTION OF APTAMERS FOR HUMAN RECOMBINANT GDF9}

The third aim of this project was to generate an aptamer specific to GDF9 that exhibited the ability to recognise multiple species of GDF9 including that of mouse, sheep, pig and human origin. Purified recombinant human GDF9 from modified HEK293 cells was used as the immobilised target for selection. The target was immobilised on nitrocellulose 
membranes and due variations in batch synthesis, a variable number of membranes were prepared for each co-incubation. Additional measures such as PCR re-amplification was required at times to generate more PCR product before progressing to the next coincubation. Due to this, a summary table (Table 3.4) is provided below which lists all the SELEX variables for each SR.

Table 3.4. Summary of SELEX conditions used for each selection round.

\begin{tabular}{|c|c|c|c|c|c|c|c|c|c|c|}
\hline & \multicolumn{10}{|c|}{ Selection Round (SR) } \\
\hline Conditions & 1 & 2 & 3 & 4 & 5 & 6 & 7 & 8 & 9 & 10 \\
\hline $\begin{array}{l}\text { Control } \\
\text { membrane }\end{array}$ & 1 & 1 & - & - & 1 & 1 & 2 & 1 & 1 & 1 \\
\hline Target Membrane & 3 & 3 & 2 & 2 & 2 & 2 & 2 & 2 & 2 & 2 \\
\hline $\begin{array}{l}\text { Membrane prep } \\
(\mathrm{dd} / \mathrm{mm} / 18)\end{array}$ & $26 / 02$ & $26 / 02$ & $\begin{array}{l}26 / 02 \\
05 / 03\end{array}$ & $\begin{array}{l}26 / 02 \\
05 / 03\end{array}$ & $\begin{array}{l}26 / 02 \\
05 / 03\end{array}$ & 05.03 & $05 / 03$ & $05 / 03$ & $05 / 03$ & $15 / 04$ \\
\hline $\begin{array}{l}\text { Incubation } \\
\text { volume }(\mu \mathrm{L})\end{array}$ & 168 & 168 & 134 & 93 & 93 & 134 & 93 & 93 & 93 & 93 \\
\hline $\begin{array}{l}\text { Incubation } \\
\text { Medium }\end{array}$ & $\begin{array}{c}\text { BWB, } \\
5 \% \\
\text { Blotto } \\
\text { (w/v) }\end{array}$ & $\begin{array}{c}\text { BWB, } \\
5 \% \\
\text { Blotto } \\
\text { (w/v) }\end{array}$ & $\begin{array}{c}\text { BWB, } \\
5 \% \\
\text { Blotto } \\
\text { (w/v) }\end{array}$ & $\begin{array}{c}\text { BWB, } \\
5 \% \\
\text { Blotto } \\
\text { (w/v) }\end{array}$ & $\begin{array}{c}\text { BWB, } \\
5 \% \\
\text { Blotto } \\
\text { (w/v) }\end{array}$ & $\begin{array}{c}\text { BWB, } \\
5 \% \\
\text { Blotto } \\
\text { (w/v) }\end{array}$ & $\begin{array}{c}\text { BWB, } \\
5 \% \\
\text { Blotto } \\
(\mathrm{w} / \mathrm{v})\end{array}$ & $\begin{array}{c}\text { BWB, } \\
5 \% \\
\text { Blotto } \\
(\mathrm{w} / \mathrm{v})\end{array}$ & $\begin{array}{c}\text { BWB, } \\
5 \% \\
\text { Blotto } \\
(w / v)\end{array}$ & $\begin{array}{c}\text { BWB, } \\
5 \% \\
\text { Blotto } \\
\text { (w/v) }\end{array}$ \\
\hline $\begin{array}{l}\text { Incubation time } \\
\text { (Hours) }\end{array}$ & $12-16$ & $12-16$ & $12-16$ & $12-16$ & $12-16$ & $12-16$ & $12-16$ & $12-16$ & $12-16$ & $12-16$ \\
\hline $\begin{array}{l}\text { Incubation } \\
\text { temperature }\left({ }^{\circ} \mathrm{C}\right)\end{array}$ & 4 & 4 & 4 & 4 & 4 & 4 & 4 & 4 & 4 & 4 \\
\hline Detergent $\%(\mathrm{~V} / \mathrm{v})$ & 0.1 & 0.1 & 0.1 & 0.1 & 0.1 & 0.1 & 0.1 & 0.1 & 0.1 & 0.1 \\
\hline PCR cycles & 35 & 35 & 35 & 35 & 35 & 35 & 35 & 35 & 35 & 35 \\
\hline Re-amplification & No & Yes & Yes & No & Yes & No & No & No & Yes & No \\
\hline $\begin{array}{l}\text { Template dilution } \\
\text { (re-amplification) }\end{array}$ & - & $\begin{array}{l}1: 25 \\
1: 50\end{array}$ & $\begin{array}{c}1: 10 \\
1: 50 \\
1: 100\end{array}$ & - & $1: 100$ & - & - & - & $1: 50$ & - \\
\hline PCR Mutation & No & No & No & No & No & No & No & Yes & No & No \\
\hline $\begin{array}{l}\text { Multiple PCR } \\
\text { bands }\end{array}$ & No & No & No & Smear & $4-5$ & $2-3$ & Smear & 4.5 & $2-3$ & 2 \\
\hline Washing medium & BWB & BWB & BWB & BWB & BWB & BWB & BWB & BWB & BWB & BWB \\
\hline $\begin{array}{l}\text { Washing Volume } \\
(\mu \mathrm{L})\end{array}$ & $\begin{array}{l}3 \mathrm{x} \\
500\end{array}$ & $\begin{array}{l}3 x \\
500\end{array}$ & $\begin{array}{l}3 \mathrm{x} \\
500\end{array}$ & $\begin{array}{l}3 x \\
500\end{array}$ & $\begin{array}{l}3 x \\
500\end{array}$ & $\begin{array}{l}3 \mathrm{x} \\
500\end{array}$ & $\begin{array}{l}3 x \\
500\end{array}$ & $\begin{array}{l}3 \mathrm{x} \\
500\end{array}$ & $\begin{array}{l}3 \mathrm{x} \\
500\end{array}$ & $\begin{array}{l}3 x \\
500\end{array}$ \\
\hline Gel \% (W/v) & 2.5 & 2.5 & 2.5 & 2.5 & 4 & 4 & 4 & 4 & 4 & 4 \\
\hline Gel type (agarose) & LE & LE & LE & $\mathrm{LE}$ & GTG & GTG & GTG & GTG & GTG & GTG \\
\hline
\end{tabular}




\subsubsection{PCR PRODUCTS FROM ALL SELECTION ROUNDS AND THE GENERATION OF MULTIPLE SIZED PCR PRODUCTS FROM A 75BP TEMPLATE}

A summary of the PCR products produced from the target GDF9 membranes can be visualised in Figure 3.4A and were aligned with a known positive control of 75bp (monoclonal; bands not shown). After several rounds of selection, the expected 75bp SELEX product (SR1-SR3) shows bands of multiple sizes between 50-150bp (SR5, SR8 and SR9). Primer dimers are also visible (SR6, SR8 and SR9). In the final rounds of selection, a 75bp and 50bp band are evident (SR9 and SR10).

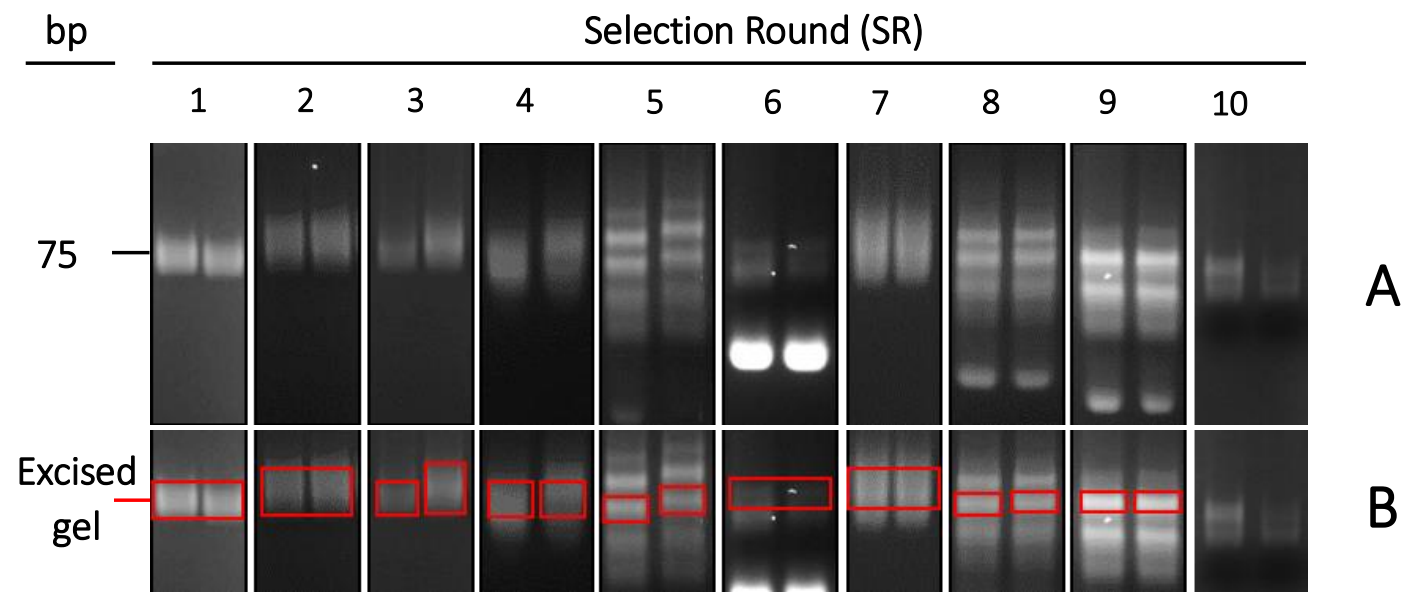

Figure 3.4A. Summary of post-PCR SELEX products following each co-incubation. GTG Agarose gel $(4 \% \mathrm{w} / \mathrm{v})$ ran under constant voltage in a horizontal gel tank. The dsDNA PCR Products stained with SYBR Safe II DNA intercalating dye. (A) Each SR showing 2 lanes for 'target' elution samples, representing the sequences of interest. All images aligned using 75bp monoclonal positive control, starting from SR1. (B) Approximate excised gel used as template for the next SR is highlighted for each SR.

\subsubsection{SELECTION ROUND 10 SHOWING SPECIFICITY FOR TARGET OVER CONTROL MEMBRANE}

SR10 was considered as the final aptamer library and products from the supernatants and membranes are illustrated in Figure 3.4B. The SR10 supernatant from the target membrane revealed two bands of 100 and 75bp (using the ladder) or 75 and 50bp (using the monoclonal positive control (Figure 3.4B; Lanes 5 and 6). In comparison, the SR10 supernatant from the control membrane and the target and control membranes showed no bands (Figure 3.4B; Lanes 7, 9-11). Band densitometry for supernatant samples was calculated using a 5-point measurement per band using Image J software. Both supernatants 
from the target membrane had stronger bands than that of the control membranes following PCR (Figure 3.4.C).

A further PCR using Corbett Rotorgene (Qiagen) machine was performed so that amplification of PCR products could be visualised in real time and the amplification cycles stopped once the reagents were depleted. Thus, real-time PCR was performed on the combined SR10 supernatants from the target membranes and the control membranes to generate more specific PCR product for cloning sequencing as illustrated in Figure 3.4D. Supernatants from the target membranes (Lanes 6-8) showed a higher abundance of 75bp sequences than that from control membranes (Lanes 2-4). The mean band densitometry showed that the supernatants from the target membrane was on average higher than that of control membranes (Figure 3.4E).

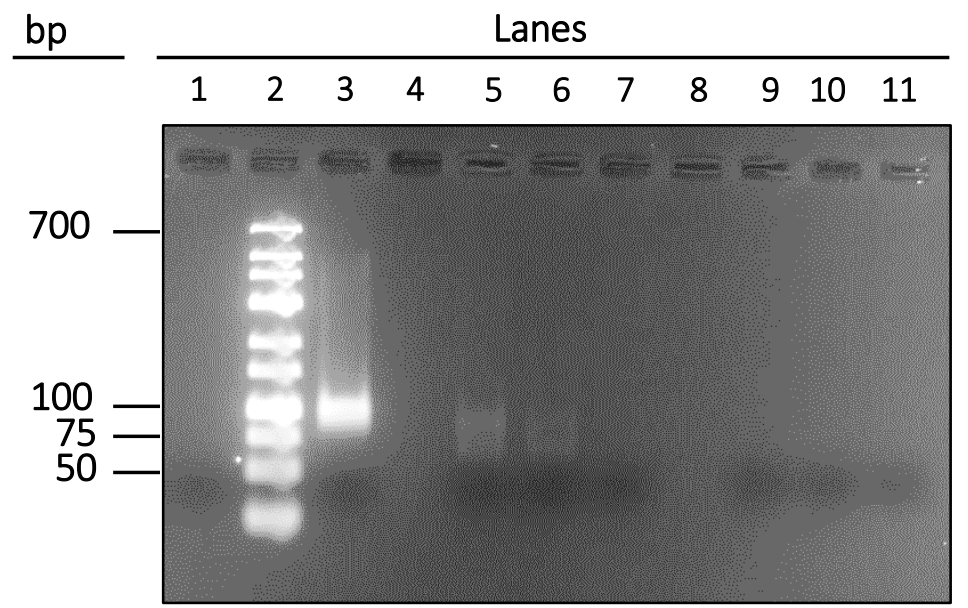

Figure 3.4B. PCR products following co-incubation of SR10. GTG Agarose gel $(4 \% \mathrm{w} / \mathrm{v})$ ran under constant voltage in a horizontal gel tank. The dsDNA PCR products stained with SYBR Safe II DNA intercalating dye. Lane 1; No template (-ve control), Lane 2; GeneRuler LR (700-25bp), Lane 3; 75bp monoclonal sequence (+ve control), Lanes 4 and 8; blank, Lanes 5 and 6; Target elution, Lane 7; Control elution, Lanes 9-11; whole membranes showing 2 lanes for 'target' elution samples, representing the sequences of interest. All images aligned using 75 bp marker of Gene Ruler LR DNA ladder, starting from SR1. 


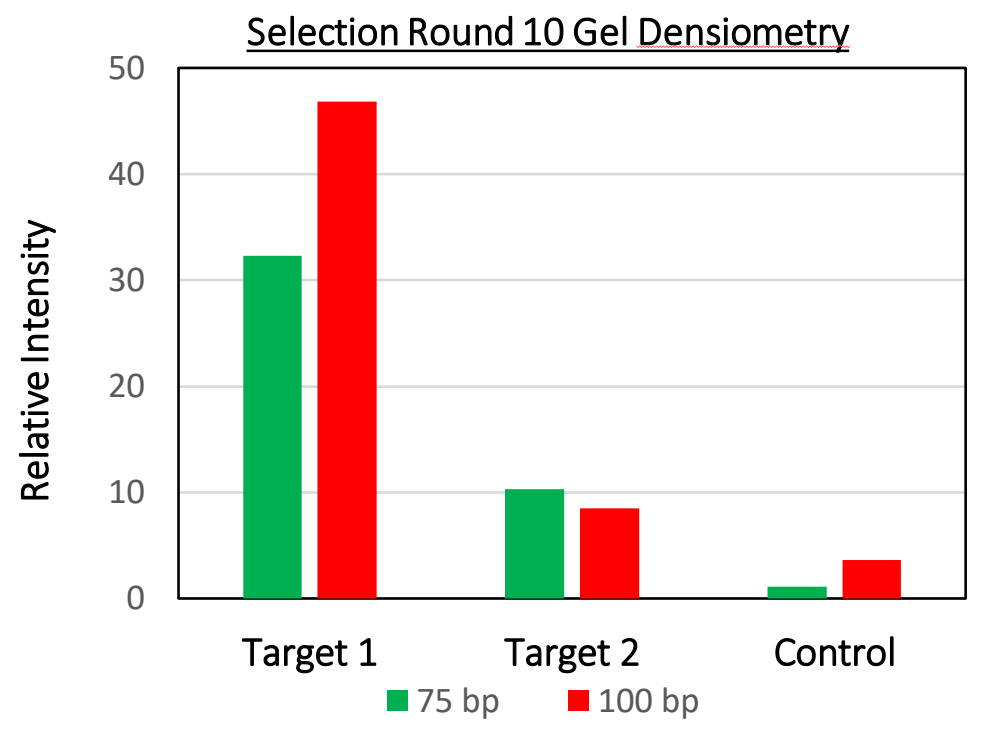

Figure 3.4C. Mean densitometry measurements of SR10 PCR products. Samples previously resolved on a GTG agarose gel (4\% w/v) and ran under constant voltage in a horizontal gel tank. The dsDNA PCR Products stained with SYBR Safe II DNA intercalating dye. 5-point measurements of the $\sim 75 \mathrm{bp}$ and $\sim 100 \mathrm{bp}$ bands (aligned with ladder) were measured using a fixed area within ImageJ software. Target and control PCR samples (lanes 5, 6 and 7 respectively) were plotted against each other and normalised against the background value.

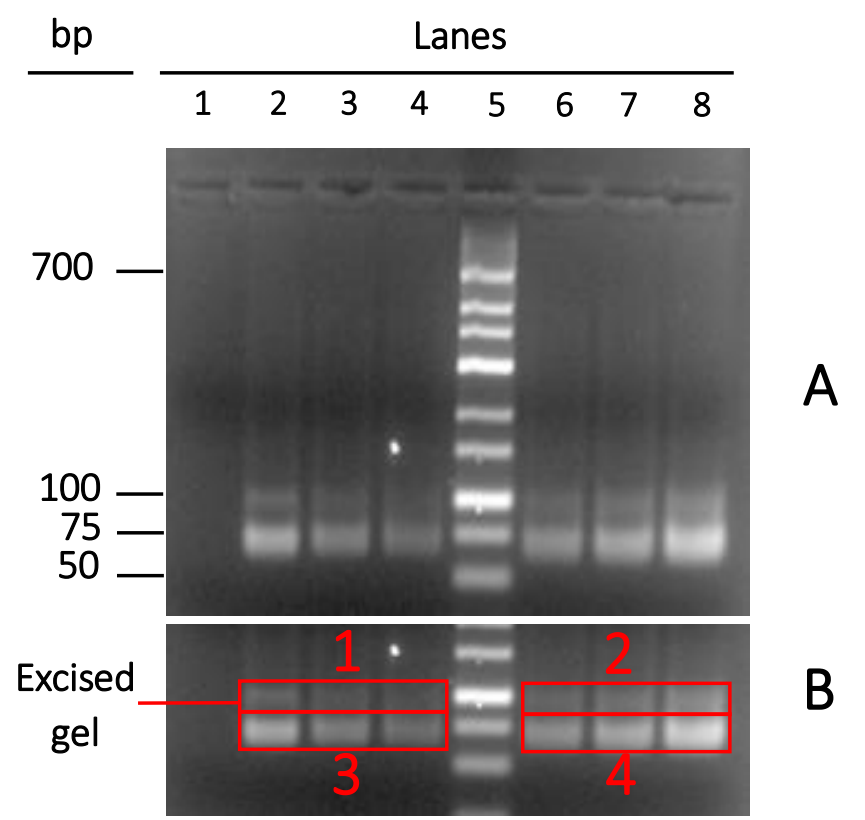

Figure 3.4D. Real-time PCR products following co-incubation of SR10. A) Lane 1; No template (-ve control), Lanes 2-4; Control elution, Lane 5; GeneRuler LR (700-25bp), Lanes 6-8; Target elution. (B) Approximate excised gel used as templates for cloning and sequencing. 


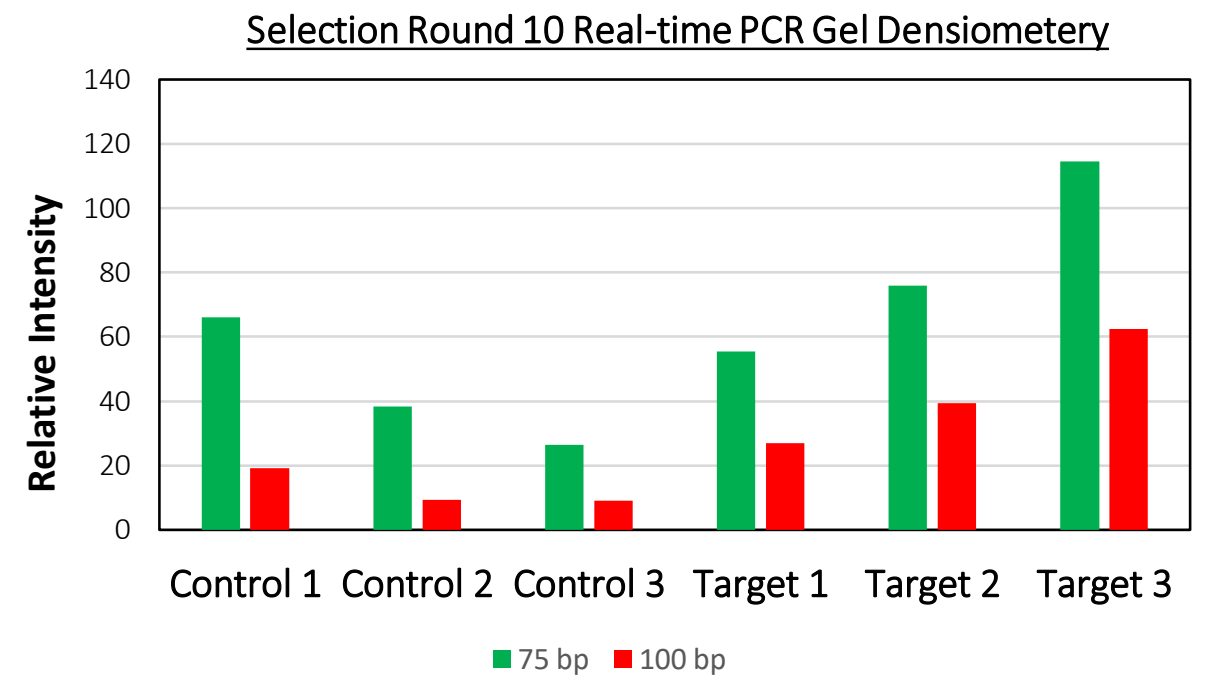

Figure 3.4E. Mean densitometry measurements of SR10 real-time PCR products. Target and control PCR samples (Lanes 2-4 and 6-8, respectively) were plotted against each other and normalised against the background value.

\subsubsection{DNA SEQUENCING OF MULTIPLE SIZED PRODUCTS}

Due to the large number of off-target bands in the PCR products throughout the SELEX rounds (Figure 3.4A), multiple products were chosen for cloning and sequencing to represent the entire library. A total of 52 clones were selected from the SR10 library generated by real-time PCR (Figure 3.4D) and all products from bands generated from either the target and control membranes were pooled. A total of 20 clones of PCR products of 75bp in size (estimated from ladder) were collected from supernatants from both control (C01-20) and target (T01-20) membranes (Figure 3.4D, Panel B, Box 3 and 4, respectively) (data not shown, see Appendix). It should be noted that following sequencing, this band was found to be 50bp in size. Therefore, another 12 clones were taken from the purified target band (T21-32), corresponding to a 100bp band (estimated from ladder) (Figure 3.4D, Panel B, Box 2). Sequencing of this '100bp' band revealed it was indeed the desired 75bp product. Thus it was obvious the ladder was not representative of the sample. A total of seven 'full-length' $75 \mathrm{bp}$ sequences including the primers and a 50bp random sequence were identified, of which five were unique (T23, T24, T25, T29 and T32) and two were identical (T21, T22) (Figure 3.4F). Within the five unique sequences, one sequence (T29) differed to T21, T22 sequences by a single nucleotide substitution. Additionally, a $29 \mathrm{bp}$ conserved region was shared between four sequences (T21, T22, T23 and T29). An additional four 
'short' 47-53bp sequences (T27, T28, T30 and T31) were also identified, of which all were identical to other short sequences found (data not shown, see Appendix). For the purpose of candidate aptamer selection, only full-length $75 \mathrm{bp}$ sequences were considered for further analysis and will be referred to as "GDF9-01...07". A phylogenetic tree analysis was performed on these sequences (Figure $3.4 \mathrm{G}$ ) to demonstrate the evolution of each individual sequence from all seven sequences.
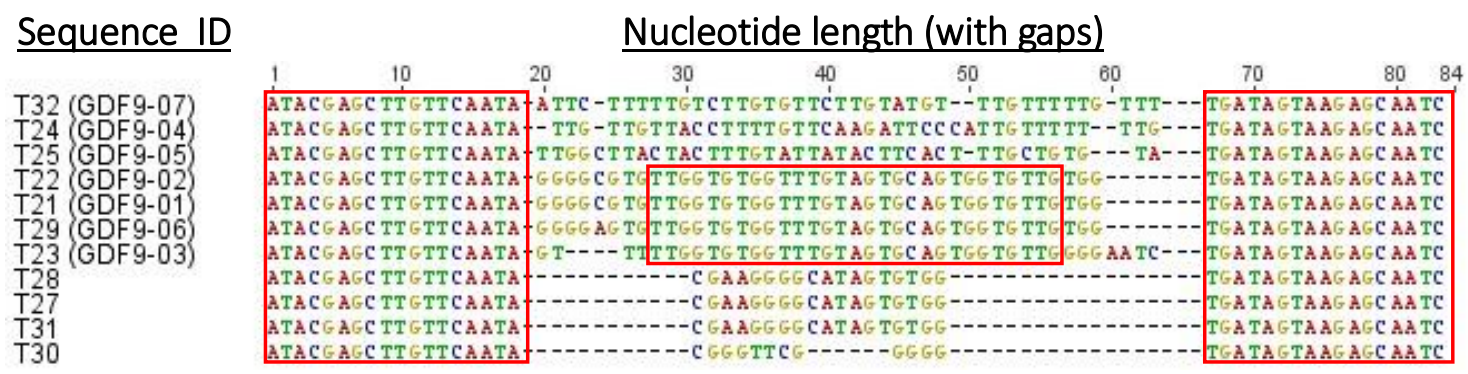

Figure 3.4F. Sequencing results from SR10. A total of $12 *$ clones were sequenced, and conserved regions indicated within the red boxes. *Some sequences are not included due to low quality base-calling.

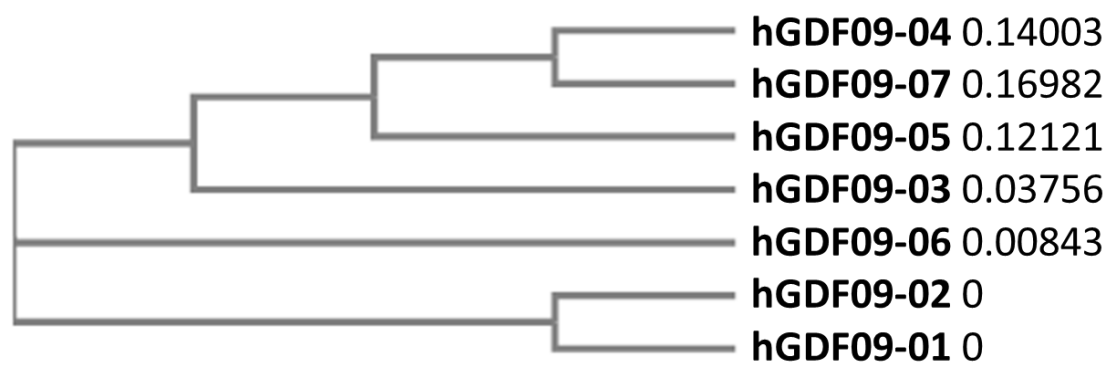

Figure 3.4G. Phylogenetic tree of full-length 75bp sequences from sequencing. Scale $0-1(0=100 \%$ identical).

\subsection{NUCLEOTIDE CONSERVATION OF THE RANDOM REGION OF TGF-B SELECTED APTAMERS}

There were four sequences (GDF9-01, 02, 03 and 06) identified as containing a 29bp conserved region (TTGGTGTGGTTTGTAGTGCAGTGGTGTTG) within the 40bp variable region. Based on the alignment shown in Figure 3.5, the sequences GDF9-01 and GDF9-02 are 100\% homologous while GDF9-06 is 97.5\% homologous to those sequences. GDF9-03 shares only the 29bp conserved region with the aforementioned sequences which constitutes a $75.5 \%$ homology to the entire 40bp variable region. Interestingly, a previously published (Jun et al., 2015) and characterised aptamer (B6) for a structurally-related TGF- 
$\beta$ family member, BMP15, also showed a relatively high level of conservation spanning the entire 40bp variable region and within the $29 \mathrm{bp}$ conserved region of the aptamers generated in this study. Based on alignment (Figure 3.5B), this represents up to $58.6 \%$ homology within the $29 \mathrm{bp}$ conserved region and up to $60 \%$ homology within the entire 40bp variable region (B6 vs. GDF9-06). This is indicative of one or more DNA binding motifs capable of binding to the mature protein of TGF- $\beta$ family proteins. This is perhaps unsurprising given the similarities between GDF9 and BMP15 amino acids sequences $(59 \%)$.

\section{Sequence ID}

Nucleotide length (with gaps)

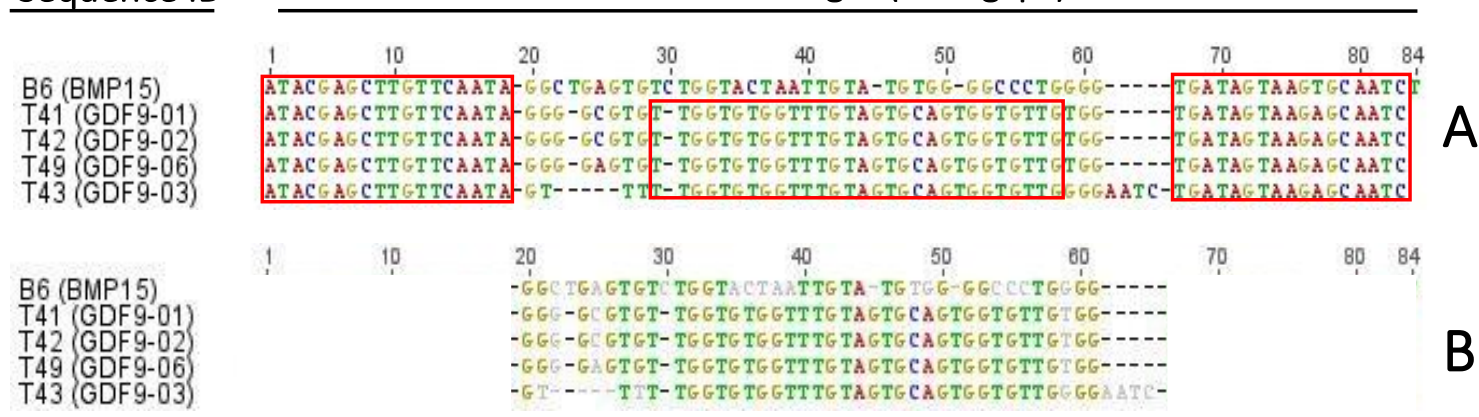

Figure 3.5. Alignment of GDF9 selected sequences with conserved region against previously selected BMP15 sequence. (A) The red box indicates primer regions and previously identified 29bp conserved region for GDF9 candidates. (B) Identical alignment for the 40bp variable region showing nucleotide *agreements only. *At least $80 \%$ of nucleotides are identical in that position, non-agreements are shaded in grey.

\subsection{COMPOSITION AND TWO-DIMENSIONAL STRUCTURE PREDICTIONS OF CANDIDATE GDF9 APTAMERS}

Further analyses of the seven full-length $75 \mathrm{bp}$ aptamer candidates were performed including comparison with the previously published and characterised 76bp aptamer (B6) for the structurally-related BMP15 protein. The GC content and nucleotide composition for the full-length and variable regions is shown for each nucleotide; dATP, dCTP, dGTP, dTTP (see Table 3.6). Two-dimensional structural predictions for each sequence were performed at both the co-incubation temperature of $4^{\circ} \mathrm{C}$ and at RT $\left(23^{\circ} \mathrm{C}\right)$ (Figure 3.6). Buffer conditions were adjusted to $1 \mathrm{xBWB}$ where possible, to match the co-incubation conditions of the SELEX. The Gibb's free energy calculation predicts which structural formation is most energetically favourable and therefore most likely to form. All sequences have a predicted secondary structure(s) with a degree of stem and loop structures. With the exception of GDF9-03, GDF9-05 and GDF9-06, the predicted secondary structure with the lowest Gibb's free energy at $4^{\circ} \mathrm{C}$ was different to that predicted at $23^{\circ} \mathrm{C}$. For all structures, the predicted Gibb's free energy at $4^{\circ} \mathrm{C}$ was 2.4 to 4.9 -fold higher than that predicted at $23^{\circ} \mathrm{C}$. 
Table 3.6. Nucleotide analysis and predicted Gibb's free energy calculation of secondary structure formation. Comparing BMP15-B6 aptamer against all seven sequences of GDF9-01 to GDF9-07. Mfold calculations performed with DNA folding form using default parameters with the following changes: $100 \mathrm{mM} \mathrm{Na}^{+}, 2 \mathrm{mM} \mathrm{K}^{+}$at both $4^{\circ} \mathrm{C}$ and $23^{\circ} \mathrm{C}$. If more than one structure predicted, the lowest predicted energy was chosen.

\begin{tabular}{|c|c|c|c|c|c|c|c|}
\hline & \multicolumn{7}{|c|}{ Full sequence } \\
\hline $\begin{array}{c}\text { Sequence } \\
\text { ID }\end{array}$ & $\begin{array}{c}\text { dATP } \\
(\%)\end{array}$ & $\begin{array}{c}\mathrm{dCTP} \\
(\%)\end{array}$ & $\begin{array}{c}\text { dGTP } \\
(\%)\end{array}$ & $\operatorname{dTTP}(\%)$ & $\begin{array}{c}\text { G-C content } \\
(\%)\end{array}$ & $\begin{array}{c}\text { Gibb's energy } \\
(\Delta \mathrm{G}=\mathrm{kcal} / \mathrm{mol}) \\
\text { at } 23^{\circ} \mathrm{C}\end{array}$ & $\begin{array}{c}\text { Gibb's energy } \\
(\Delta \mathrm{G} \\
=\mathrm{kcal} / \mathrm{mol}) \text { at } \\
4^{\circ} \mathrm{C}\end{array}$ \\
\hline BMP15-B6 & 22.7 & 14.7 & 32.0 & 30.7 & 46.7 & -3.89 & -10.80 \\
\hline GDF9-01 & 20.0 & 9.3 & 37.3 & 33.3 & 46.7 & -2.54 & -7.08 \\
\hline GDF9-02 & 20.0 & 9.3 & 37.3 & 33.3 & 46.7 & -2.54 & -7.08 \\
\hline GDF9-03 & 22.7 & 9.3 & 32.0 & 36.0 & 41.3 & -3.44 & -9.20 \\
\hline GDF9-04 & 22.7 & 9.3 & 32.0 & 36.0 & 41.3 & -4.43 & -10.57 \\
\hline GDF9-05 & 26.7 & 16.0 & 17.3 & 40.0 & 33.3 & -6.53 & $\begin{array}{l}-16.18 \\
\end{array}$ \\
\hline GDF9-06 & 21.3 & 8.0 & 37.3 & 33.3 & 45.3 & $\begin{array}{ll}-1.8 \\
\end{array}$ & -7.08 \\
\hline GDF9-07 & 20.0 & 10.7 & 18.7 & 50.7 & 29.3 & -1.63 & -7.93 \\
\hline \multicolumn{8}{|c|}{ Variable region } \\
\hline BMP15-B6 & 12.5 & 15.0 & 42.5 & 30.0 & 57.5 & $\mathrm{n} / \mathrm{a}$ & $\mathrm{n} / \mathrm{a}$ \\
\hline GDF9-01 & 5.0 & 5.0 & 52.5 & 37.5 & 57.5 & $\mathrm{n} / \mathrm{a}$ & $\mathrm{n} / \mathrm{a}$ \\
\hline GDF9-02 & 5.0 & 5.0 & 52.5 & 37.5 & 57.5 & $\mathrm{n} / \mathrm{a}$ & $\mathrm{n} / \mathrm{a}$ \\
\hline GDF9-03 & 10.0 & 5.0 & 42.5 & 42.5 & 47.5 & $\mathrm{n} / \mathrm{a}$ & $\mathrm{n} / \mathrm{a}$ \\
\hline GDF9-04 & 12.5 & 15.0 & 15.0 & 57.5 & 30.0 & $\mathrm{n} / \mathrm{a}$ & $\mathrm{n} / \mathrm{a}$ \\
\hline GDF9-05 & 17.5 & 17.5 & 15.0 & 50.0 & 32.5 & $\mathrm{n} / \mathrm{a}$ & $\mathrm{n} / \mathrm{a}$ \\
\hline GDF9-06 & 7.5 & 2.5 & 52.5 & 37.5 & 55.0 & $\mathrm{n} / \mathrm{a}$ & $\mathrm{n} / \mathrm{a}$ \\
\hline GDF9-07 & 5.0 & 7.5 & 17.5 & 70.0 & 25.0 & $\mathrm{n} / \mathrm{a}$ & $\mathrm{n} / \mathrm{a}$ \\
\hline
\end{tabular}




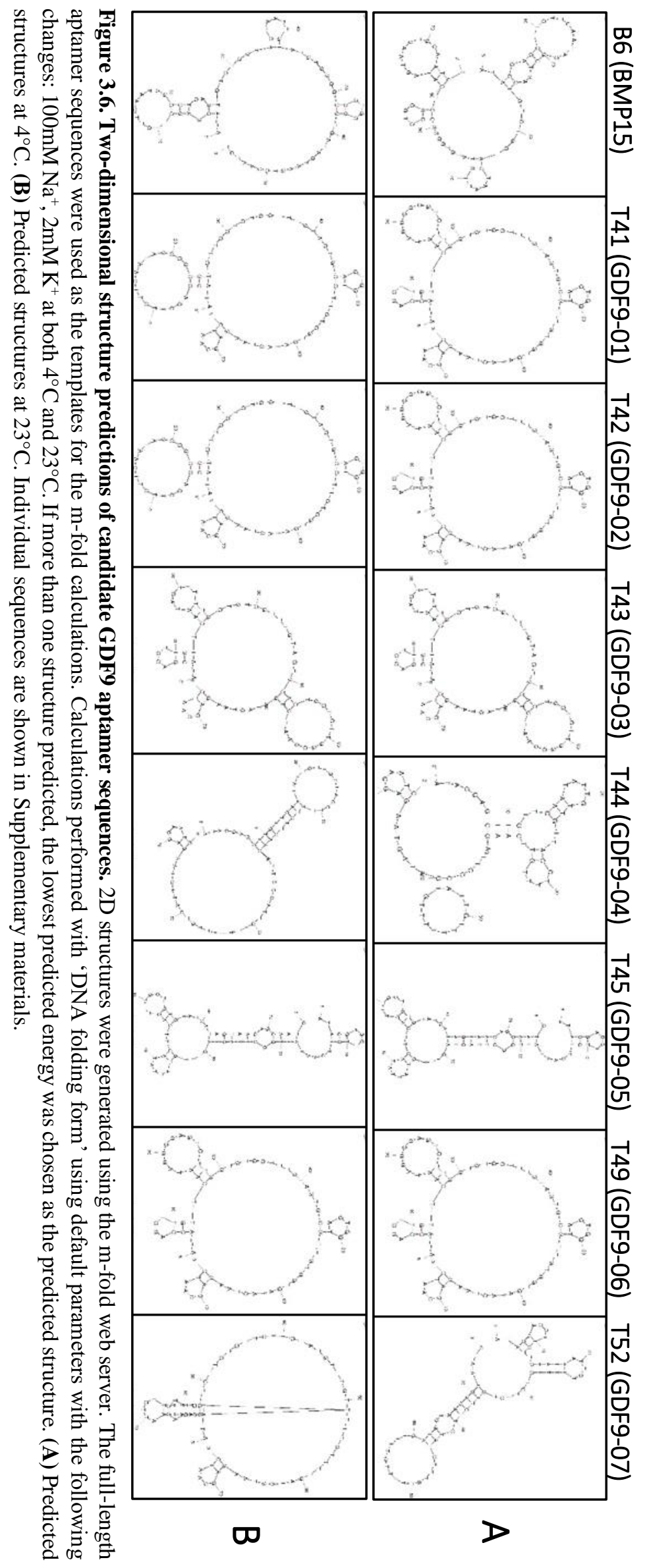




\section{CHAPTER 4: DISCUSSION}

\subsection{GENERAL DISCUSSION}

Since its inception in 1990, great advancements have been made in the relatively new research field of aptamer generation. Namely, aptamer research has experienced a great diversification and development of both novel and successful methodologies for generating and characterising aptamers. Because of this, we have seen an ever-increasing number of aptamers being published for a wide array of target molecules. As an example of method variation, a general review of aptamer literature would likely report between 6-20 rounds of SELEX is required to generate specific aptamers. However, there are many publications reporting the generation of aptamers after only one round of SELEX. Therefore, an increasing emphasis is placed on the need for more data and evidence regarding how aptamer libraries interact and evolve over time with target molecules. This research involved the generation of candidate aptamers against a purified protein target, GDF9, which is a member of the large TGF- $\beta$ superfamily. After ten rounds of SELEX, several candidate aptamers were identified with conserved regions highly homologous for a previously characterised aptamer for BMP15, also a TGF- $\beta$ superfamily member (Lin et $a l ., 2015)$. The main purpose of this discussion was to evaluate the strengths and weaknesses of the methodology which was employed to generate these candidate aptamers reported in Chapter 3. This discussion will also examine the molecular forms of the recombinant BMP15 and GDF9 proteins produced in Chapter 3, and additionally provide future direction and insights for the characterisation of these candidate aptamers.

\subsection{INITIAL DESIGN FOR GENERATING RECOMBINANT BMP15 AND GDF9 AS APTAMER TARGETS}

One of the objectives of this project was to generate aptamers capable of recognising BMP15 or GDF9 in multiple mammalian species. Stably-expressing, genetically-modified HEK293 cell lines were chosen as the source for these recombinant proteins as they were readily available from a previous research project. These cell lines possessed features suitable for the aptamer development and endpoint criteria including being transfected with GDF9 or BMP15 from a suite of mammalian species, as well as evidence that the recombinant proteins produced by these cell lines possessed biological activity and exhibited the predicted glycosylation residues (Alhussini, 2016). Recombinant forms of oBMP15, mBMP15, oGDF9 and mGDF9 proteins were selected for batch production and 
purification. However, because these cell lines were established several decades ago in the AgResearch Wallaceville laboratories, vector information regarding whether pEFIRES-P contained a His-tag sequence was not available. Furthermore, previously produced recombinant proteins from these cells had not been purified by IMAC or HPLC and therefore, it was unknown if purification would be possible.

\subsection{CHARACTERISATION OF RECOMBINANT MURINE AND OVINE BMP15 AND GDF9}

The characterisation of these proteins was performed using immunoblotting under reducing conditions. The monoclonal antibodies (mAbs) mAb61A and mAb37A were previously generated and had been well characterised within our, and other laboratories and were capable of detecting multiple molecular forms of both BMP15 and GDF9 across a range of mammalian species (Lin et al., 2012; Alhussini, 2016; Heath, 2016; Swinerd, 2016). The results herein showed that recombinant protein expression, purification and characterisation was generally successful. The tests conducted during the early stages of cell culture were indicative that recombinant protein expression of BMP15 and GDF9 was successful. Pro-mature forms of mBMP15, oBMP15 and oGDF9 were detected around $60 \mathrm{kDa}$ (Figure 3.1A and 3.1B, respectively) and mature forms of mGDF9 and oGDF9 were detected around 15-18kDa (Figure 3.1B). No mature forms of BMP15 were detected.

IMAC purification was effective at purifying GDF9, with mature mGDF9 and oGDF9 of $15-18 \mathrm{kDa}$ in size eluted in abundance in early fractions, and pro-mature mGDF9 and oGDF9 of $60 \mathrm{kDa}$ in size eluted in the later fractions (Figure 3.2C and 3.2D, respectively). Further purification by HPLC provided concentrated mature mGDF9 and oGDF9 proteins of 20 and $15 \mathrm{kDa}$ in size, respectively (Figure 3.3A and 3.3B, respectively). Unknown bands of low molecular weight $(<14 \mathrm{kDa})$ in oGDF9 samples were detected at multiple stages (see Figure 3.2D and 3.1B) and detected for both mGDF9 and oGDF9 following HPLC purification (see Figure $3.3 \mathrm{~A}$ and $3.3 \mathrm{~B}$, respectively). This could possibly be due to partially-denatured proteins caused by the solvents used in HPLC and or the conditions of the HPLC process, generating multiple fragments similar or lower in size than the expected mature GDF9 monomers.

IMAC purification was unsuccessful for recombinant oBMP15 and mBMP15 proteins with no molecular forms of BMP15 detected in any eluates following post-incubation of EM with the $\mathrm{Ni}^{2+}$ beads. As the EM was previously confirmed to contain oBMP15 and mBMP15, it was concluded that these proteins did not contain any form of His-tag and 
therefore were unable to interact with the $\mathrm{Ni}^{2+}$ beads. Subsequently, BMP15 proteins were not purified from the media and were not further subjected to HPLC purification. It was proposed to use purified forms of recoBMP15 and recmBMP15 to test the cross-reactivity of the GDF9 aptamers however time constraints did not allow for this.

\subsection{APTAMER LIBRARY SPECIFICITY FOR GDF9}

A total of ten rounds of SELEX was performed to generate candidate aptamers for the target protein, i.e. recombinant human GDF9. The results illustrated in Figures 3.4B-E were taken as a positive indication that, as expected, the N40 library had evolved a higher specificity for the target membranes than the control membranes. Densitometry was measured on the gel images to quantify the results and revealed that the target band was brighter than the control band. For most of the SELEX rounds however, the difference in band densities between target and control membranes was indistinguishable and/or limited by the nonquantitative interpretation of end-point PCR.

Another limitation to the strategy used herein was the concentration of target versus control proteins, due to fact that both the control and target membranes were blocked with an excess of milk protein during each co-incubation. The $50 \mu \mathrm{L}$ volume of $5 \%$ blocking solution used to block the target and control membranes contained approximately $2.5 \mathrm{mg}$ of dry milkpowder and would be used to block several membranes at most. In comparison, the target protein was no more than $6 \mu \mathrm{g}$ of protein adsorbed equally onto 10 pieces of nitrocellulose membrane. Thus, on target membranes, the milk proteins were in much greater concentration than the target protein. Therefore, it is possible that the N40 library was evolving specificity for the milk proteins rather than the target protein. To counter this, the co-incubation was also performed using the blocking solution, which would in theory, allow for any milk-protein binding sequences to be removed in-solution when the coincubation supernatant was discarded and subsequently washed from the target membranes several times prior to PCR. Two notable methods of improving library specificity for the target is by performing counter-SELEX against a similar target molecule, and by performing negative-SELEX against the immobilisation-matrix itself. In this case, the use of milk-proteins to block the nitrocellulose membrane serves as both, where a blocked membrane is representative of the target membrane without the target protein (negativeSELEX), while also being representative of other protein molecules such as casein (counter-SELEX). Additionally, only DNA recovered from target membranes was used for 
the subsequent co-incubation which would, in theory, favour the proliferation of target binding sequences as the number of SELEX rounds increased. Although this is the standard methodology for SELEX, it is important to understand that this step is designed to facilitate affinity maturation.

\subsection{MULTIPLE PCR PRODUCTS}

After several rounds of SELEX, the expected 75bp band corresponding to the N40 library became increasingly smeared (Figure 3.4A). Initially, it was thought this was caused by contaminating nuclease digestion (Tsui et al., 2002) or degradation of the PCR product prior to running the gel, however this could not account for dsDNA products appearing above the expected 75bp, that is, products of larger size. Therefore, it was hypothesised that the low annealing temperature of the PCR $\left(52^{\circ} \mathrm{C}\right)$ may result in a low efficiency of the PCR reaction and therefore, enabling the generation of dsDNA products of multiple lengths. Possibly due to incomplete template extensions, template duplexes, primer dimers or mis-priming. It is also likely that the introduction of non-favourable PCR products was introduced after SR1-2, where PCR re-amplification was required to generate enough template to be detected with SYBR Safe II DNA staining dye. Previous studies have confirmed that the re-amplification of template DNA will result in the formation of such products and may also be detrimental to the success of affinity maturation during SELEX (Tolle et al., 2014). Another well-known study shows that the use of conventional PCR methods, as used herein, when performed on complex DNA libraries, results in the generation of longer PCR artefacts while also favouring the amplification of shorter sequences (Williams et al., 2006). This is a consideration to be made of SELEX in general, where the same library is amplified multiple times. In this case, 14 PCR reactions were performed on the N40 library over the entire ten rounds of SELEX (see Table 3.4A for summary) which may have facilitated the generation and proliferation of non-target PCR products of various lengths due to limited DNA separation during gel electrophoresis, unoptimised PCR conditions, incorrect molecular weight markers and the gel extraction of sequences other than the desired 75bp product. Because round-by-round DNA sequencing was not performed, the selection of the correct-sized DNA template for the next round is subject to physically excising the gel band at the correct size from the gel (see Figure 3.4A, panel B). In some cases, the accuracy of cutting the correctly-sized product was difficult for SR1-4, where a standard 2.5\% agarose gel was used. Methods were subsequently changed to use $4 \%$ high-resolution agarose gel to enable better resolution of the products 
(see Table 3.4A for summary). This strategy immediately reduced the smearing as observed in SR4 to produce distinct bands as observed in SR5 (see Figure 3.4A). In the rounds where, multiple bands of similar weights were present, i.e. SR5, SR7 and SR8, the band aligning to the $75 \mathrm{bp}$ positive control was excised in an attempt to remove the non-target species from the subsequent SELEX rounds. However, the recurrence of the multiple bands was not entirely prevented by this method, and due to the variation between PCR results for each round of SELEX, and the small amount of template DNA from each co-incubation, it was not possible to re-optimise PCR conditions for each reaction. This is perhaps why nontarget PCR products were reforming despite not being excised from the gel after the previous PCR. This phenomenon has previously been reported, where the PCR by-products would return each round due to 'trans-priming' which resulted in the duplication of primer regions within the original template and would serve as a template for PCR products of multiple lengths (Tolle et al., 2014). However, for SR6 and SR10, excision of the 75bp band from the previous round appeared to have reduced the number of bands from 4-5 to just two, with one being at the correct 75bp size (see Figure 3.4A). Because of the reduced number of bands and specificity for target membrane over the control membrane (as discussed in Section 4.4), the PCR products from SR10 were considered a positive indication that the library was specific for the target.

Another reason why PCR products varied after each round of SELEX could be because the recovered ssDNA from any given co-incubation is of such a low concentration it is unable to be accurately quantified in our laboratory and therefore the variation in PCR products could, in part, be caused by varying template concentration. Although the template concentration is thought to have an impact on the total DNA post-PCR, it is said that it is not a factor in the formation of certain PCR by-products when compared to other variables such as polymerase and primer concentrations (Williams et al., 2006).

\subsection{MEMBRANE-BASED SELEX}

Several research collaborators generating aptamers to similar protein targets such as FSH and BMP15 (Lin et al., 2009; 2015) also immobilised their target proteins by adsorbing onto small pieces of nitrocellulose membrane. A major benefit of membrane-SELEX is that there is no complicated chemistry required to conjugate the protein target to a solid matrix support prior to co-incubation. The interaction of proteins to nitrocellulose is well 
understood to be a charge-based interaction between the protein and membrane and is applicable for a broad range of proteins.

In practice, it was difficult to cut evenly-sized nitrocellulose membranes and more so to handle them in a manner to avoid potential contamination. This was additionally concerning because it was not possible or feasible to detect contamination of the membrane from DNA or proteins. Another major concern for membrane-SELEX and any SELEX method for a protein target is degradation of the protein target. To counter this, membranes would be prepared in small batches and kept at $4^{\circ} \mathrm{C}$ for no longer than 3 weeks. However, because the protein concentration was very low and there was no addition of enzyme inhibitors or anti-microbial compounds due to potential adverse effects with the N40 library, it is possible that some level of target degradation was occurring. The method of producing target membranes was later revised prior to SR10 by preparing the target membranes several hours before use with a new aliquot of rechGDF9 that had been stored at $-20^{\circ} \mathrm{C}$ and had not been subjected to repeated freeze-thaw cycles. Thereafter, the results for SR10 seemed to show the first indication of specificity for the target over the control, which suggested that the fresh preparation of proteins had a positive impact on the library favouring target-binding sequences.

It was previously thought that the potential degradation of target protein, along with the concerns regarding the target concentration, would result in sequences that would bind with high affinity to the milk protein used in the blocking step (as discussed above) and may explain why control samples were showing signal throughout the SELEX. If this hypothesis were true, it could partly explain why an increase in target-binding sequences would be seen if the target membranes were prepared fresh i.e. not degraded. The low concentration of the target protein was always thought to be a limiting factor in this experiment and was largely due to the source of recombinant protein. There are few commercial suppliers of this protein and they command a high price making it unfeasible to saturate the nitrocellulose membranes with the target and ensure maximum target adsorption to the surface. Another issue surrounding membrane-based SELEX is how to recover the ssDNA from the target membrane following co-incubation. Heat denaturation of the membrane for prolonged period at $95^{\circ} \mathrm{C}$ in ultra-pure DNase-free water was employed herein. After denaturation, the membranes were washed and also included in the PCR to evaluate if there was still DNA bound to the membrane. In most cases, there was no observable difference in the band intensities of PCR samples from either DNA eluates or the eluted membranes 
themselves. This was indicative that the membrane elution was not always effective at dislodging the DNA from the membrane. As the PCR product was only ever recovered from eluates from the membrane, disregarding what remained on the membranes, to add to the next round of SELEX, the total quantity of DNA recovered after each-co-incubation may have been reduced. However, SR10 was again another exception to this, where no PCR products were detected on the eluted membranes and added further validity to our previous indications that the N40 library was showing specificity for GDF9 after the final SR10.

Other conventional methods for fixing a protein to a solid matrix support, such as conjugation to amine or carboxyl activated sepharose beads, were considered. However, the cost and availability of the target protein together with the potential risk that conjugation would not work or would result in denaturation of the target protein made optimisation of the conjugation methodology unfeasible. Perhaps an easier method would have been to couple the protein via His-tags to a charged nickel bead or column but given that a commercial source of recombinant GDF9 containing a His-tag was not available, this was not possible. However, coupling of the purified recGDF9 would have been possible because it had already successfully conjugated to the same beads for IMAC purification. However, concerns surrounding protein quantity and proteins of multiple sizes being present after HPLC purification of the in-house recombinant proteins precluded this. Moreover, non-specific interactions between ssDNA and charged nickel beads had been reported in literature (Nastasijevic et al., 2008) and this method had not previously been performed in our laboratory. However, these proteins were intended for use to validate the aptamers against multiple species after candidate aptamers were identified but time constraints did not allow for this. Information provided in the literature do not include discussions on optimisation and problems during the SELEX methodology therefore it is difficult to determine the best methods developing protein aptamers. It is unknown whether the problems encountered during my experiment were unique or had been encountered by other groups previously.

\subsection{SEQUENCING OF SELECTION ROUND 10}

The PCR products from SR10 were chosen as the template for sequencing and to represent the candidate library of aptamers for GDF9. Real-time PCR was performed on the SR10 template because the apparent amount of dsDNA product from the initial end-point PCR 
was low (Figure 3.4B) but showed a good difference in relative band intensity when compared with the control (Figure 3.4C). Real-time PCR gave the opportunity to stop the amplifications reaction at a cycle number shortly after the reaction was being severely limited by reagent deficiencies.

The decision to sequence the control sequences, in addition to the target sequences, was due to the large amount of control signal that had been observed in previous SELEX rounds. This information could also serve to eliminate any common sequences appearing in both the target and control data. Real-time PCR gave the additional advantage of being able to visually monitor the amplification of both the control and target samples (Figure 3.4D). From this, 20 samples for both control and target reactions were prepared by excising from the gel and purifying the band aligning with the 75bp ladder marker (Figure 3.4D) before sequencing using the Sanger method. In addition, 12 samples were also prepared and sequenced in the same manner for the target band aligning with the 100bp ladder marker (Figure 3.4D) that would provide some insight into the multiple species present in the sample. Surprisingly, the first samples that aligned to the $75 \mathrm{bp}$ ladder returned two conserved sequences of either 47bp or 52bp lengths (supplementary Figure 1), while the 12 additional sequences corresponding to the $100 \mathrm{bp}$ marker returned a mixture of $75 \mathrm{bp}$ sequences and several copies of the $47 \mathrm{bp}$ and $52 \mathrm{bp}$ repeats (Figure 3.4F). It appears that the ladder did not resolve on the gel at the same rate as the dsDNA and the 75bp dsDNA should have been included in all gels. As a result, of the total 52 samples sequenced, only seven were candidate aptamers of $75 \mathrm{bp}$ length while the other 45 comprised of low-quality reads or $47 \mathrm{bp}$ and $52 \mathrm{bp}$ repeats.

\subsection{CANDIDATE GDF9 APTAMER HOMOLOGY AND 29BP CONSERVED REGION}

The seven resultant 75bp sequences consisted of two identical sequences (GDF9-01, GDF9-02) and another similar sequence that differed by a single nucleotide (GDF9-06), which in itself would not constitute a conserved domain but rather suggests high copy numbers of that sequence with single bp variants. A unique sequence, GDF9-03, shared a $29 \mathrm{bp}$ region with the three previously mentioned sequences which had a reading frame shifted by 4 bases and was further flanked by a remaining 11 bases which were also not shared. Therefore, it is probable that the region is highly conserved for the target protein, recombinant human GDF9. The remaining three sequences (GDF9-04, GDF9-05 and GDF9-07) all presented unique sequences independent of each other and the four sequences 
that shared the conserved region. Interestingly, the sequences GDF9-04, GDF9-05 and GDF9-07 all had a similar nucleotide composition (see Table 3.6) despite having low homology and conservation with each other. When comparing the variable region of these three unique sequences (as a group) to the sequences shared in the 29bp conserved region of GDF9-01, GDF9-02, GDF9-03 and GDF9-06, the unique sequences had an average guanine/cytosine (GC) content of $29.17 \pm 3.12 \%$ compared to $54.38 \pm 4.10 \%$, respectively. Interestingly, these unique sequences were thymine (T)-rich (50-70\%), and the four conserved sequences may also be considered T-rich (37.5-42.5\%) with comparatively equal proportions of guanine residues. Another interesting observation in those sequences sharing the $29 \mathrm{bp}$ conserved region is the low percentage of adenine (A) or cytosine residues within the variable region, combined representing only $10-15 \%$ of the total nucleotides (Table 3.6).

Therefore, it appears as if there are two distinct features of the seven candidate aptamers that target recombinant human GDF9. Firstly, a 29bp conserved nucleotide region within the 40bp variable region and secondly, a GT-rich variable region. Because the N40 library was not originally sequenced, it is possible that a nucleotide bias was previously incorporated during synthesis. However, it would still be unlikely that such a small percentage of $\mathrm{A}$ and $\mathrm{C}$ nucleotides would be present after 14 PCR reactions of using a 1:1:1:1 (A:C:G:T) ratio of dNTPs and factoring for wrongful base incorporation, mutation and a lack of proof-reading exonuclease activity.

\subsection{HOMOLOGY OF GDF9 CANDIDATE APTAMERS WITH A PREVIOUSLY CHARACTERISED BMP15 APTAMER}

An aptamer for recombinant ovine BMP15 (reported as clone A15/B6) was published with an affinity of $80.9 \pm 12.8 \mathrm{nM}$ (Lin et al., 2015). This aptamer was of interest to this research because the two proteins, BMP15 and GDF9, are known to be structurally-related members of the TGF- $\beta$ superfamily. They are also known to interact together in various ways to the regulate fertility status of various mammalian species (as discussed in Chapter 1). The project's original scope was to generate an aptamer for both BMP15 and GDF9, however BMP15 was later excluded from the project design because the recombinant BMP15 proteins produced could not be purified. When performing the sequence alignment and nucleotide analysis for the seven $75 \mathrm{bp}$ candidate aptamers, the aforementioned BMP15 aptamer (referred to here as B6-BMP15 or BMP15-B6) was included for analyses. It was found that this aptamer had a similar nucleotide composition (Table 3.6) and showed 
homology to the 4 sequences sharing the $29 \mathrm{bp}$ conserved region (Figure 3.5). Based on these findings, it could be suggested that this aptamer for BMP15 and the candidate aptamers for GDF9 have undergone convergent evolution because of their structurally similar targets. The data presented herein shows that sequences for both protein targets appear to favour GT rich sequences and are conserving one or more motifs within either the $29 \mathrm{bp}$ conserved region or the whole sequence.

\subsection{PREDICTED SECONDARY STRUCTURES OF GDF9 CANDIDATE APTAMERS}

It was one of the first publications reporting aptamer generation where it was hypothesised that aptamer target interaction was largely dependent on the formation of secondary structures by ssDNA (Ellington \& Szostak, 1990). This can be illustrated in more recent research with the example of a well-studied cocaine aptamer (Stojanovic et al., 2001; Stojanovic \& Landry, 2002) which forms a predicted structure consisting of two 'arms' which stem from a central loop domain, which is subject to forming a third arm upon target binding. This conformational change is utilised as a probe, whereby a chromophore is released from the loop domain upon formation of the third arm. Similarly, G-quadruplex forming aptamers are also of interest for aptamer-based probes and an extensive range of G-quadruplex forming aptamers targeting protein targets can be shown in a recent review (Tucker et al., 2012). One of the most cited papers in aptamer research reports the specific binding and inhibition of the protein, thrombin, by the conserved motif within their SELEX library, GGTTGG and the full-length sequence, GGTTGGTGTGGTTGG (Bock et al., 1992). The sequence was later shown to form a G-quadruplex by spectroscopy (Macaya $e t$ al., 1993; Vairamani and Gross, 2003).

Therefore, it is reasonable to access our candidate aptamers likelihood to possess the properties to bind to their target in relation to their predicted secondary structures (Figure 3.6, panel B) and potential to form G-quadruplexes. Based on these predictions, the BMP15 aptamer's predicted structure, previously discussed in this chapter (see Section 4.9), was used as an indication of potentially relevant secondary structures capable of binding to structurally similar target. The BMP15 aptamer was highly comparable in structure to the seven candidate aptamers for GDF9. All of which contain several stem and loop structures, usually with as little 4-6 nucleotides being involved in the individual stem and loop itself. The presence of a larger loop was also common, with up to 19 nucleotides incorporated (GDF9-01 and GDF9-02). GDF9-04 presented a much longer stem structure with 18 
nucleotides involved. Similar to this was GDF9-05, which presented an overall high degree of stem-stabilised structures with various loop domains on each end, similar to the cocaine aptamers multiple stem domains. These two sequences also possessed the lowest Gibb's free energy score (Table 3.6), which is an indication of the enthalpy and therefore likelihood of forming these structures from the linear sequence.

An obscure secondary structure was predicted for GDF9-07, a sequence with the highest T content in the variable region $(70 \%)$. However, when we compare this to GDF9-07 predicted structure at $4^{\circ} \mathrm{C}$, we see a much more energetically favourable secondary structure comprising of several stem domains with loops at each end, not too dissimilar to that of the predicted structure for GDF9-05. In general, the other candidate aptamer showed little variation in stem and loop structures when comparing $4^{\circ} \mathrm{C}$ to $23^{\circ} \mathrm{C}$ (Figure 3.6, panels A and B, respectively). The predicted structures and Gibb's free energies were calculated at both temperatures because those temperatures were relevant to the co-incubation $\left(4^{\circ} \mathrm{C}\right)$ and the RT $\left(23^{\circ} \mathrm{C}\right)$ at which the N40 library was often handled. It cannot be said, in this case, which temperature is correct in assessing the most likely secondary structure, especially when considering potential binding mechanisms of the aptamer to its target. But when considering Gibb's free energy alone, it is obvious that a co-incubation at lower temperatures is more energetically favourable by 2.4-4.9-fold (Table 3.6). Further analysis of the nucleotide composition is suggestive of properties conducive of G-quadruplex formation. With reference to the G-quadruplex formation of DNA aptamers binding to protein targets (reviewed in Tucker et al., 2012), it is apparent that G-quadruplex forming aptamers are commonly dominant in G and GT residues, and in some cases completely absent in A or C residues (Bock et al., 1992; Wyatt et al., 1994; Kankia et al., 2001). Moreover, G-quadruplex forming nucleotides are also associated with nuclease degradation and high melting temperatures (reviewed in Lane et al., 2008) and the G-rich sequence is hypothesised to be directly associated with the apparent interaction with some biologically active proteins and DNA/mRNA (demonstrated in Bates et al., 1999; reviewed in Ireson and Kelland, 2006). The candidate aptamers presented herein have been previously discussed to contain a high GT content, specifically; GDF9-01, 02, 03, 06 and 07 comprise between $85-90 \%$ of the total nucleotides as GT residues. Moreover, the 29bp conserved region TTGGTGTGGTTTGTAGTGCAGT $\underline{G G T G T T G}$ and extracted sequence from GDF9-01, 02 and 06 GGGGNGTGTTGGTGTGG contain a pattern of multiple motifs of poly-G ( $\mathrm{n}=2-4$, underlined) separated by several nucleotides also common among G- 
quadruplex forming aptamers (Tucker et al., 2012) and matching parameters of Gquadruplex domains as defined by the QGRS Mapper (Kikin et al., 2006).

\subsection{CONCLUSIONS AND SUMMARY}

The experiments performed herein clearly demonstrated that the membrane-SELEX method is capable of generating candidate aptamers for the target molecule, namely recombinant human GDF9. It also demonstrates that by this methodology, evolution towards a consensus sequence and conserved DNA domain was achieved after 10 rounds of SELEX. Interestingly, homology was observed with a published aptamer for a structurally similar target, BMP15. Therefore, suggesting that the SELEX performed herein was a potential demonstration of convergent evolution towards the obtained sequences and conserved region, this would imply these domains are important in aptamer recognition to the conserved domains of these targets. The results of this study were also important in showing how some of the limitations and variables of the current SELEX methodologies and parameters (as discussed in the introduction) can easily lead to the generation of complex or unexpected results such as the formation of multiple PCR by-products.

This study also showed that the predicted secondary structures of the seven candidate aptamers obtained possessed some features common to other G-quadruplex forming protein-binding aptamers in the literature. Namely, aptamers with a high GT-content (85$90 \%$ ) and repeated domains of either $\mathrm{G}$ doublets, triads or quartets interspaced with $\mathrm{T}$ residues were obtained, which indicates that these candidate aptamers may be capable of binding to their protein target, recombinant human GDF9.

This study also showed that the purification of recombinant mouse and ovine GDF9 protein was possible using HEK293 cells using IMAC and HPLC purification. Furthermore, the method of immunoblotting with the mAb37A was reliable in characterising the multiple forms of GDF9 produced and hence confirming that the production and purification of this protein yielded multiple molecular forms and was potentially suitable for use as an aptamer target for co-incubation. However, this study was not successful in purifying recombinant BMP15 by IMAC or HPLC. 


\subsection{FUTURE DIRECTION}

To better understand the sequencing results presented herein, it would be of interest to perform next-generation sequencing on the final selection round, SR10, if not the entire SELEX library from each round. Using this methodology, it could be possible to the entire population of the off-target PCR products presented herein and allow for the potential development of models that may explain how these products formed. If this was achieved, it would help to optimise and subsequently improve the PCR methodology and thereby the overall efficiency and power of SELEX. In addition, next-generation sequencing would be of interest in this case because it would valuable to know if the $29 \mathrm{bp}$ conserved region, and other potential conserved domains are present in more aptamer candidates than the 12 sequenced.

Furthermore, a full characterisation of the seven candidate aptamers in regard to their binding constants $(\mathrm{Kd})$ to their target molecule, recombinant human GDF9, would be required before the status of 'aptamer' could be confirmed. After which, the ability of the aptamer(s) to recognise and bind to its target would need to be validated and evaluated. The intention was to utilise the recombinant human (purchased), and HPLC-purified murine and ovine (produced herein) GDF9 in an Eastern blot (i.e. Western blot using aptamers instead of antibodies) or enzyme-linked oligonucleotide assay (i.e. ELISA using aptamers instead of antibodies) format to test the specificity of the aptamer to GDF9 of the species it was generated against, as well as GDF9 from other species that share $\mathrm{x}-\mathrm{x}$ homology. If successful, it is likely that the aptamer(s) generated may recognise native GDF9. The first step would be to culture oocytes in culture media and test the ability of the aptamer to recognise the native oocyte-secreted forms. If successful, the next step would have been to test whether the aptamer could measure native GDF9 in complex biological fluids such as follicular fluid. Not only would the outcomes of such research generate novel information on molecular forms of GDF9 in biological fluids, it could potentially be used to modulate a fertility response in mammalian species through aptamer-induced inhibition of GDF9 in vivo. 


\section{CHAPTER 5: REFERENCES}

Ahirwar, R., Nahar, S., Aggarwal, S., Ramachandran, S., Maiti, S., \& Nahar, P. (2016). In silico selection of an aptamer to estrogen receptor alpha using computational docking employing estrogen response elements as aptamer-alike molecules. Scientific Reports, 6(1). doi:10.1038/srep21285

Alhussini, A. A. (2016). The molecular forms of GDF9 in a range of mammalian species. Masters thesis, Victoria University of Wellington, New Zealand. http://hdl.handle.net/10063/5395

Bates, P. J., Kahlon, J. B., Thomas, S. D., Trent, J. O., \& Miller, D. M. (1999). Antiproliferative Activity of G-rich Oligonucleotides Correlates with Protein Binding. Journal of Biological Chemistry, 274(37), 26369-26377. doi:10.1074/jbc.274.37.26369

Bittker, J. A., Le, B. V., \& Liu, D. R. (2002). Nucleic acid evolution and minimization by nonhomologous random recombination. Nature Biotechnology, 20(10), 10241029. doi:10.1038/nbt736

Blackwell, T., \& Weintraub, H. (1990). Differences and similarities in DNA-binding preferences of MyoD and E2A protein complexes revealed by binding site selection. Science, 250(4984), 1104-1110. doi:10.1126/science.2174572

Bock, L. C., Griffin, L. C., Latham, J. A., Vermaas, E. H., \& Toole, J. J. (1992). Selection of single-stranded DNA molecules that bind and inhibit human thrombin. Nature, 355(6360), 564-566. doi:10.1038/355564a0

Bruno, J. G., \& Kiel, J. L. (1999). In vitro selection of DNA aptamers to anthrax spores with electrochemiluminescence detection. Biosensors and Bioelectronics, 14(5), 457-464. doi:10.1016/s0956-5663(99)00028-7

Bunka, D. H., \& Stockley, P. G. (2006). Aptamers come of age - at last. Nature Reviews Microbiology, 4(8), 588-596. doi:10.1038/nrmicro1458

Chu, T. C., Marks III, J. W., Lavery, L. A., Faulkner, S., Rosenblum, M. G., Ellington, A. D., \& Levy, M. (2006). Aptamer:Toxin Conjugates that Specifically Target Prostate Tumor Cells. Cancer Research, 66(12), 5989-5992. doi:10.1158/00085472.can-05-4583

Cox, J., Rudolph, P., \& Ellington, A. (1998). Automated RNA Selection. Biotechnology Progress, 14(6), 845-850. doi:10.1021/bp980097h

Cox, J., \& Ellington, A. D. (2001). Automated selection of anti-Protein aptamers. Bioorganic \& Medicinal Chemistry, 9(10), 2525-2531. doi:10.1016/s09680896(01)00028-1

Cruz-Aguado, J. A., \& Penner, G. (2008). Determination of Ochratoxin A with a DNA Aptamer.J. Agric. Food Chem, 56(22), 10456-10461. doi:10.1021/jf801957h 
Darmostuk, M., Rimpelova, S., Gbelcova, H., \& Ruml, T. (2015). Current approaches in SELEX: An update to aptamer selection technology. Biotechnology Advances, 33(6), 1141-1161. doi:10.1016/j.biotechadv.2015.02.008

Dong, J., Albertini, D. F., Nishimori, K., Kumar, T. R., Lu, N., \& Matzuk, M. M. (1996). Growth differentiation factor-9 is required during early ovarian folliculogenesis. Nature,383(6600), 531-535. doi:10.1038/383531a0

Duan, N., Wu, S., Chen, X., Huang, Y., \& Wang, Z. (2012). Selection and Identification of a DNA Aptamer Targeted to Vibrio parahemolyticus. Journal of Agricultural and Food Chemistry, 60(16), 4034-4038. doi:10.1021/jf300395z

Dube, J. L. (1998). The Bone Morphogenetic Protein 15 Gene Is X-Linked and Expressed in Oocytes. Molecular Endocrinology, 12(12), 1809-1817. doi:10.1210/me.12.12.1809

Duclair, S., Gautam, A., Ellington, A., \& Prasad, V. R. (2015). High-affinity RNA Aptamers Against the HIV-1 Protease Inhibit Both In Vitro Protease Activity and Late Events of Viral Replication. Molecular Therapy - Nucleic Acids, 4(228). doi:10.1038/mtna.2015.1

El-fouly, M. A., Cook, B., Nekola, M., \& Nalbandov, A. V. (1970). Role of the Ovum in Follicular Luteinization. Endocrinology, 87(2), 288-293. doi:10.1210/endo-87-2288

Ellington, A. D., \& Szostak, J. W. (1990). In vitro selection of RNA molecules that bind specific ligands. Nature, 346(6287), 818-822. doi:10.1038/346818a0

Famulok, M. (1994). Molecular Recognition of Amino Acids by RNA-Aptamers: An LCitrulline Binding RNA Motif and Its Evolution into an L-Arginine Binder. Journal of the American Chemical Society, 116(5), 1698-1706. doi: $10.1021 / \mathrm{ja} 00084 \mathrm{a} 010$

Galloway, S. M., McNatty, K. P., Cambridge, L. M., Laitinen, M. P., Juengel, J. L., Jokiranta, T. S., ... Ritvos, O. (2000). Mutations in an oocyte-derived growth factor gene (BMP15) cause increased ovulation rate and infertility in a dosagesensitive manner. Nature Genetics, 25(3), 279-283. doi:10.1038/77033

Hamula, C. L., Zhang, H., Guan, L. L., Li, X., \& Le, X. C. (2008). Selection of Aptamers against Live Bacterial Cells. Analytical Chemistry, 80(20), 7812-7819. doi:10.1021/ac801272

Hamula, C. L., Peng, H., Wang, Z., Newbigging, A. M., Tyrrell, G. J., Li, X., \& Le, X. C. (2015). The Effects of SELEX Conditions on the Resultant Aptamer Pools in the Selection of Aptamers Binding to Bacterial Cells. J Mol Evol, 81(5-6), 194-209. doi:10.1007/s00239-015-9711-y

Hanrahan, J. P., Gregan, S. M., Mulsant, P., Mullen, M., Davis, G. H., Powell, R., \& Galloway, S. (2003). Mutations in the Genes for Oocyte-Derived Growth Factors GDF9 and BMP15 Are Associated with Both Increased Ovulation Rate and 
Sterility in Cambridge and Belclare Sheep (Ovis aries). Biology of Reproduction, 70(4), 900-909. doi:10.1095/biolreprod.103.023093

Hashimoto, O., Moore, R. K., \& Shimasaki, S. (2005). Posttranslational processing of mouse and human BMP-15: Potential implication in the determination of ovulation quota. Proceedings of the National Academy of Sciences, 102(15), 5426-5431. doi:10.1073/pnas.0409533102

Heath D.A., Pitman J.L., \& McNatty K.P. (2017) Molecular forms of ruminant BMP15 and GDF9 and putative interactions with receptors. Reproduction 154, 521-534. doi: 10.1530/REP-17-0188

Heath D. A (2016). Oocyte-derived forms of ruminant BMP15 and GDF9 and a theoretical model to explain their synergistic response. Doctoral Thesis, Victoria University of Wellington, New Zealand. http://hdl.handle.net/10063/5353

Hermann, T., \& Patel, D. J. (2000). Adaptive Recognition by Nucleic Acid Aptamers. Science, 287(5454), 820-825. doi:10.1126/science.287.5454.820

Huang, Q., Cheung, A. P., Zhang, Y., Huang, H., Auersperg, N., \& Leung, P. C. (2009). Effects of growth differentiation factor 9 on cell cycle regulators and ERK42/44 in human granulosa cell proliferation. AJP: Endocrinology and Metabolism, 296(6), E1344-E1353. doi:10.1152/ajpendo.90929.2008

Ireson, C. R., \& Kelland, L. R. (2006). Discovery and development of anticancer aptamers. Molecular Cancer Therapeutics, 5(12), 2957-2962. doi:10.1158/1535-7163.mct06-0172

Juengel, J. L., Hudson, N. L., Whiting, L., \& McNatty, K. P. (2004). Effects of Immunization Against Bone Morphogenetic Protein 15 and Growth Differentiation Factor 9 on Ovulation Rate, Fertilization, and Pregnancy in Ewes. Biology of Reproduction, 70(3), 557-561. doi:10.1095/biolreprod.103.023333

Juengel, J. L., Proctor, L. E., Wearne, K., Olliver, D., Hudson, N. L., Jensen, D., ... McNatty, K. P. (2013). Effects of immunization against androstenedione or bone morphogenetic protein 15 (BMP15) on reproductive performance in sheep. Journal of Animal Science, 91(12), 5946-5953. doi:10.2527/jas.2012-6085

Keefe, A. D., Pai, S., \& Ellington, A. (2010). Aptamers as therapeutics. Nature Reviews Drug Discovery, 9(8), 660-660. doi:10.1038/nrd3249

Kankia, B. I., \& Marky, L. A. (2001). Folding of the Thrombin Aptamer into a GQuadruplex with Sr2 : Stability, Heat, and Hydration. Journal of the American Chemical Society, 123(44), 10799-10804. doi:10.1021/ja010008o

Kikin, O., Dantonio, L., \& Bagga, P. S. (2006). QGRS Mapper: A web-based server for predicting G-quadruplexes in nucleotide sequences. Nucleic Acids Research, 34(Web Server). doi:10.1093/nar/gk1253 
Larkin, M., Blackshields, G., Brown, N., Chenna, R., Mcgettigan, P., Mcwilliam, H et al (2007). Clustal W and Clustal X version 2.0. Bioinformatics, 23(21), 2947-2948. doi:10.1093/bioinformatics/btm404

Lane, A. N., Chaires, J. B., Gray, R. D., \& Trent, J. O. (2008). Stability and kinetics of Gquadruplex structures. Nucleic Acids Research, 36(17), 5482-5515. doi:10.1093/nar/gkn517

Liang, H., Hu, G., Zhang, T., Yang, Y., Zhao, L., Qi, Y et al (2012). Isolation of ssDNA aptamers that inhibit rabies virus. International Immunopharmacology, 14(3), 341-347. doi:10.1016/j.intimp.2012.06.019

Liang, H., Liu, Q., Zheng, X., Gai, W., Xue, X., Hu, G et al (2013). Aptamers targeting rabies virus-infected cells inhibit viral replication both in vitro and in vivo. Virus Research, 173(2), 398-403. doi:10.1016/j.virusres.2012.12.017

Liao, W. X., Moore, R. K., Otsuka, F., \& Shimasaki, S. (2002). Effect of Intracellular Interactions on the Processing and Secretion of Bone Morphogenetic Protein-15 (BMP-15) and Growth and Differentiation Factor-9. Implication Of The Aberrant Ovarian Phenotype Of Bmp-15 Mutant Sheep. Journal of Biological Chemistry, 278(6), 3713-3719. doi:10.1074/jbc.m210598200

Lin, H. Y., Wang, X., Ng-Eaton, E., Weinberg, R. A., \& Lodish, H. F. (1992). Expression cloning of the TGF- $\beta$ type II receptor, a functional transmembrane serine/threonine kinase. Cell, 68(4), 775-785. doi:10.1016/0092-8674(92)90152-3

Lin, J. S., Kauff, A., Diao, Y., Yang, H., Lawrence, S., \& Juengel, J. L. (2016). Creation of DNA aptamers against recombinant bone morphogenetic protein 15. Reprod. Fertil. Dev,28(8), 1164. doi:10.1071/rd14409

Lin, J. S., \& McNatty, K. P. (2009). Aptamer-Based Regionally Protected PCR for Protein Detection. Clinical Chemistry, 55(9),

1686-1693. doi:10.1373/clinchem.2009.127266

Lin, J. Y., $\quad$ Pitman-Crawford, J. L., $\quad$ Bibby, A. H., Hudson, N. L., $\quad$ McIntosh, C. J., Juengel, J. L., \& McNatty, K. P. (2012). Effects of species differences on oocyte regulation of granulosa cell function. Reproduction, 144(5), 557-567. doi:10.1530/rep-12-0267

Little, M., Kipriyanov, S., Le Gall, F., \& Moldenhauer, G. (2000). Of mice and men: hybridoma and recombinant antibodies. Immunology Today, 21(8), 364-370. doi:10.1016/s0167-5699(00)01668-6

Liu, Y., Wang, C., Li, F., Shen, S., Tyrrell, D. L., Le, X. C., \& Li, X. (2012). DNaseMediated Single-Cycle Selection of Aptamers for Proteins Blotted on a Membrane. Analytical Chemistry, 84(18), 7603-7606. doi:10.1021/ac302047e

Low, S. Y., Hill, J. E., \& Peccia, J. (2009). A DNA aptamer recognizes the Asp f 1 allergen of Aspergillus fumigatus. Biochemical and Biophysical Research Communications, 386(3), 544-548. doi:10.1016/j.bbrc.2009.06.089 
Lupold, S. E., Hicke, B. J., Lin, Y., \& Coffey, D. S. (2002). Identification and characterization of nuclease-stabilized RNA molecules that bind human prostate cancer cells via the prostate-specific membrane antigen. Cancer Research, 62(14), 4029-4033. Retrieved from PMID: 12124337

Macaya, R. F., Schultze, P., Smith, F. W., Roe, J. A., \& Feigon, J. (1993). Thrombinbinding DNA aptamer forms a unimolecular quadruplex structure in solution. Proceedings of the National Academy of Sciences, 90(8), 3745-3749. doi:10.1073/pnas.90.8.3745

Massagué, J. (1998). TGF- $\beta$ SIGNAL TRANSDUCTION. Annu. Rev. Biochem, 67(1), 753-791. doi:10.1146/annurev.biochem.67.1.753

Massagué, J. (2012). TGF $\beta$ signalling in context. Nature Reviews Molecular Cell Biology,13(10), 616-630. doi:10.1038/nrm3434

McIntosh, C. J., Lawrence, S., Smith, P., Juengel, J. L., \& McNatty, K. P. (2012). Active immunization against the proregions of GDF9 or BMP15 alters ovulation rate and litter size in mice. Reproduction, 143(2), 195-201. doi:10.1530/rep-11-0336

McIntosh, C. J., Lun, S., Lawrence, S., Western, A. H., McNatty, K. P., \& Juengel, J. L. (2008). The Proregion of Mouse BMP15 Regulates the Cooperative Interactions of BMP15 and GDF9. Biology of Reproduction, 79(5), 889-896. doi:10.1095/biolreprod.108.068163

Mckeague, M., \& Derosa, M. C. (2012). Challenges and Opportunities for Small Molecule Aptamer Development. Journal of Nucleic Acids, 2012, 1-20. doi: $10.1155 / 2012 / 748913$

McNatty, K. P., Hudson, N. L., Whiting, L., Reader, K. L., Lun, S., Western, A. et al (2007). The Effects of Immunizing Sheep with Different BMP15 or GDF9 Peptide Sequences on Ovarian Follicular Activity and Ovulation Rate. Biology of Reproduction, 76(4), 552-560. doi:10.1095/biolreprod.106.054361

McNatty, K. P., Juengel, J. L., Reader, K. L., Lun, S., Myllymaa, S., Lawrence, S. B., Laitinen, M. P. (2005). Bone morphogenetic protein 15 and growth differentiation factor 9 co-operate to regulate granulosa cell function. Reproduction, 129(4), 473480. doi:10.1530/rep.1.0511

Mondal, B., Ramlal, S., Lavu, P. S., Murali, H. S., \& Batra, H. V. (2015). A combinatorial systematic evolution of ligands by exponential enrichment method for selection of aptamer against protein targets. Appl Microbiol Biotechnol, 99(22), 9791-9803. doi:10.1007/s00253-015-6858-9

Monestier, O., Servin, B., Auclair, S., Bourquard, T., Poupon, A., Pascal, G., \& Fabre, S. (2014). Evolutionary Origin of Bone Morphogenetic Protein 15 and Growth and Differentiation Factor 9 and Differential Selective Pressure Between Mono- and Polyovulating Species. Biology of Reproduction,91(4), 83-83. doi:10.1095/biolreprod.114.119735 
Moore, R. K., Otsaku, F., \& Shimasaki, S. (2002). Molecular Basis of Bone Morphogenetic Protein-15 Signaling in Granulosa Cells. Journal of Biological Chemistry, 278(1), 304-310. doi:10.1074/jbc.m207362200

Moore, R. K., \& Shimasaki, S. (2004). Molecular biology and physiological role of the oocyte factor, BMP-15. Molecular and Cellular Endocrinology, 234(1-2), 67-73. doi:10.1016/j.mce.2004.10.012

Mueller, T. D., \& Nickel, J. (2012). Promiscuity and specificity in BMP receptor activation.FEBS Letters, 586(14), 1846-1859. doi:10.1016/j.febslet.2012.02.043

Murphy, M. B., Fuller, S. T., Richardson, P. M., \& Doyle, S. A. (2003). An improved method for the in vitro evolution of aptamers and applications in protein detection and purification. Nucleic Acids Research, 31(18). doi:10.1093/nar/gng110

Ng, E. W., Shima, D. T., Calias, P., Cunningham, E. T., Guyer, D. R., \& Adamis, A. P. (2006). Pegaptanib, a targeted anti-VEGF aptamer for ocular vascular disease. Nature Reviews Drug Discovery, 5(2), 123-132. doi:10.1038/nrd1955

Nastasijevic, B., Becker, N. A., Wurster, S. E., \& Maher, L. J. (2008). Sequence-specific binding of DNA and RNA to immobilized Nickel ions. Biochemical and Biophysical Research Communications, 366(2), 420-425. doi:10.1016/j.bbrc.2007.11.169

Nimjee, S. M., Rusconi, C. P., \& Sullenger, B. A. (2005). Aptamers: An Emerging Class of Therapeutics. Annual Review of Medicine, 56(1), 555-583. doi:10.1146/annurev.med.56.062904.144915

Otsuka, F., Yamamoto, S., Erickson, G. F., \& Shimasaki, S. (2001). Bone Morphogenetic Protein-15 Inhibits Follicle-stimulating Hormone (FSH) Action by Suppressing FSH Receptor Expression. Journal of Biological Chemistry, 276(14), 1138711392. doi:10.1074/jbc.m010043200

Patel, D. (1997). Structural analysis of nucleic acid aptamers. Current Opinion in Chemical Biology, 1(1), 32-46. doi:10.1016/s1367-5931(97)80106-8

Reverdatto, S., Burz, D. S., \& Shekhtman, A. (2015). Peptide aptamers: Development and applications. Current Topics in Medicinal Chemistry, 15(12), 1082-1101. PMCID: PMC4428161

Ruckman, J., Green, L. S., Beeson, J., Waugh, S., Gillette, W. L., Henninger, D. D. et al (1998). 2'-Fluoropyrimidine RNA-based Aptamers to the 165-Amino Acid Form of Vascular Endothelial Growth Factor (VEGF165): Inhibition Of Receptor Binding And Vegf-Induced Vascular Permeability Through Interactions Requiring The Exon 7-Encoded Domain. Journal of Biological Chemistry, 273(32), 2055620567. doi:10.1074/jbc.273.32.20556

Schmierer, B., \& Hill, C. S. (2007). TGF $\beta-S M A D$ signal transduction: molecular specificity and functional flexibility. Nature Reviews Molecular Cell Biology, 8(12), 970-982. doi:10.1038/nrm2297 
Sanghavi, B. J., Moore, J. A., Chávez, J. L., Hagen, J. A., Kelley-Loughnane, N., Chou, C., \& Swami, N. S. (2016). Aptamer-functionalized nanoparticles for surface immobilization-free electrochemical detection of cortisol in a microfluidic device. Biosensors and Bioelectronics, 78, 244-252. doi:10.1016/j.bios.2015.11.044

Shi, Y., \& Massagué, J. (2003). Mechanisms of TGF- $\beta$ Signalling from Cell Membrane to the Nucleus. Cell, 113(6), 685-700. doi:10.1016/s0092-8674(03)00432-x

Sievers, F., Wilm, A., Dineen, D., Gibson, T. J., Karplus, K., Li, W. et al (2014). Fast, scalable generation of high-quality protein multiple sequence alignments using Clustal Omega. Molecular Systems Biology, 7(1), 539-539. doi: $10.1038 / \mathrm{msb} .2011 .75$

Slobodin, B., \& Gerst, J. E. (2010). A novel mRNA affinity purification technique for the identification of interacting proteins and transcripts in ribonucleoprotein complexes. RNA, 16(11), 2277-2290. doi:10.1261/rna.2091710

Song, K., Cho, M., Jo, H., Min, K., Jeon, S. H., Kim, T. et al (2011). Gold nanoparticlebased colorimetric detection of kanamycin using a DNA aptamer. Analytical Biochemistry, 415(2), 175-181. doi:10.1016/j.ab.2011.04.007

Song, K., Lee, S., \& Ban, C. (2012). Aptamers and Their Biological Applications. Sensors, 12(1), 612-631. doi:10.3390/s120100612

Stojanovic, M. N., De Prada, P., \& Landry, D. W. (2001). Aptamer-Based Folding Fluorescent Sensor for Cocaine. J. Am. Chem. Soc, 123(21), 4928-4931. doi:10.1021/ja003817

Stojanovic, M. N., \& Landry, D. W. (2002). Aptamer-Based Colorimetric Probe for Cocaine. Journal of the American Chemical Society, 124(33), 9678-9679. doi:10.1021/ja0259483

Stoltenburg, R., Reinemann, C., \& Strehlitz, B. (2005). FluMag-SELEX as an advantageous method for DNA aptamer selection. Analytical and Bioanalytical Chemistry, 383(1), 83-91. doi:10.1007/s00216-005-3388-9

Stoltenburg, R., Schubert, T., \& Strehlitz, B. (2015). In vitro Selection and Interaction Studies of a DNA Aptamer Targeting Protein A. Plos One, 10(7). doi:10.1371/journal.pone.0134403

Su, Y., Wu, X., O'Brien, M. J., Pendola, F. L., Denegre, J. N., Matzuk, M. M., \& Eppig, J. J. (2004). Synergistic roles of BMP15 and GDF9 in the development and function of the oocyte-cumulus cell complex in mice: genetic evidence for an oocyte-granulosa cell regulatory loop. Developmental Biology, 276(1), 64-73. doi:10.1016/j.ydbio.2004.08.020

Svobodová, M., Pinto, A., Nadal, P., \& O’ Sullivan, C. K. (2012). Comparison of different methods for generation of single-stranded DNA for SELEX processes. Analytical and Bioanalytical Chemistry, 404(3), 835-842. doi:10.1007/s00216-012-6183-4 
Swinerd, G. W. (2016). The molecular forms of BMP15 in a range of mammalian species. Masters Thesis, Victoria University of Wellington, New Zealand. http://hdl.handle.net/10063/5184

Tang, Z., Parekh, P., Turner, P., Moyer, R. W., \& Tan, W. (2009). Generating Aptamers for Recognition of Virus-Infected Cells. Clinical Chemistry, 55(4), 813-822. doi:10.1373/clinchem.2008.113514

Tolle, F., Wilke, J., Wengel, J., \& Mayer, G. (2014). By-Product Formation in Repetitive PCR Amplification of DNA Libraries during SELEX. PLoS ONE, 9(12). doi:10.1371/journal.pone.0114693

Tsui, NB., Ng, EK., \& YM., Lo. (2002). Stability of Endogenous and Added RNA in Blood Specimens, Serum, and Plasma. Clinical Chemistry, 48(10), 1647-1653. PMID: 12324479

Tucker, W. O., Shum, K. T., \& Tanner, J. A. (2012). G-quadruplex DNA Aptamers and their Ligands: Structure, Function and Application. Current Pharmaceutical Design, 18(14), 2014-2026. doi:10.2174/138161212799958477

Tuerk, C., \& Gold, L. (1990). Systematic evolution of ligands by exponential enrichment: RNA ligands to bacteriophage T4 DNA polymerase. Science, 249(4968), 505-510. doi:10.1126/science.2200121

Tuerk, C., Macdougal, S., \& Gold, L. (1992). RNA pseudoknots that inhibit human immunodeficiency virus type 1 reverse transcriptase. Proceedings of the National Academy of Sciences, 89(15), 6988-6992. doi:10.1073/pnas.89.15.6988

UniProt: The universal protein knowledgebase. (2016). Nucleic Acids Research, 45(D1). doi:10.1093/nar/gkw1099

Vairamani, M., \& Gross, M. L. (2003). G-Quadruplex Formation of Thrombin-Binding Aptamer Detected by Electrospray Ionization Mass Spectrometry. Journal of the American Chemical Society, 125(1), 42-43. doi:10.1021/ja0284299

Vitt, U. A., Mazerbourg, S., Klein, C., \& Hsueh, J. A. (2002). Bone Morphogenetic Protein Receptor Type II Is a Receptor for Growth Differentiation Factor9. Biology of Reproduction, 67(2), 473-480. doi:10.1095/biolreprod67.2.473

Vu, M., Jameson, N., Masuda, S., Lin, D., Larralde-Ridaura, R., \& Lupták, A. (2012). Convergent Evolution of Adenosine Aptamers Spanning Bacterial, Human, and Random Sequences Revealed by Structure-Based Bioinformatics and Genomic SELEX. Chemistry \& Biology, 19(10), 1247-1254. doi:10.1016/j.chembiol.2012.08.010

White, R., Rusconi, C., Scardino, E., Wolberg, A., Lawson, J., Hoffman, M., \& Sullenger, B. (2001). Generation of Species Cross-reactive Aptamers Using "Toggle" SELEX.Molecular Therapy, 4(6), 567-573. doi: $10.1006 /$ mthe.2001.0495 
Williams, R., Peisajovich, S. G., Miller, O. J., Magdassi, S., Tawfik, D. S., \& Griffiths, A. D. (2006). Amplification of complex gene libraries by emulsion PCR. Nature Methods, 3(7), 545-550. doi:10.1038/nmeth896

Wyatt, J. R., Vickers, T. A., Roberson, J. L., Buckheit, R. W., Klimkait, T., Debaets, E. et al (1994). Combinatorially selected guanosine-quartet structure is a potent inhibitor of human immunodeficiency virus envelope-mediated cell fusion. Proceedings of the National Academy of Sciences, 91(4), 1356-1360. doi:10.1073/pnas.91.4.1356

Yamamoto, R., Katahira, M., Nishikawa, S., Baba, T., Taira, K., \& Kumar, P. K. (2000). A novel RNA motif that binds efficiently and specifically to the Tat protein of HIV and inhibits the trans-activation by Tat of transcription in vitro and in vivo. Genes to Cells, 5(5), 371-388. doi:10.1046/j.1365-2443.2000.00330.x

Yan, C., Wang, P., DeMayo, J., DeMayo, F. J., Elvin, J. A., Carino, C., Matzuk, M. M. (2001). Synergistic Roles of Bone Morphogenetic Protein 15 and Growth Differentiation Factor 9 in Ovarian Function. Molecular Endocrinology, 15(6), 854-866. doi:10.1210/mend.15.6.0662

Zuker, M. (2003). Mfold web server for nucleic acid folding and hybridization prediction. Nucleic Acids Research, 31(13), 3406-3415. doi:10.1093/nar/gkg595 


\section{CHAPTER 6: APPENDIX 1 - MATERIALS}

Table 6.1. Tissue culture reagents

\begin{tabular}{|c|c|c|c|}
\hline $\begin{array}{l}\text { Reagent/Equipment } \\
\text { name }\end{array}$ & Common name/Contents & $\begin{array}{l}\text { Catalogue/Lot } \\
\text { number }\end{array}$ & Manufacturer \\
\hline Ampicillin & - & A9393 & \multirow{5}{*}{$\begin{array}{l}\text { Sigma-Aldrich, St } \\
\text { Louis, USA }\end{array}$} \\
\hline Heparin & - & H3149 & \\
\hline Bovine serum albumin & BSA & A450 & \\
\hline Puromycin dihydrochloride & Puromycin & P8833 & \\
\hline Trypan blue & - & T8154 & \\
\hline Glutamax & GMAX & 35050061 & \multirow{9}{*}{$\begin{array}{c}\text { Life Technologies, } \\
\text { NZ }\end{array}$} \\
\hline $\begin{array}{c}\text { Dulbeccós Modified Eagle } \\
\text { Medium }\end{array}$ & D-MEM & 11965092 & \\
\hline $\begin{array}{l}\text { Dulbeccó s Modified Eagle } \\
\text { Medium: Hams F12 (1:1), }\end{array}$ & D-MEM: Hams F12 & 12634010 & \\
\hline Fetal Calf Serum & FCS & & \\
\hline Penicillin/Streptomycin & $\begin{array}{l}\text { PenStrep, Penicillin, } \\
\text { Streptomycin }\end{array}$ & 15070063 & \\
\hline $\begin{array}{c}\text { Phosphate Buffered Saline } \mathrm{pH} \\
7.4\end{array}$ & PBS & 10010023 & \\
\hline $\begin{array}{c}\text { TrypLETM Express Enzyme } \\
(1 \mathrm{X})\end{array}$ & TrypLE & 12604054 & \\
\hline Tissue culture Flasks & $\begin{array}{l}\text { NUNC Growth flasks; } \\
\text { T25, T175 }\end{array}$ & $\begin{array}{l}136196, \\
178883\end{array}$ & \\
\hline 6-well culture plates & NUNC culture plates & 140675 & \\
\hline $\begin{array}{l}\text { Complete EDTA-free protease } \\
\text { inhibitor cocktail }\end{array}$ & Protease inhibitors & & Roche \\
\hline Filter $(0.22 \mu \mathrm{m})$ & Filter & 431118 & Corning Inc USA \\
\hline
\end{tabular}

Table 6.2. DNA cloning and sequencing reagents

\begin{tabular}{|c|c|c|c|}
\hline $\begin{array}{l}\text { Reagent/Equipment } \\
\text { name }\end{array}$ & Common name & $\begin{array}{l}\text { Catalogue/Lot } \\
\text { number }\end{array}$ & Manufacturer \\
\hline $\begin{array}{l}\text { 5-bromo-4-chloro-3-indolyl- } \\
\text { b-D-galactopyranoside }\end{array}$ & X-Gal & B4252 & $\begin{array}{l}\text { Sigma-Aldrich, St } \\
\text { Louis, USA }\end{array}$ \\
\hline $\begin{array}{l}\text { pGEM®-T-Easy Vector } \\
\text { Cloning Kit System I }\end{array}$ & Cloning Kit & A1360 & Promega \\
\hline DH5 $\alpha^{\mathrm{TM}}$ Competent Cells & $\begin{array}{c}\text { DH5 } \alpha, \text { competent } E \text {. } \\
\text { coli }\end{array}$ & $18265-017$ & Life Technologies \\
\hline $\begin{array}{c}\text { Ampicillin anhydrous, 96.0- } \\
100.5 \%\end{array}$ & Ampicillin & $69-53-4$ & $\begin{array}{l}\text { Sigma-Aldrich, St } \\
\text { Louis, USA }\end{array}$ \\
\hline EcoR I restriction enzyme & EcoRI & 10703737001 & \multirow[b]{2}{*}{ Roche } \\
\hline $\begin{array}{c}\text { SuRE/Cut Buffer } \mathrm{H} \text { for } \\
\text { restriction digest }\end{array}$ & $\begin{array}{c}\text { Digestion buffer, Buffer } \\
\text { H } \\
\end{array}$ & 11417991001 & \\
\hline BactoTM Yeast Extract & Yeast extract & 212750 & \multirow{3}{*}{$\begin{array}{c}\text { Becton, Franklin, } \\
\text { Germany }\end{array}$} \\
\hline BactoTM Agar & Agar & 211705 & \\
\hline BactoTM Tryptone & Tryptone & 214010 & \\
\hline QIAprep Spin Miniprep Kit & & 27106 & Qiagen. Germany \\
\hline
\end{tabular}


Table 6.3. Protein purification reagents

\begin{tabular}{|c|c|c|c|}
\hline $\begin{array}{l}\text { Reagent/Equipment } \\
\text { name }\end{array}$ & Common name/Contents & $\begin{array}{l}\text { Catalogue/Lot } \\
\text { number }\end{array}$ & Manufacturer \\
\hline Trifluoroacetic acid & TFA & 302031 & $\begin{array}{l}\text { Sigma-Aldrich, } \mathrm{St} \\
\text { Louis, USA }\end{array}$ \\
\hline Water (HPLC grade) & Water & 1.15333 .2500 & MERCK \\
\hline Acetonitrile & $\mathrm{ACN}$ & 1.00030 .2500 & MERCK \\
\hline HPLC reverse phase column & Jupiter, $5 \mu \mathrm{m}, \mathrm{C} 4,300 \AA$ & OOG4167EO & $\begin{array}{c}\text { Phenomenix, Lane } \\
\text { Cove, NSW, } \\
\text { Australia }\end{array}$ \\
\hline $\begin{array}{c}\text { cOmplete } \\
\text { Protease Inhibitor Cocktail }\end{array}$ & Protease inhibitor & 4693132001 & Roche, Germany \\
\hline Protein LoBind Tubes & Lo-bind tubes & 0030108132 & Eppendorf \\
\hline Ni-NTA Agarose & - & 30210 & Qiagen \\
\hline W0 Buffer & $\begin{array}{c}\text { 50mM TRIS, 300mM } \\
\mathrm{NaCl}\end{array}$ & \multirow{6}{*}{\multicolumn{2}{|c|}{ Made in house to required volume }} \\
\hline W5 Buffer & $\begin{array}{c}\text { 50mM TRIS, } 1 \mathrm{M} \mathrm{NaCl} \& \\
5 \mathrm{mM} \text { Imidazole }\end{array}$ & & \\
\hline W10 Buffer & $\begin{array}{c}\text { 50mM TRIS, } 300 \mathrm{mM} \\
\mathrm{NaCl} \& 10 \mathrm{mM} \text { Imidazole }\end{array}$ & & \\
\hline W20 Buffer & $\begin{array}{c}\text { 50mM TRIS, 300mM } \\
\mathrm{NaCl} \& 20 \mathrm{mM} \text { Imidazole }\end{array}$ & & \\
\hline E1 Buffer & $\begin{array}{c}\text { 50mM TRIS, 300mM } \\
\mathrm{NaCl}, \& \text { 7M Urea }\end{array}$ & & \\
\hline E2 Buffer & $\begin{array}{c}\text { 50mM TRIS, 300mM } \\
\mathrm{NaCl} \& 500 \mathrm{mM} \text { Imidazole }\end{array}$ & & \\
\hline
\end{tabular}

Table 6.4. Synthetic oligonucleotides

\begin{tabular}{|c|c|c|c|}
\hline $\begin{array}{l}\text { Primer } \\
\text { name }\end{array}$ & Sequence $\left(5^{\prime} \rightarrow 3^{\prime}\right)$ & Purification & Manufacturer \\
\hline $\begin{array}{c}\text { Forward } \\
\text { Primer }(\mathrm{Pf})\end{array}$ & ATACGAGCTTGTTCAATA & \multirow{4}{*}{$\begin{array}{c}\text { Poly-Acrylamide } \\
\text { Gel } \\
\text { Electrophoresis, } \\
\text { High } \\
\text { Performance } \\
\text { Liquid } \\
\text { Chromatography }\end{array}$} & \multirow{4}{*}{$\begin{array}{c}\text { Integrated DNA } \\
\text { Technologies (IDT), } \\
\text { USA }\end{array}$} \\
\hline $\begin{array}{c}\text { Reverse } \\
\text { Primer (Pr) }\end{array}$ & TGATAGTAAGAGCAATC & & \\
\hline $\begin{array}{l}\text { Biotinylated } \\
\text { - Forward } \\
\text { Primer (PfB) } \\
\end{array}$ & Biotin-ATACGAGCTTGTTCAATA & & \\
\hline $\begin{array}{l}\text { Biotinylated } \\
\text { - Reverse } \\
\text { Primer (PrB) }\end{array}$ & Biotin- TGATAGTAAGAGCAATC & & \\
\hline $\begin{array}{c}\text { N40 } \\
\text { Polyclonal } \\
\text { Aptamer } \\
\text { library } \\
\end{array}$ & $\begin{array}{c}\text { ATACGAGCTTGTTCAATA -N40- } \\
\text { TGATAGTAAGAGCAATC }\end{array}$ & $\begin{array}{l}\text { Poly-Acrylamide } \\
\text { Gel } \\
\text { Electrophoresis }\end{array}$ & $\begin{array}{c}\text { Life Technologies, } \\
\text { Carlsbad, } \\
\text { California, CA, USA }\end{array}$ \\
\hline
\end{tabular}


Table 6.5. Polymerase chain reaction reagents

\begin{tabular}{|c|c|c|c|}
\hline $\begin{array}{l}\text { Reagent/Equipment } \\
\text { name }\end{array}$ & Common name/Contents & $\begin{array}{l}\text { Catalogue/Lot } \\
\text { number }\end{array}$ & Manufacturer \\
\hline $\begin{array}{c}\text { Eppendorf } \\
\text { Mastercycler } \AA \\
\text { Pro } \\
\end{array}$ & PCR machine/Thermal Cycler & $\begin{array}{l}\text { Mastercycler® } \\
\text { Pro }\end{array}$ & $\begin{array}{c}\text { Eppendorf, Hamburg, } \\
\text { Germany }\end{array}$ \\
\hline Corbett Rotor-Gene & RT-PCR machine & & \multirow{3}{*}{ Qiagen } \\
\hline Gene-Disc 72 Rotor & - & 6001014 & \\
\hline $\begin{array}{c}\text { Gene-Disc } 72 \text { Locking } \\
\text { Ring }\end{array}$ & Locking ring & 6001006 & \\
\hline $\begin{array}{l}\text { UltraPure }^{\mathrm{TM}} \text { Distilled } \\
\text { Water, DNAse, RNAse } \\
\text { Free }\end{array}$ & Ultra-pure water & 10977015 & $\begin{array}{l}\text { Invitrogen, Life } \\
\text { Technologies }\end{array}$ \\
\hline Magnesium & $\mathrm{Mg}^{2+}$ & 201203 & \multirow[t]{2}{*}{$\begin{array}{l}\text { Qiagen, Hilden, } \\
\text { Germany }\end{array}$} \\
\hline $\begin{array}{c}\text { Taq DNA Polymerase } \\
\text { Kit }(5000)\end{array}$ & 10x PCR Buffer, Taq & 201207 & \\
\hline Nucleotides & dNTPs & $10297-018$ & Life Technologies \\
\hline Primers (Various) & See Table 6 & ynthetic Oligonu & eotides \\
\hline
\end{tabular}

Table 6.6. Gel electrophoresis, gel extraction and strand separation reagents

\begin{tabular}{|c|c|c|c|}
\hline $\begin{array}{l}\text { Reagent/Equipment } \\
\text { name }\end{array}$ & Common name /Contents & Catalogue/Lot number & Manufacturer \\
\hline $6 \mathrm{X}$ DNA loading dye & DNA Loading dye & SM-1191 & $\begin{array}{l}\text { Thermo } \\
\text { Scientific }\end{array}$ \\
\hline $\begin{array}{l}\text { SYBR Green DNA } \\
\text { staining dye }\end{array}$ & SYBR green & S-7567 & $\begin{array}{c}\text { Life } \\
\text { Technologies }\end{array}$ \\
\hline $\begin{array}{c}\text { GeneRuler® Low } \\
\text { Range }\end{array}$ & DNA ladder & SM-1191 & $\begin{array}{c}\text { Thermo } \\
\text { Scientific }\end{array}$ \\
\hline SeaKem $®$ LE Agarose & Agarose gel & 50004 & \multirow{2}{*}{$\begin{array}{l}\text { Lonza, New } \\
\text { Jersey, USA }\end{array}$} \\
\hline $\begin{array}{c}\text { NuSieve }^{\mathrm{TM}} \mathrm{GTG}^{\mathrm{TM}} \\
\text { Agarose }\end{array}$ & GTG gel & 50080 & \\
\hline $\begin{array}{c}\text { Gel Electrophoresis } \\
\text { tanks }\end{array}$ & Horizontal gel tank & $\begin{array}{l}\text { Sub-cell model 96, mini } \\
\text { sub-cell model } 96 \\
\end{array}$ & \multirow{2}{*}{$\begin{array}{c}\text { BioRad, } \\
\text { Hercules, } \\
\text { California, USA }\end{array}$} \\
\hline $\begin{array}{c}\text { Electrophoresis } \\
\text { powerpack }\end{array}$ & - & PowerPac HC & \\
\hline Qiagen MinElute® Kit & $\begin{array}{c}\text { Gel extraction kit: coloumn, } \\
\text { Buffer PE, Bufffer EB, } \\
\text { Buffer QG }\end{array}$ & 28006 & $\begin{array}{l}\text { Qiagen, } \\
\text { Germany }\end{array}$ \\
\hline Propan-2-ol & Isopropanol & AL0323 & $\begin{array}{l}\text { Scharlau } \\
\text { Chemie, } \\
\text { Adelaide, } \\
\text { Australia }\end{array}$ \\
\hline $\begin{array}{c}\text { Streptavidin Magnetic } \\
\text { beads }\end{array}$ & SMBs & S1420S & $\begin{array}{l}\text { New England } \\
\text { BioLabs, } \\
\text { Massachusetts, } \\
\text { USA }\end{array}$ \\
\hline PickPen $® 1-M$ & PickPen $®$ & \multirow{2}{*}{34096} & \multirow{2}{*}{$\begin{array}{l}\text { Bio Noble, } \\
\text { Zurich, } \\
\text { Switzerland }\end{array}$} \\
\hline Silicon PickPen $®$ tips & PickPen ${ }^{\circledR}$ tips & & \\
\hline
\end{tabular}


Table 6.7. Western blotting reagents

\begin{tabular}{|c|c|c|c|}
\hline $\begin{array}{l}\text { Reagent/Equipment } \\
\text { name }\end{array}$ & Common name & $\begin{array}{l}\text { Catalogue/Lot } \\
\text { number }\end{array}$ & Manufacturer \\
\hline 2-mercapto-ethanol (2-ME) & 2-ME & 46496KMV & Sigma Life Sciences \\
\hline $30 \%$ Acrylamide/Bis Solution & Bis-acrylamide mix (30\%) & $161-0158$ & Bio-Rad, USA \\
\hline TEMED & - & $161-0800$ & \multirow{2}{*}{$\begin{array}{l}\text { Bio-Rad, USA } \\
\text { Sigma-Aldrich }\end{array}$} \\
\hline $\begin{array}{l}\text { Streptavidin-Peroxidase } \\
\text { Polymer, Ultrasensitive }\end{array}$ & Strep-HRP & S2438 & \\
\hline $\begin{array}{c}\text { WesternBright ECL-Spray } \\
\text { Western Blotting Detection } \\
\text { System }\end{array}$ & ECL-Spray & K-12049-D50 & Advansta, NZ \\
\hline Criterion Blotter ${ }^{\mathrm{TM}}$ & Criterion transfer tank & 1704070 & Bio-Rad \\
\hline $\begin{array}{c}\text { Mini-PROTEAN Tetra Cell } \\
\text { Casting Module }\end{array}$ & $\begin{array}{c}\text { SDS-PAGE gel cast, gel } \\
\text { cast }\end{array}$ & $165-8008$ & \multirow{3}{*}{ Bio-Rad } \\
\hline $\begin{array}{c}\text { Mini-PROTEAN II Tetra } \\
\text { Electrophoresis System }\end{array}$ & Vertical gel tank & $165-8000$ & \\
\hline $\begin{array}{c}\text { Precision Plus }{ }^{\mathrm{TM}} \text { Dual Colour } \\
\text { Protein Ladder }\end{array}$ & Ladder & 1610374 & \\
\hline Gel Blotting Paper & Blotting paper & GB003 & $\begin{array}{c}\text { Whatman Schleicher \& } \\
\text { Schuell }\end{array}$ \\
\hline $\begin{array}{c}\text { Amersham }^{\mathrm{TM}} \text { Protran } \\
\text { nitrocellulose blotting } \\
\text { membrane }\end{array}$ & $\begin{array}{c}\text { Nitrocellulose membrane } \\
\text { (Western and Eastern } \\
\text { blots) }\end{array}$ & 10600016 & $\begin{array}{l}\text { GE Healthcare Life } \\
\text { Sciences }\end{array}$ \\
\hline $\begin{array}{l}\text { Hybond }{ }^{\mathrm{TM}_{-} \mathrm{C} \text { Extra }} \\
\text { nitrocellulose membrane }\end{array}$ & $\begin{array}{l}\text { Nitrocellulose membrane } \\
\text { (Dot blotting and SELEX) }\end{array}$ & RPN303E & $\begin{array}{c}\text { Amersham GE } \\
\text { Biosciences, Little } \\
\text { Chalfont, UK }\end{array}$ \\
\hline ImageJ Software & ImageJ Software & & $\begin{array}{c}\text { U. S. National } \\
\text { Institutes of Health }\end{array}$ \\
\hline Transparent Film & Transparent Film & & $3 \mathrm{M}$ \\
\hline $\begin{array}{l}\text { Peroxidise conjugated rabbit } \\
\text { anti mouse IgG }\end{array}$ & Secondary antibody & 315035045 & $\begin{array}{c}\text { Jackson Immuno } \\
\text { Research Laboratories } \\
\text { Ltd, } \\
\text { West Grove, PA, }\end{array}$ \\
\hline Omega Lum G & $\begin{array}{c}\text { Omega Lum G Imaging } \\
\text { System }\end{array}$ & & Aplegen \\
\hline Tween 20 & Tween 20 & 115125 & Fisher Scientific \\
\hline Skim Milk powder & Milk-powder & & $\begin{array}{l}\text { Fonterra Auckland, } \\
\text { New Zealand }\end{array}$ \\
\hline $\begin{array}{l}\text { Monoclonal Antibody 37A } \\
\text { anti-GDF9 in PBS/0.1\% } \\
\text { Sodium azide }\end{array}$ & \multirow{2}{*}{$\begin{array}{c}\text { mAb37A, } \\
\text { Targets sequence } \\
\text { DQESASSELKKPLV(C) } \\
\text { (near N-terminal of the } \\
\text { mature ovine GDF9) } \\
\text { mAb61A, } \\
\text { Targets sequence } \\
\text { SEVPGPSREHDGPES } \\
\text { (near N-terminal of the } \\
\text { mature ovine BMP15) }\end{array}$} & \multirow{2}{*}{$\begin{array}{l}\text { Ordered by } \\
\text { AgResearch }\end{array}$} & \multirow{2}{*}{$\begin{array}{l}\text { Oxford Brookes } \\
\text { University, } \\
\text { United Kingdom }\end{array}$} \\
\hline $\begin{array}{l}\text { Monoclonal Antibody } 61 \mathrm{~A} \\
\text { Anti-BMP15 in PBS/0.1\% } \\
\text { Sodium azide }\end{array}$ & & & \\
\hline
\end{tabular}


Table 6.8. Recipes

\begin{tabular}{|c|c|c|c|}
\hline Reagent name & Common name & Reagents & Storage \\
\hline $\begin{array}{l}\text { Aptamer Binding } \\
\text { and Washing } \\
\text { Buffer }\end{array}$ & $\begin{array}{l}\text { 2x BWB, 1x BWB, } \\
\text { BWB }\end{array}$ & $\begin{array}{c}\text { For } 1 \mathrm{xBWB} \text { : Tris- } \mathrm{HCl} \mathrm{pH} 7.5 \\
(2 \mathrm{mM}), \mathrm{NaCl}(10 \mathrm{mM}), \mathrm{KCl} \\
(0.5 \mathrm{mM}), \mathrm{MgCl} 2(0.2 \mathrm{mM}), \mathrm{CaCl} 2 \\
(0.1 \mathrm{mM}), \mathrm{IGEPAL}(0.1 \% \mathrm{v} / \mathrm{v})\end{array}$ & Room Temperature \\
\hline $\begin{array}{l}\text { TAE Running } \\
\text { Buffer }\end{array}$ & TAE Buffer & Tris-HCl, Acetic Acid, & Room Temperature \\
\hline $\begin{array}{c}\text { Aptamer and } \\
\text { Membrane } \\
\text { Blocking Solution }\end{array}$ & Blocking solution & $\begin{array}{c}1 \mathrm{xBWB}, 5 \% \text { or } 2.5 \% \mathrm{w} / \mathrm{v} \text { low-fat } \\
\text { skim milk powder }\end{array}$ & $4^{\circ} \mathrm{C}$ for up to 24 hours \\
\hline $\begin{array}{l}\text { 10x Tris-Glycine } \\
\text { Stock }\end{array}$ & 10x Tris-Glycine & $\begin{array}{c}\text { Tris-Base } 30.3 \mathrm{~g} \text {, Glycine } 144 \mathrm{~g}, \\
\text { final volume of } 1 \mathrm{~L} \text { with HighQ } \\
\text { water }\end{array}$ & Room Temperature \\
\hline $\begin{array}{c}\text { 5x Western } \\
\text { Running Buffer } \\
\text { pH } 8.3 \\
\end{array}$ & 5x Running Buffer & $\begin{array}{c}\text { Glycine } 144 \mathrm{~g}, \text { Tris-Base } 30 \mathrm{~g}, \text { SDS } \\
10 \mathrm{~g} \text {, final volume of } 2 \mathrm{~L} \text { with } \\
\text { distilled water }\end{array}$ & Room Temperature \\
\hline $\begin{array}{l}\text { Western Transfer } \\
\text { Buffer }\end{array}$ & Transfer Buffer & $\begin{array}{c}10 \% \text { v/v 10x Tris-Glycine solution, } \\
20 \% \text { v/v Methanol, final volume } \\
\text { with distilled water }\end{array}$ & $4^{\circ} \mathrm{C}$ \\
\hline $\begin{array}{l}\text { 1.5M Tris- } \mathrm{HCl} \mathrm{pH} \\
8.8\end{array}$ & 1.5M Tris- $\mathrm{HCl}$ & $\begin{array}{l}\text { Tris- } \mathrm{HCl} 36.34 \mathrm{~g} \text {, adjust } \mathrm{pH} \text { with } \\
\mathrm{NaOH} \text {, final volume of } 200 \mathrm{~mL} \\
\text { with distilled water, autoclave }\end{array}$ & Room Temperature \\
\hline $\begin{array}{l}0.5 \mathrm{M} \text { Tris- } \mathrm{HCl} \mathrm{pH} \\
6.8\end{array}$ & $0.5 \mathrm{M}$ Tris- $\mathrm{HCl}$ & $\begin{array}{l}\text { Tris- } \mathrm{HCl} 6.06 \mathrm{~g} \text {, adjust } \mathrm{pH} \text { with } \\
\mathrm{NaOH} \text {, final volume of } 100 \mathrm{~mL} \\
\text { with distilled water, autoclave }\end{array}$ & Room Temperature \\
\hline $10 \% \mathrm{SDS}$ & $10 \%$ SDS & $\begin{array}{l}20 \mathrm{~g} \text { SDS, final volume of } 200 \mathrm{~mL} \\
\text { with High-Q water }\end{array}$ & Room Temperature \\
\hline $\begin{array}{l}\text { Ammonium } \\
\text { Persulfate }\end{array}$ & $\begin{array}{l}\text { Ammonium } \\
\text { Persulfate }\end{array}$ & $\begin{array}{l}10 \% \mathrm{w} / \mathrm{v} \text { ammonium persulfate in } \\
\text { HighQ Water }\end{array}$ & $-20^{\circ} \mathrm{C}$ \\
\hline Ponceau S Stain & Ponceau S Stain & $\begin{array}{l}\text { 1.0g Ponceau S, } 2.0 \mathrm{~mL} \text { Acetic } \\
\text { Acid, final volume of } 200 \mathrm{~mL} \text { with } \\
\text { HighQ Water }\end{array}$ & Room Temperature \\
\hline Western Buffer & Western Buffer & $\begin{array}{l}20 \mathrm{~mL} 1 \mathrm{M} \text { Tris-HCL } \mathrm{pH} 7.5,8.76 \mathrm{~g} \\
\mathrm{NaCl}, 1 \mathrm{~mL} \text { Tween } 20, \text { final volume } \\
\text { of } 1 \mathrm{~L} \text { with High-Q water }\end{array}$ & Room Temperature \\
\hline $0.3 \mathrm{M} \mathrm{NaOH}$ & $\mathrm{NaOH}$ & $\begin{array}{l}\text { For } 1 \mathrm{M}: 30 \mathrm{~g} \mathrm{NaOH} \text {, make up to } \\
\text { 150mL High-Q water. Dilute to } \\
\text { working concentration with High- } \\
\text { Q water }\end{array}$ & Room Temperature \\
\hline $1 \mathrm{M} \mathrm{HCl}$ & $\mathrm{HCl}$ & & Room Temperature \\
\hline LB Agar & - & $\begin{array}{c}\text { Per } 100 \mathrm{~mL} \text { of LB Broth add: } 1.5 \mathrm{~g} \\
\text { Bacto }^{\mathrm{TM}} \text { Agar, } 100 \mu \mathrm{L} \text { ampicillin } \\
(1000 \mathrm{x})\end{array}$ & Use immediately \\
\hline LB Broth & - & $\begin{array}{l}1 \mathrm{~g} \mathrm{NaCl}^{1} 1 \mathrm{~g} \mathrm{Bacto}^{\mathrm{TM}} \text { Tryptone, } \\
0.5 \mathrm{~g} \mathrm{Bacto}^{\mathrm{TM}} \text { Yeast Extract. Make } \\
\text { to } 100 \mathrm{~mL} \text { with High-Q water. }\end{array}$ & $4^{\circ} \mathrm{C}$ \\
\hline
\end{tabular}


Table 6.9. General reagents and chemicals

\begin{tabular}{|c|c|c|c|}
\hline $\begin{array}{l}\text { Reagent/Equipment } \\
\text { name }\end{array}$ & Common name & $\begin{array}{l}\text { Catalogue/Lot } \\
\text { number/model } \\
\text { number }\end{array}$ & Manufacturer \\
\hline $\begin{array}{l}\text { Methanol - AnalaR } \\
\text { Normapur }\end{array}$ & Methanol & & VWR Prolabo \\
\hline $\begin{array}{l}\text { Bromophenol blue } \\
\text { sodium salt }\end{array}$ & Bromophenol blue & 04693159001 & Roche \\
\hline Glycine & Glycine & $2 \mathrm{~A} 002393$ & \multirow{2}{*}{$\begin{array}{c}\text { Applichem, Darmstadt, } \\
\text { Germany }\end{array}$} \\
\hline $\begin{array}{l}\text { Tris Hydrochloride } \\
\text { Molecular Biology } \\
\text { grade }\end{array}$ & Tris- $\mathrm{HCl}$ & A 3452,1000 & \\
\hline $\begin{array}{c}\text { Dithiothreitol - } \\
\text { Electrophoresis Purity }\end{array}$ & DTT & 1610611 & Bio-Rad, USA \\
\hline Sodium Dodecyl Sulfate & SDS & 115377 & Fisher Chemical, USA \\
\hline Sodium Chloride & $\mathrm{NaCl}$ & 1333838 & Fisher Chemical, USA \\
\hline Ponceau S & Ponceau S & & \multirow{4}{*}{$\begin{array}{l}\text { BDH Laboratory } \\
\text { Supplies, UK } \\
\text { BDH Laboratory } \\
\text { Supplies, UK } \\
\end{array}$} \\
\hline Glycerol & Glycerol & K32056060-325 & \\
\hline Sodium Acetate & $\mathrm{NaOAc}$ & $102363 \mathrm{P}$ & \\
\hline Magnesium Chloride & $\mathrm{MgCl}_{2}$ & $101494 \mathrm{~V}$ & \\
\hline IGEPAL® CA-630 & IGEPAL & $\mathrm{I} 3021-100 \mathrm{~mL}$ & \multirow{4}{*}{$\begin{array}{l}\text { Sigma-Aldrich, St } \\
\text { Louis, USA }\end{array}$} \\
\hline Potassium Chloride & $\mathrm{KCl}$ & P9541-500G & \\
\hline Magnesium Chloride & $\mathrm{MgCl}_{2}$ & M8266-100G & \\
\hline $\begin{array}{c}\text { Sodium phosphate } \\
\text { monobasic }\end{array}$ & $\mathrm{NaH}_{2} \mathrm{PO}_{4}$ & S3139-250G & \\
\hline Calcium Chloride & $\mathrm{CaCl}_{2}$ & $1-02378-0500$ & $\begin{array}{c}\text { Merck, Darmstadt, } \\
\text { Germany }\end{array}$ \\
\hline $\begin{array}{l}\text { Sodium Hydroxide } \\
\text { Pellets }\end{array}$ & $\mathrm{NaOH}$ & SO04250500 & Scharlau S.L, Spain \\
\hline Hydrochloric Acid $36 \%$ & $\mathrm{HCl}$ & 1367 & $\begin{array}{c}\text { Thermo Fisher } \\
\text { Scientific, Walthem, } \\
\text { USA }\end{array}$ \\
\hline
\end{tabular}

Table 6.10. Equipment

\begin{tabular}{|c|c|c|c|}
\hline $\begin{array}{l}\text { Equipment } \\
\text { name }\end{array}$ & Common name & Model number & Manufacturer \\
\hline Water still & - & High-Q 103S & High-Q, Wilmette, USA \\
\hline Autoclave & - & Systec DX 65 & Systec, Wattenberg, Germany \\
\hline $\begin{array}{l}\text { NuAire, class II, Type } \\
\text { A2 Biosafety Cabinet }\end{array}$ & Laminar Flow & NU-437-400 & NuAire \\
\hline Minispin ${ }^{\mathrm{TM}}$ Plus & Centrifuge & & Eppendorf \\
\hline $\begin{array}{c}\text { Pipettes P2, P10, P100, } \\
\text { P1000 }\end{array}$ & Not referenced & & Hamilton \\
\hline Stuart ${ }^{\circledR}$ see-saw rocker & $\begin{array}{l}\text { See-saw rocker, } \\
\text { horizontal shaker }\end{array}$ & Model: SSL4 & Bibby Scientific Ltd, \\
\hline $\begin{array}{l}\text { Low-Speed orbital } \\
\text { shaker }\end{array}$ & Orbital rocker & Orbit LS & Labnet \\
\hline Vortex & Vortex & $\begin{array}{l}\text { Wisemix VM- } \\
10\end{array}$ & Wisd Laboratory Instruments \\
\hline Water bath & Water bath & BW-1 & Lab companion- \\
\hline $\mathrm{IKA}^{\mathrm{TM}}, \mathrm{RCT}$ Basic & Heated magnetic stirrer & RCT Basic & IKA \\
\hline Balance & Not referenced & $573-36 \mathrm{NM}$ & Kern \\
\hline $\begin{array}{c}\text { ND-1000 } \\
\text { Spectrophotometer }\end{array}$ & NanoDrop & ND-1000 & NanoDrop Technologies, Inc \\
\hline
\end{tabular}




\section{CHAPTER 7: SUPPLEMENTARY MATERIALS}

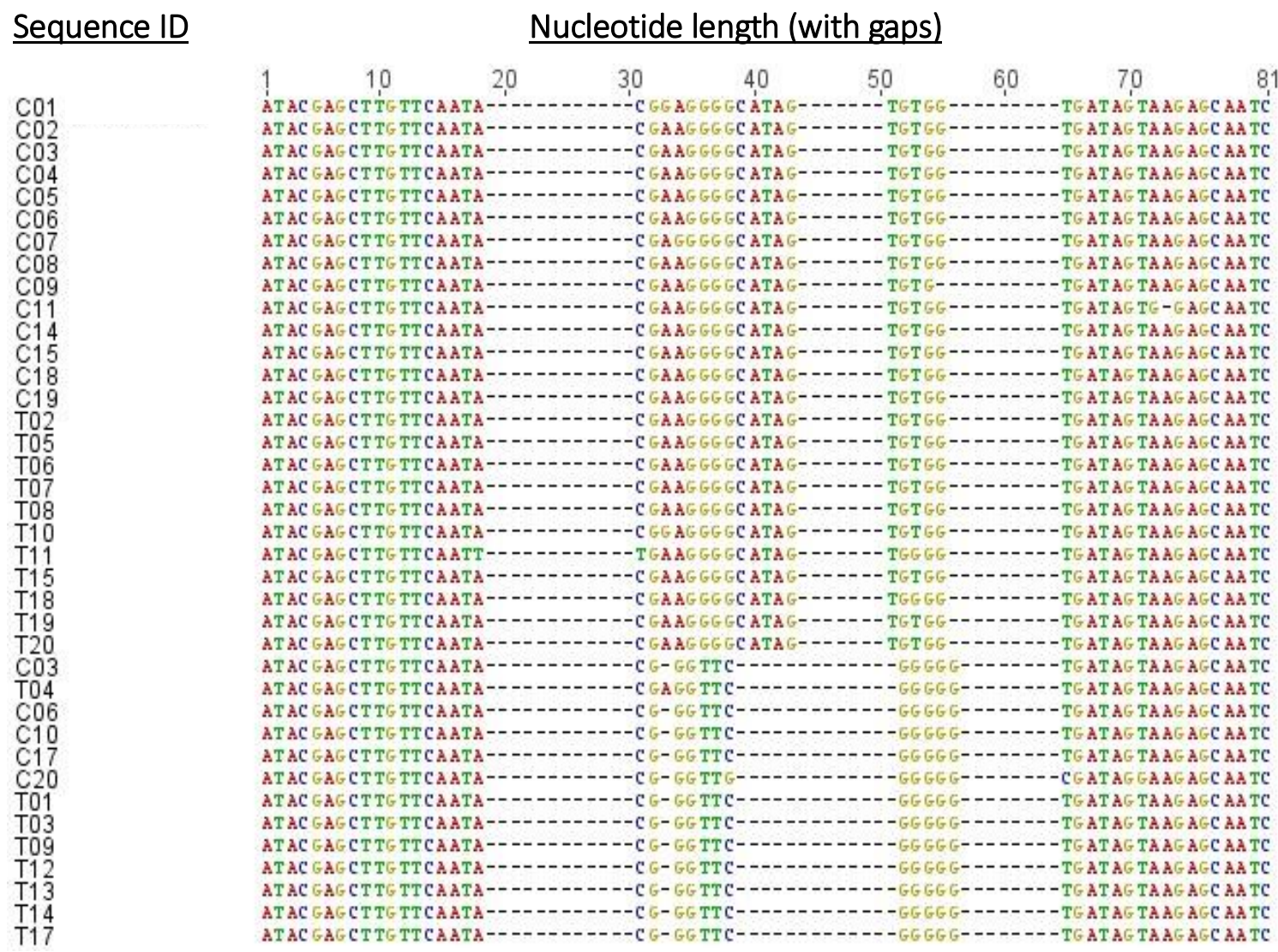

Supplementary Figure 1. Additional sequencing results from SR10. A total of $40^{*}$ Control (C) and Target $(\mathrm{T})$ clones were sequenced aligned using a Clustal W. *Some sequences are not included due to low quality base-calling. 12 additional sequences were presented in Results 3.3. 
Supplementary Table 1. Nucleotide analysis and predicted Gibb's free energy calculation of secondary structure formation. Comparing all BMP15 aptamers against all seven sequences of GDF9-01 to GDF9-07. M-fold calculations performed with DNA folding form using default parameters with the following changes: $100 \mathrm{mM} \mathrm{Na}^{+}, 2 \mathrm{mM} \mathrm{K}^{+}$at both $4^{\circ} \mathrm{C}$ and $23^{\circ} \mathrm{C}$. If more than one structure predicted, the lowest predicted energy was chosen.

\begin{tabular}{|c|c|c|c|c|c|c|}
\hline & \multicolumn{6}{|c|}{ Full sequence } \\
\hline Apt ID & dATP & $\mathrm{dCTP}$ & dGTP & dTTP & G-C content $(\%)$ & $\begin{array}{c}\text { Gibbs energy } \\
(\Delta \mathrm{G}=\mathrm{kcal} / \mathrm{mol})\end{array}$ \\
\hline BMP15-B6 & 17 & 11 & 24 & 23 & 46.1 & -3.89 \\
\hline BMP15-A3 & 18 & 15 & 26 & 17 & 53.9 & -8.67 \\
\hline BMP15-A5 & 18 & 14 & 26 & 18 & 52.6 & -6.29 \\
\hline BMP15-A12 & 19 & 9 & 28 & 20 & 48.70 & -1.39 \\
\hline BMP15-A15 & 17 & 11 & 24 & 24 & 46.1 & -3.89 \\
\hline BMP15-A16 & 18 & 8 & 30 & 20 & 50.00 & -3.16 \\
\hline GDF9-01 & 15 & 7 & 28 & 25 & 46.7 & -2.54 \\
\hline GDF9-02 & 15 & 7 & 28 & 25 & 46.7 & -2.54 \\
\hline GDF9-03 & 17 & 7 & 24 & 27 & 41.3 & -3.44 \\
\hline GDF9-04 & 17 & 7 & 24 & 27 & 32 & -4.43 \\
\hline GDF9-05 & 20 & 12 & 13 & 30 & 33 & -6.53 \\
\hline GDF9-06 & 16 & 6 & 28 & 25 & 45.3 & -1.8 \\
\hline \multirow[t]{2}{*}{ GDF9-07 } & 15 & 8 & 14 & 38 & 29.3 & -1.63 \\
\hline & \multicolumn{6}{|c|}{ Variable region } \\
\hline BMP15-B6 & 5 & 6 & 17 & 12 & 57.5 & $\mathrm{n} / \mathrm{a}$ \\
\hline BMP15-A3 & 6 & 10 & 19 & 5 & 75.5 & $\mathrm{n} / \mathrm{a}$ \\
\hline BMP15-A5 & 6 & 9 & 19 & 6 & 70 & $\mathrm{n} / \mathrm{a}$ \\
\hline BMP15-A12 & 7 & 4 & 21 & 8 & 62.5 & $\mathrm{n} / \mathrm{a}$ \\
\hline BMP15-A15 & 5 & 6 & 17 & 12 & 57.5 & $\mathrm{n} / \mathrm{a}$ \\
\hline BMP15-A16 & 6 & 3 & 23 & 8 & 65 & $\mathrm{n} / \mathrm{a}$ \\
\hline GDF9-01 & 2 & 2 & 21 & 15 & 57.5 & $\mathrm{n} / \mathrm{a}$ \\
\hline GDF9-02 & 2 & 2 & 21 & 15 & 57.5 & $\mathrm{n} / \mathrm{a}$ \\
\hline GDF9-03 & 4 & 2 & 17 & 17 & 47.5 & $\mathrm{n} / \mathrm{a}$ \\
\hline GDF9-04 & 5 & 6 & 6 & 23 & 30 & $\mathrm{n} / \mathrm{a}$ \\
\hline GDF9-05 & 7 & 7 & 6 & 20 & 32.5 & $\mathrm{n} / \mathrm{a}$ \\
\hline GDF9-06 & 3 & 1 & 21 & 15 & 55 & $\mathrm{n} / \mathrm{a}$ \\
\hline GDF9-07 & 2 & 3 & 7 & 28 & 25 & $\mathrm{n} / \mathrm{a}$ \\
\hline
\end{tabular}




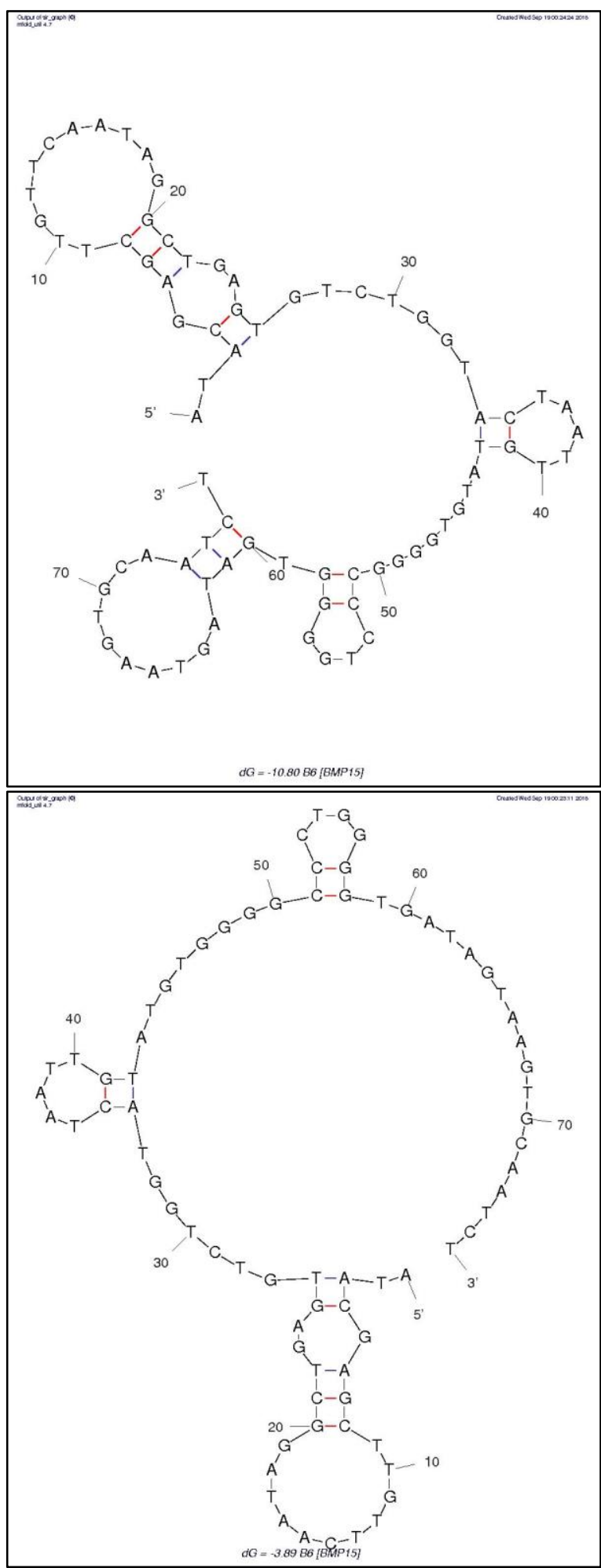

Supplementary Figure 2. 2D structure predictions of BMP15 aptamer at $4^{\circ} \mathrm{C}$ (Lin $e t$ al., 2015). Two-dimensional structures were generated using the $\mathrm{m}$-fold web server. The fulllength aptamer sequences were used as the templates for the $\mathrm{m}$-fold calculations. Calculations performed with 'DNA folding form' using default parameters with the following changes: $100 \mathrm{mM}$ $\mathrm{Na}^{+}, 2 \mathrm{mM} \mathrm{K}^{+}$at $4^{\circ} \mathrm{C}$. Structure with the lowest energy is displayed.

Supplementary Figure 3. 2D structure predictions of BMP15 aptamer at $23^{\circ} \mathrm{C}$ (Lin et al., 2015). Two-dimensional structures were generated using the $\mathrm{m}$-fold web server. The fulllength aptamer sequences were used as the templates for the $\mathrm{m}$-fold calculations. Calculations performed with 'DNA folding form' using default parameters with the following changes: $100 \mathrm{mM}$ $\mathrm{Na}^{+}, 2 \mathrm{mM} \mathrm{K}^{+}$at $23^{\circ} \mathrm{C}$. Structure with the lowest energy is displayed. 


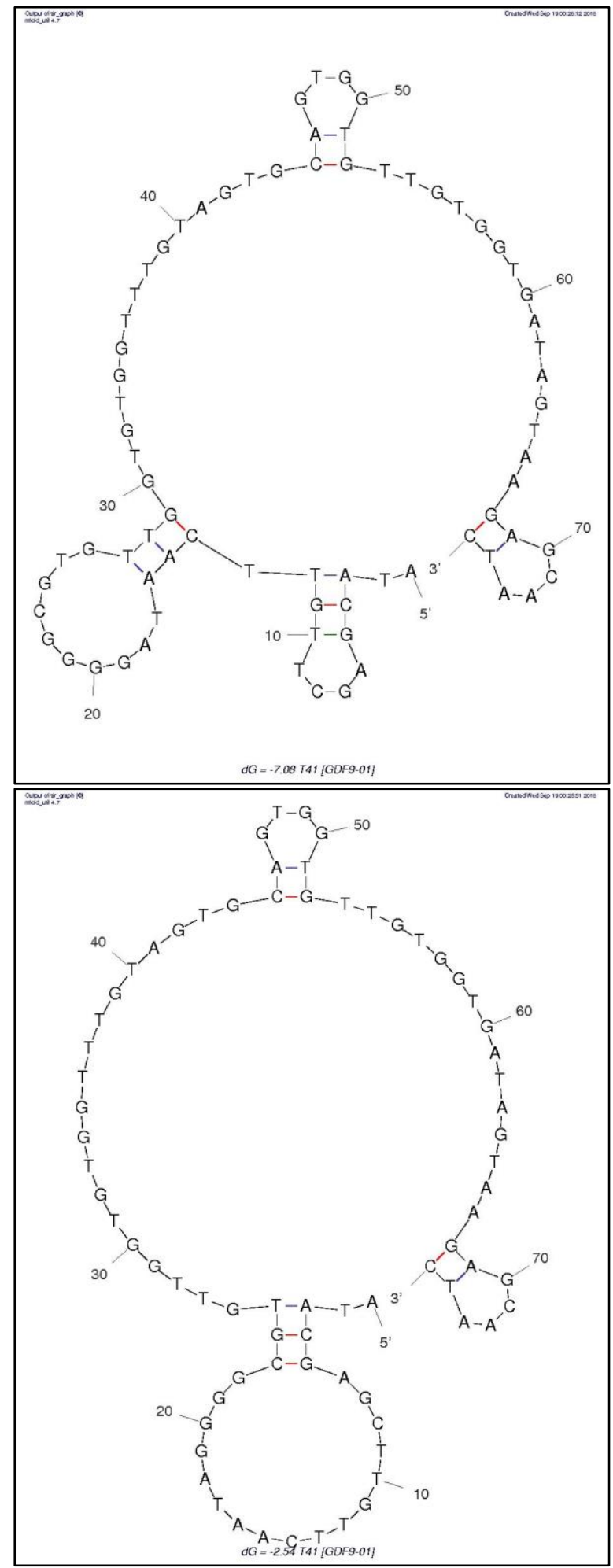

Supplementary Figure 4. 2D structure predictions of GDF9-01 aptamer at $4^{\circ} \mathrm{C}$. Twodimensional structures were generated using the $\mathrm{m}$-fold web server. The full-length aptamer sequences were used as the templates for the $\mathrm{m}$ fold calculations. Calculations performed with 'DNA folding form' using default parameters with the following changes: $100 \mathrm{mM} \mathrm{Na}^{+}, 2 \mathrm{mM} \mathrm{K}^{+}$at $4^{\circ} \mathrm{C}$. Structure with the lowest energy is displayed.

\section{Supplementary Figure 5. 2D structure} predictions of GDF9-01 aptamer at $23^{\circ} \mathrm{C}$.

Two-dimensional structures were generated using the $\mathrm{m}$-fold web server. The full-length aptamer sequences were used as the templates for the $\mathrm{m}$ fold calculations. Calculations performed with 'DNA folding form' using default parameters with the following changes: $100 \mathrm{mM} \mathrm{Na}^{+}, 2 \mathrm{mM}$ $\mathrm{K}^{+}$at $23^{\circ} \mathrm{C}$. Structure with the lowest energy is displayed. 


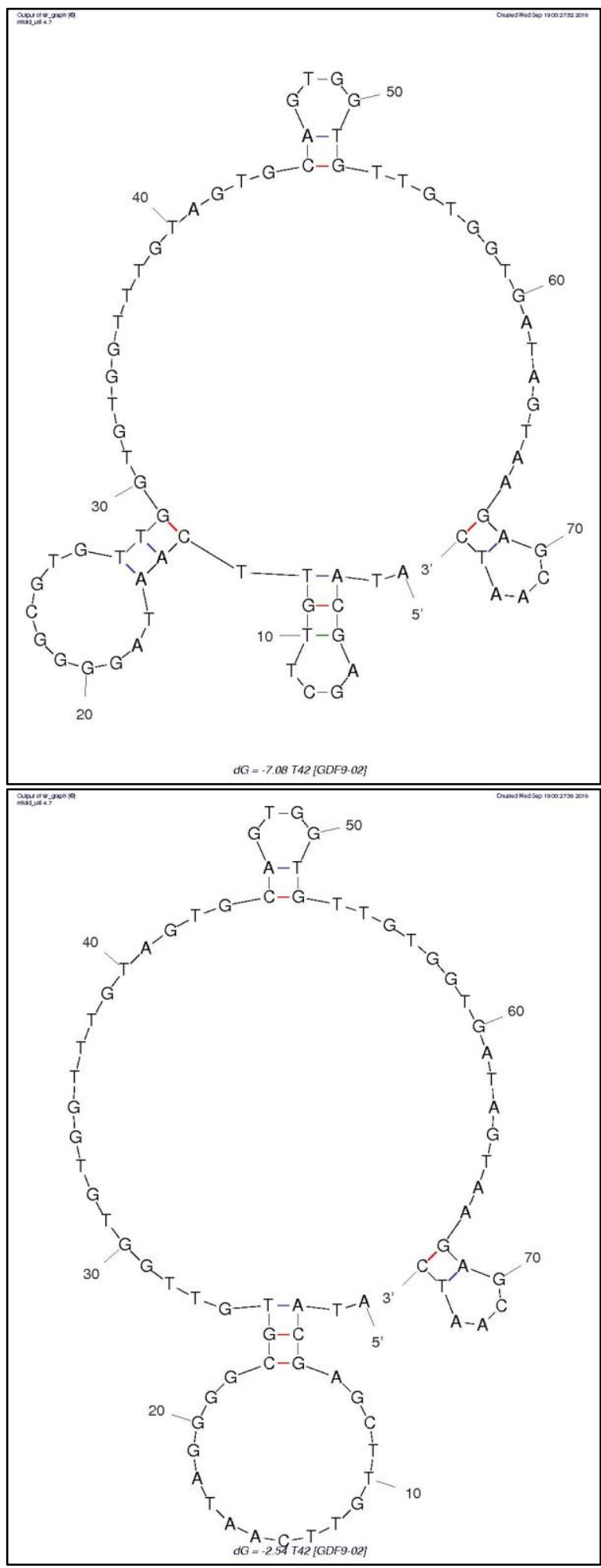

Supplementary Figure 6. 2D structure predictions of GDF9-02 aptamer at $4^{\circ} \mathrm{C}$. Twodimensional structures were generated using the $\mathrm{m}$-fold web server. The full-length aptamer sequences were used as the templates for the $\mathrm{m}$ fold calculations. Calculations performed with 'DNA folding form' using default parameters with the following changes: $100 \mathrm{mM} \mathrm{Na}^{+}, 2 \mathrm{mM}$ $\mathrm{K}^{+}$at $4^{\circ} \mathrm{C}$. Structure with the lowest energy is displayed.

Supplementary Figure 7. 2D structure predictions of GDF9-02 aptamer at $23^{\circ} \mathrm{C}$. Two-dimensional structures were generated using the $\mathrm{m}$-fold web server. The full-length aptamer sequences were used as the templates for the $\mathrm{m}$ fold calculations. Calculations performed with 'DNA folding form' using default parameters with the following changes: $100 \mathrm{mM} \mathrm{Na}^{+}, 2 \mathrm{mM}$ $\mathrm{K}^{+}$at $23^{\circ} \mathrm{C}$. Structure with the lowest energy is displayed. 


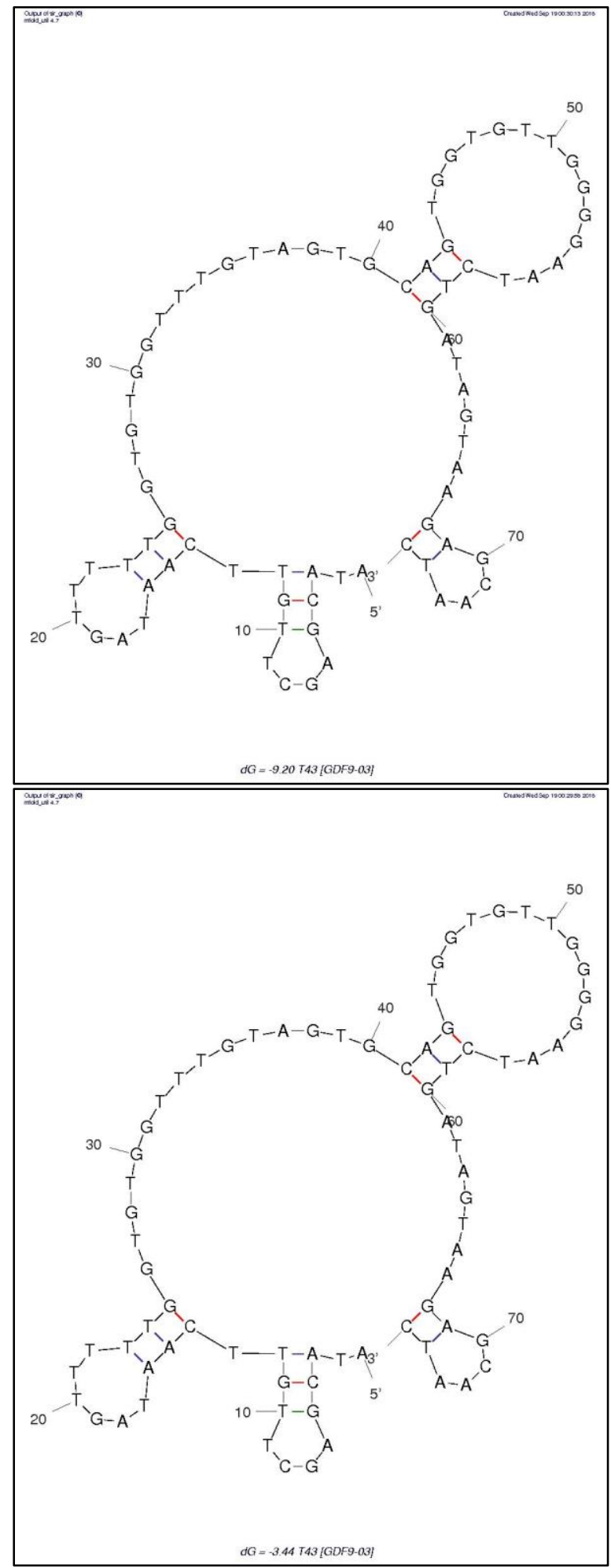

Supplementary Figure 8. 2D structure predictions of GDF9-03 aptamer at $4^{\circ} \mathrm{C}$. Twodimensional structures were generated using the $\mathrm{m}$-fold web server. The full-length aptamer sequences were used as the templates for the $\mathrm{m}$ fold calculations. Calculations performed with 'DNA folding form' using default parameters with the following changes: $100 \mathrm{mM} \mathrm{Na}^{+}, 2 \mathrm{mM} \mathrm{K}^{+}$at $4^{\circ} \mathrm{C}$. Structure with the lowest energy is displayed.

Supplementary Figure 9. 2D structure predictions of GDF9-03 aptamer at $23^{\circ} \mathrm{C}$. Twodimensional structures were generated using the $\mathrm{m}$-fold web server. The full-length aptamer sequences were used as the templates for the $\mathrm{m}$ fold calculations. Calculations performed with 'DNA folding form' using default parameters with the following changes: $100 \mathrm{mM} \mathrm{Na}^{+}, 2 \mathrm{mM} \mathrm{K}^{+}$at $23^{\circ} \mathrm{C}$. Structure with the lowest energy is displayed. 


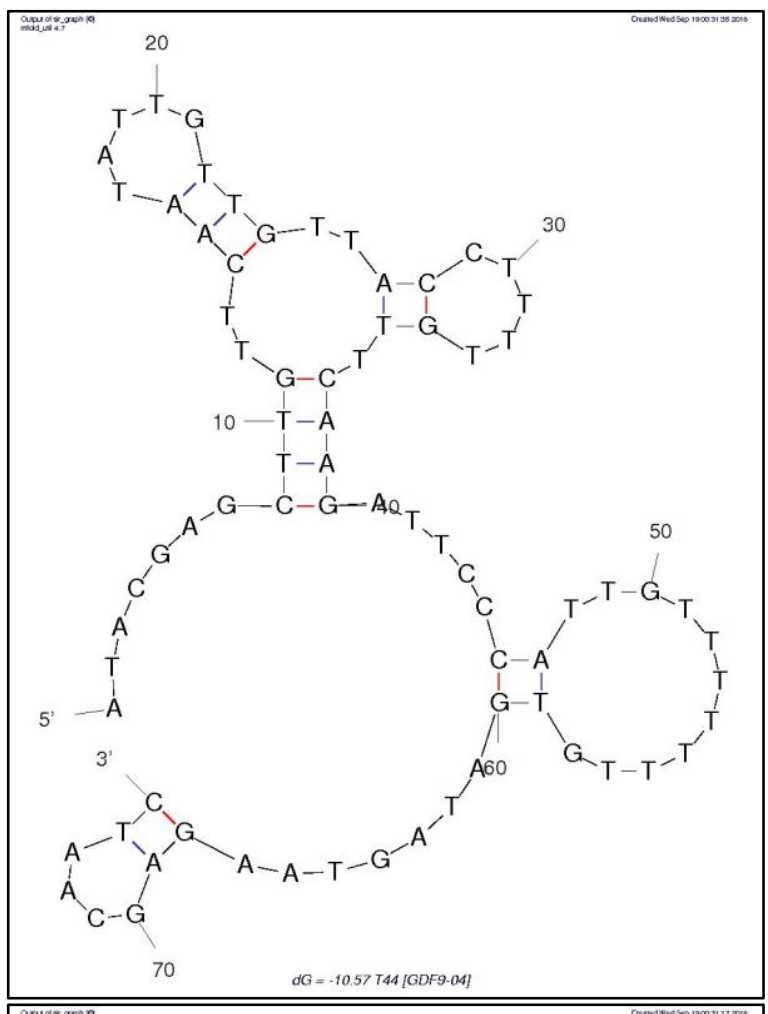

Supplementary Figure 10. 2D structure predictions of GDF9-04 aptamer at $4^{\circ} \mathrm{C}$. Twodimensional structures were generated using the $\mathrm{m}$-fold web server. The full-length aptamer sequences were used as the templates for the $\mathrm{m}$ fold calculations. Calculations performed with 'DNA folding form' using default parameters with the following changes: $100 \mathrm{mM} \mathrm{Na}^{+}, 2 \mathrm{mM} \mathrm{K}^{+}$at $4^{\circ} \mathrm{C}$. Structure with the lowest energy is displayed.

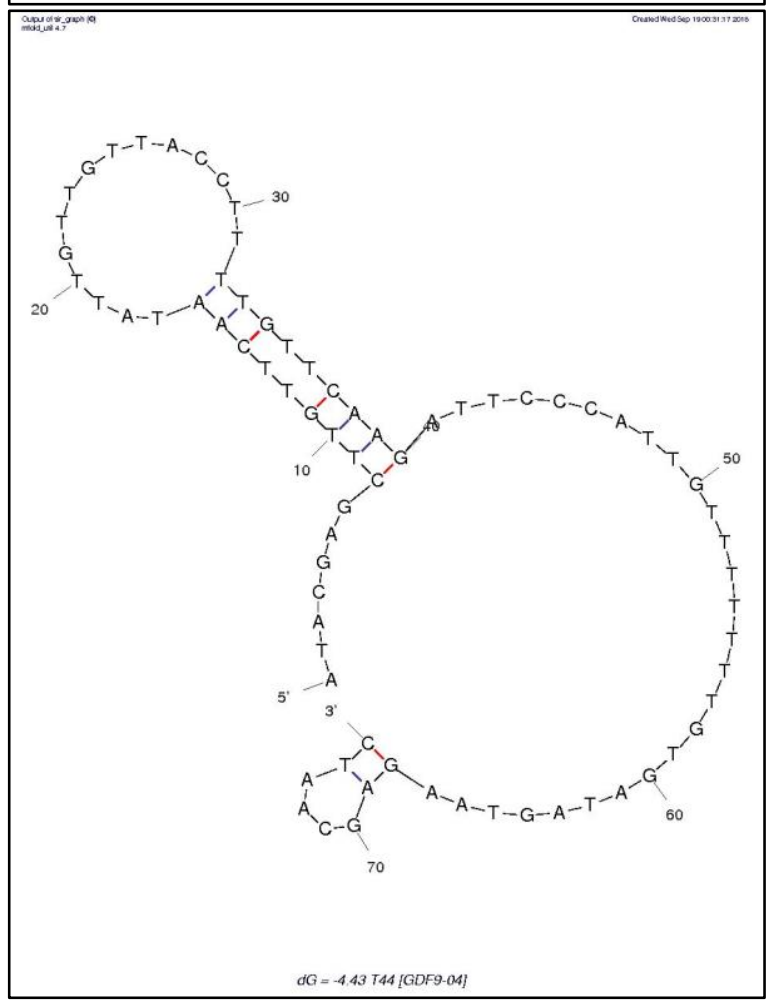

Supplementary Figure 11. 2D structure predictions of GDF9-04 aptamer at $23^{\circ} \mathrm{C}$. Twodimensional structures were generated using the $\mathrm{m}$-fold web server. The full-length aptamer sequences were used as the templates for the $\mathrm{m}$ fold calculations. Calculations performed with 'DNA folding form' using default parameters with the following changes: $100 \mathrm{mM} \mathrm{Na}^{+}, 2 \mathrm{mM} \mathrm{K}^{+}$at $23^{\circ} \mathrm{C}$. Structure with the lowest energy is displayed. 


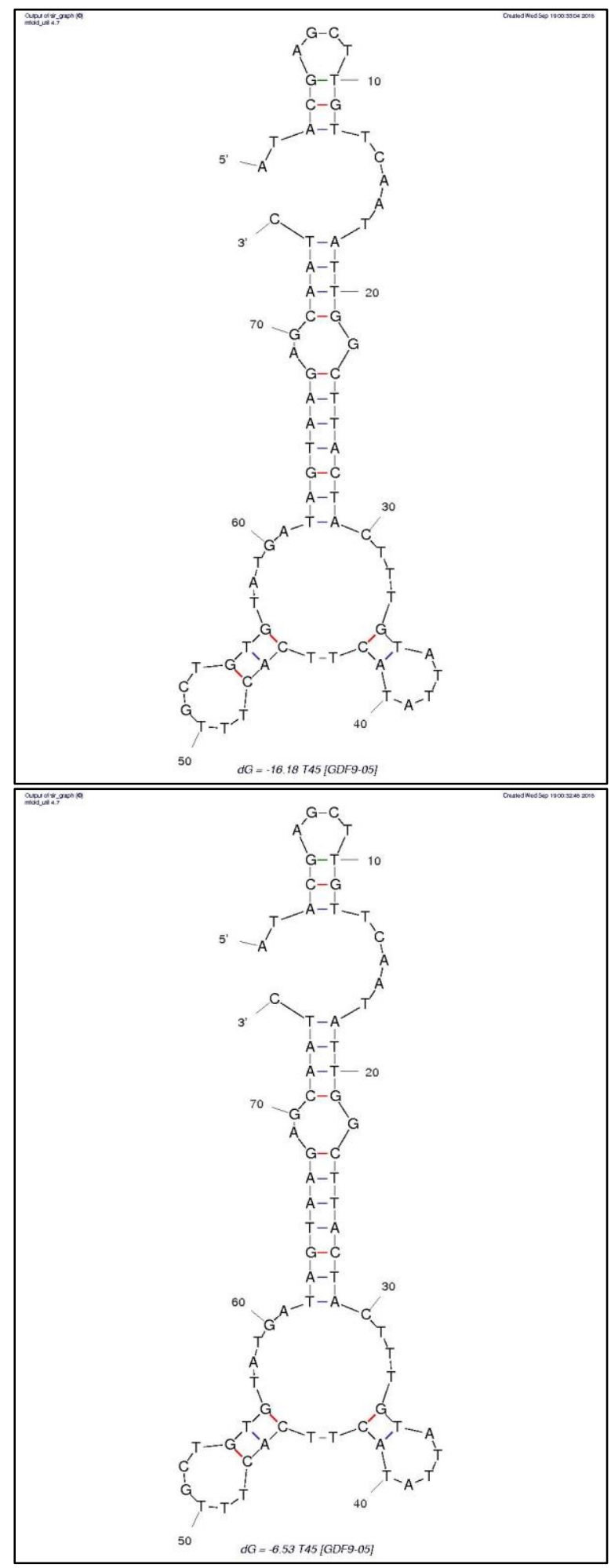

Supplementary Figure 12. 2D structure predictions of GDF9-05 aptamer at $4^{\circ} \mathrm{C}$. Twodimensional structures were generated using the $\mathrm{m}$-fold web server. The full-length aptamer sequences were used as the templates for the $\mathrm{m}$ fold calculations. Calculations performed with 'DNA folding form' using default parameters with the following changes: $100 \mathrm{mM} \mathrm{Na}^{+}, 2 \mathrm{mM} \mathrm{K}^{+}$at $4^{\circ} \mathrm{C}$. Structure with the lowest energy is displayed.

Supplementary Figure 13. 2D structure predictions of GDF9-05 aptamer at $23^{\circ} \mathrm{C}$. Twodimensional structures were generated using the $\mathrm{m}$-fold web server. The full-length aptamer sequences were used as the templates for the $\mathrm{m}$ fold calculations. Calculations performed with 'DNA folding form' using default parameters with the following changes: $100 \mathrm{mM} \mathrm{Na}^{+}, 2 \mathrm{mM} \mathrm{K}^{+}$at $23^{\circ} \mathrm{C}$. Structure with the lowest energy is displayed. 


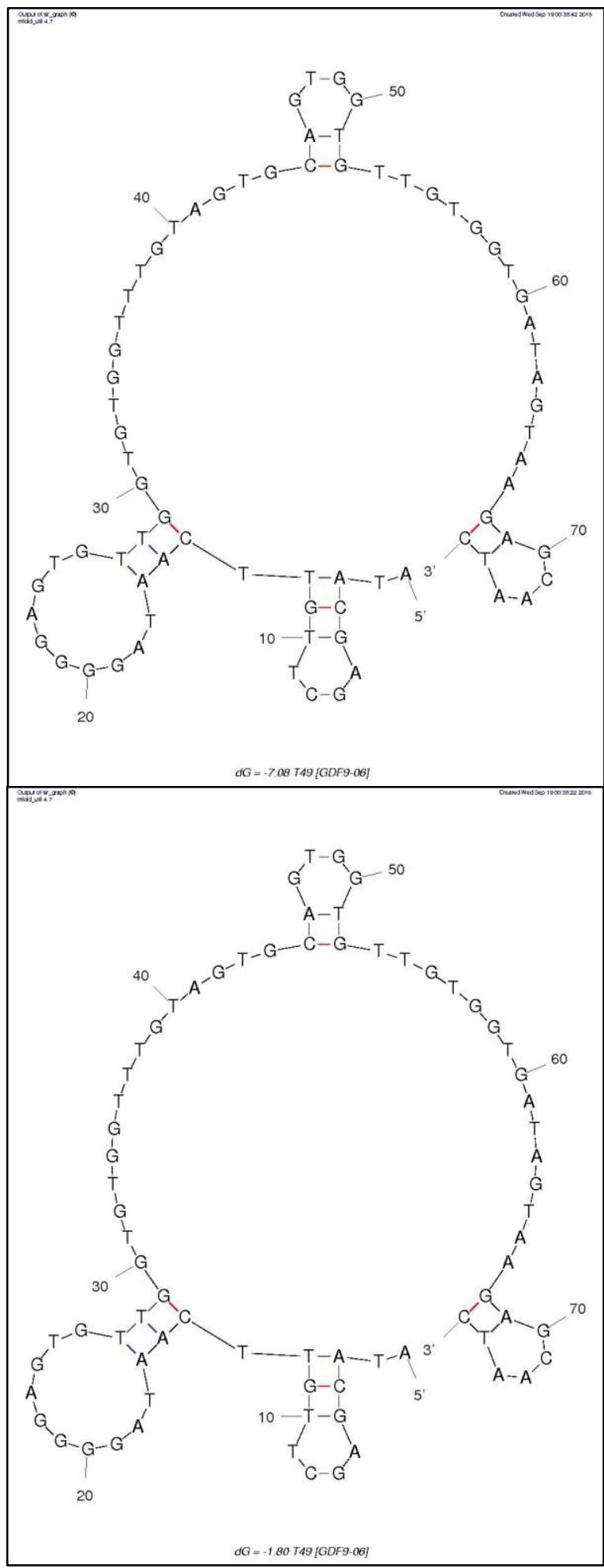

Supplementary Figure 14. 2D structure predictions of GDF9-06 aptamer at $4^{\circ} \mathrm{C}$. Twodimensional structures were generated using the $\mathrm{m}$-fold web server. The full-length aptamer sequences were used as the templates for the $\mathrm{m}$ fold calculations. Calculations performed with 'DNA folding form' using default parameters with the following changes: $100 \mathrm{mM} \mathrm{Na}^{+}, 2 \mathrm{mM}$ $\mathrm{K}^{+}$at $4^{\circ} \mathrm{C}$. Structure with the lowest energy is displayed.

Supplementary Figure 15. 2D structure predictions of GDF9-06 aptamer at $23^{\circ} \mathrm{C}$. Two-dimensional structures were generated using the $\mathrm{m}$-fold web server. The full-length aptamer sequences were used as the templates for the $\mathrm{m}$ fold calculations. Calculations performed with 'DNA folding form' using default parameters with the following changes: $100 \mathrm{mM} \mathrm{Na}^{+}, 2 \mathrm{mM}$ $\mathrm{K}^{+}$at $23^{\circ} \mathrm{C}$. Structure with the lowest energy is displayed. 


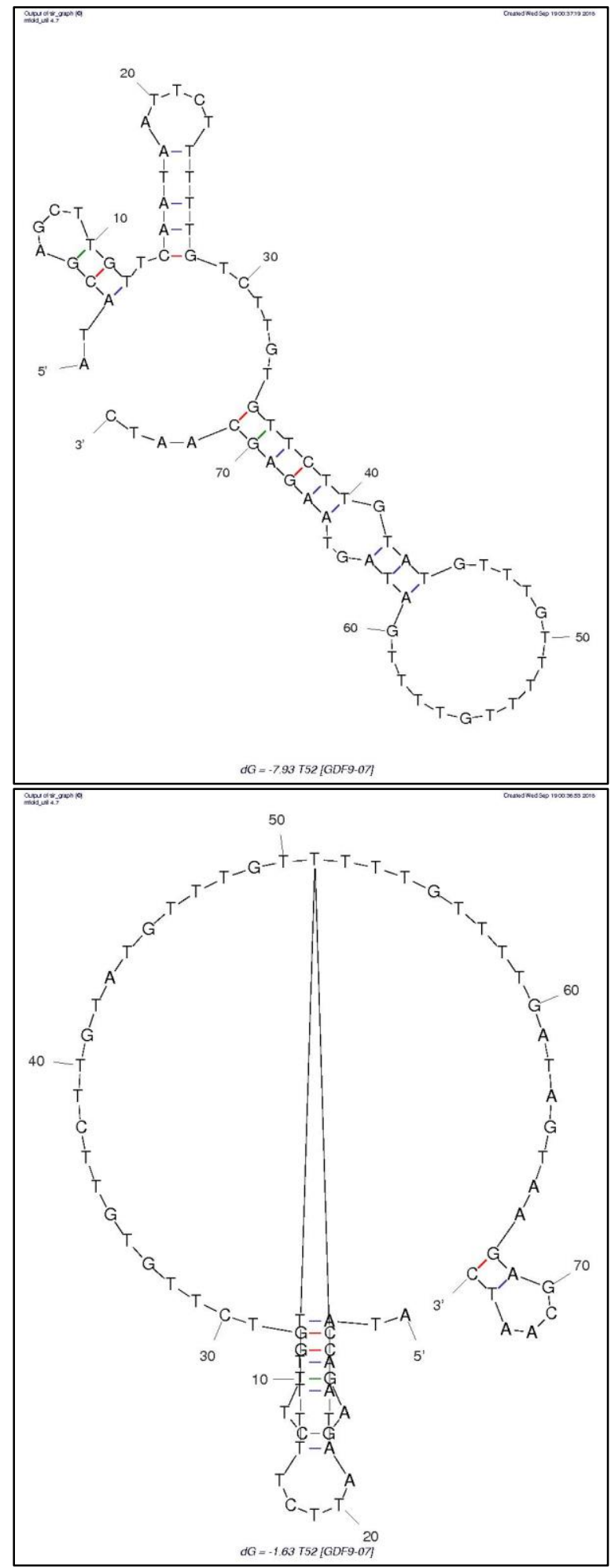

Supplementary Figure 16. 2D structure predictions of GDF9-07 aptamer at $4^{\circ} \mathrm{C}$. Twodimensional structures were generated using the $\mathrm{m}$-fold web server. The full-length aptamer sequences were used as the templates for the $\mathrm{m}$ fold calculations. Calculations performed with 'DNA folding form' using default parameters with the following changes: $100 \mathrm{mM} \mathrm{Na}^{+}, 2 \mathrm{mM}$ $\mathrm{K}^{+}$at $4^{\circ} \mathrm{C}$. Structure with the lowest energy is displayed.

Supplementary Figure 17. 2D structure predictions of GDF9-07 aptamer at $23^{\circ} \mathrm{C}$. Twodimensional structures were generated using the $\mathrm{m}$-fold web server. The full-length aptamer sequences were used as the templates for the $\mathrm{m}$ fold calculations. Calculations performed with 'DNA folding form' using default parameters with the following changes: $100 \mathrm{mM} \mathrm{Na}^{+}, 2 \mathrm{mM} \mathrm{K}^{+}$at $23^{\circ} \mathrm{C}$. Structure with the lowest energy is displayed. 


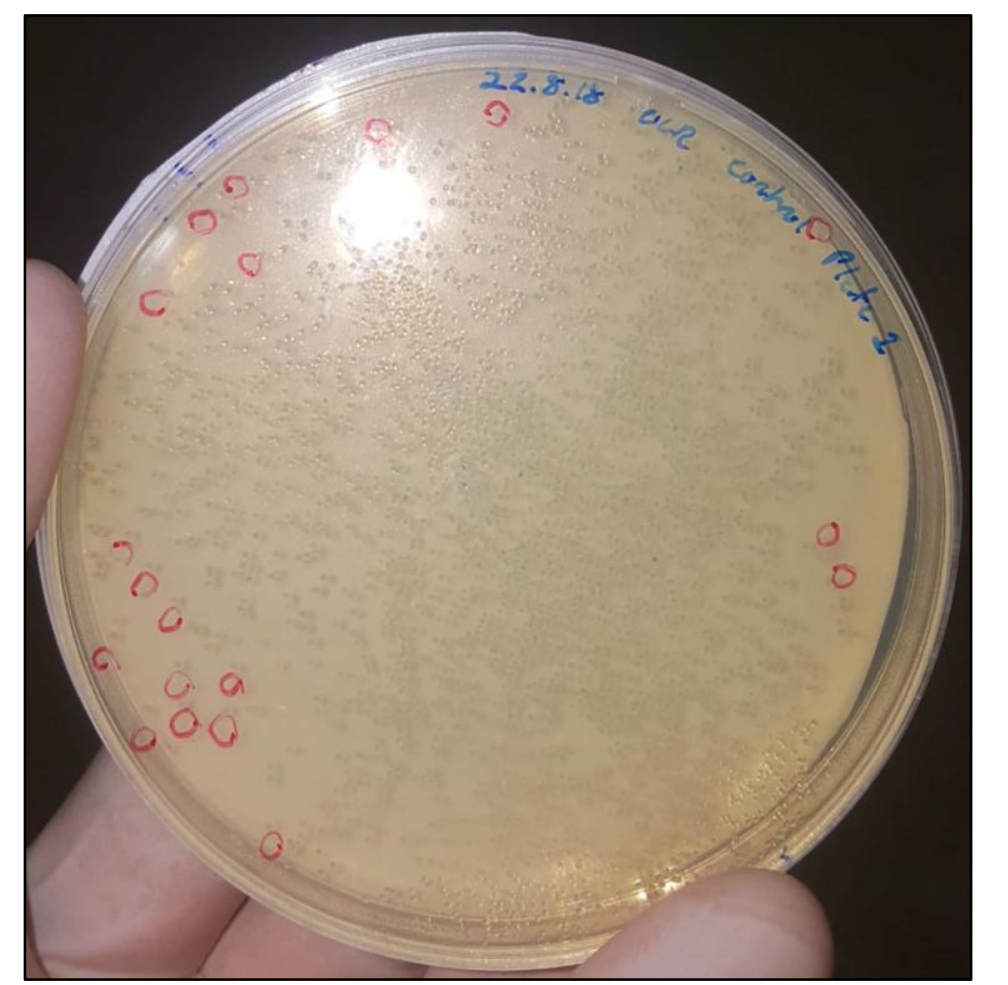

A

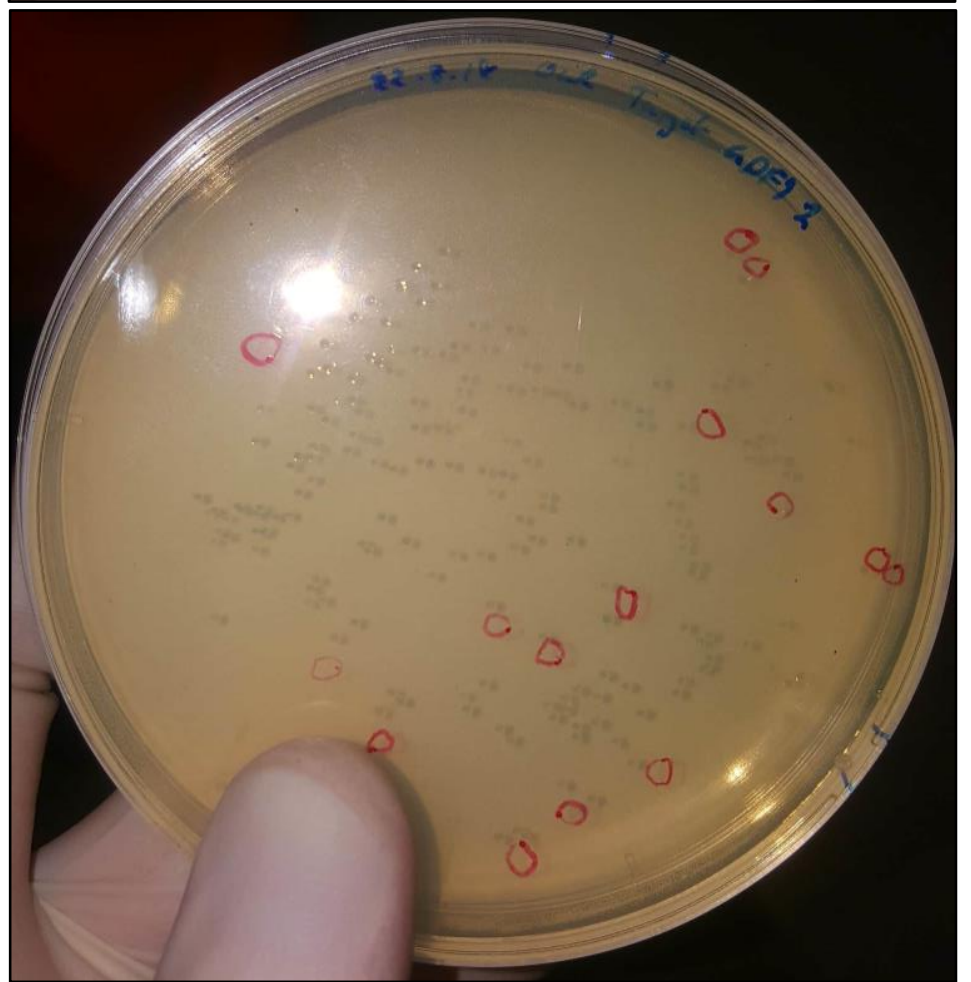

B

Supplementary Figure 18. Agar plated DH5- $\alpha$ cells for colony selection. White colonies were aseptically taken and cultured for DNA sequencing (circled in red). Blue colonies were not selected. (A) Control library (B) Target library. 


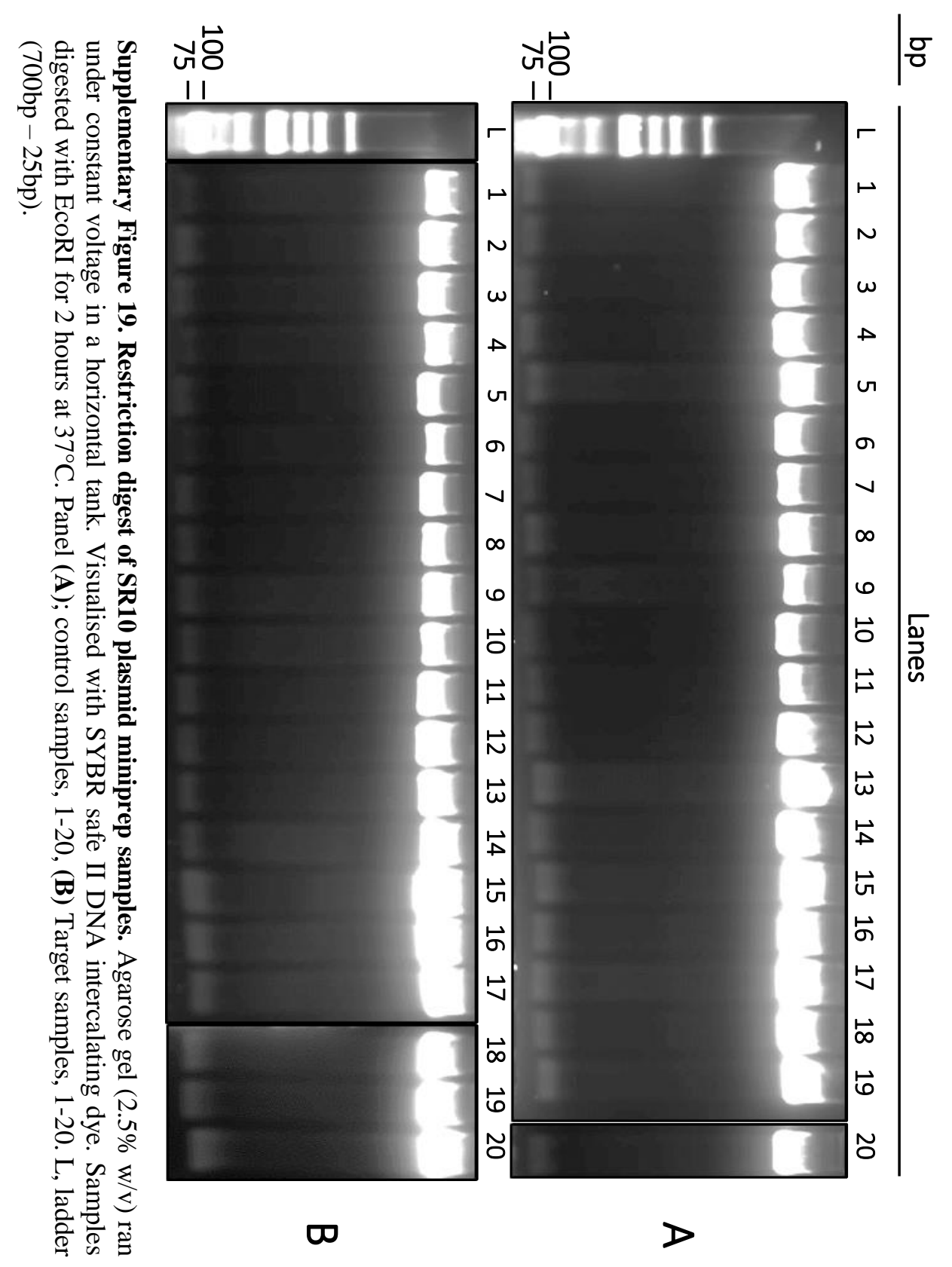


Supplementary Table 2. ACN concentration gradients over time for HPLC. Showing acetonitrile (ACN) concentration range at the start and finish of each time period during the HPLC purification.

\begin{tabular}{|c|c|c|}
\hline $\begin{array}{c}\text { Total time } \\
(\mathbf{m i n})\end{array}$ & $\begin{array}{c}\text { Time at fixed } \\
\text { ACN \% (min) }\end{array}$ & $\begin{array}{c}\text { ACN percentage } \\
\text { Range (\%, v/v) }\end{array}$ \\
\hline 0 & 0 & 6 \\
\hline 10 & 10 & 6 \\
\hline 15 & 5 & $6-30$ \\
\hline 45 & 30 & $30-60$ \\
\hline 46 & 1 & $60-80$ \\
\hline 49 & 3 & $80-80$ \\
\hline 50 & 1 & $80-95$ \\
\hline 52 & 2 & $95-95$ \\
\hline 53 & 1 & $95-6$ \\
\hline 55 & 2 & $6-6$ \\
\hline 60 & END & $6-6$ \\
\hline
\end{tabular}

Supplementary Table 3. Step-by-step IMAC protocol with Buffers. Buffers listed in Appendix 1.

\begin{tabular}{|c|c|c|c|}
\hline Step & Function & Volume & Buffer \\
\hline 0 & Add Ni-NTA Agarose & $200 \mu \mathrm{L}$ & $\mathrm{n} / \mathrm{a}$ \\
\hline 1 & \multirow{3}{*}{$\begin{array}{c}\mathrm{Ni}-\mathrm{NTA} \\
\text { washing/preparation }\end{array}$} & $10 \mathrm{~mL}$ & Distilled $\mathrm{H}_{2} \mathrm{O}$ \\
\hline 2 & & $5 \mathrm{~mL}$ & W5 \\
\hline 3 & & $5 \mathrm{~mL}$ & W5 \\
\hline 4 & $\begin{array}{l}\text { Sample/Ni-NTA co- } \\
\text { incubation }\end{array}$ & \multirow[t]{2}{*}{$200 \mathrm{~mL}$} & $\begin{array}{c}\text { Expression media } \\
\text { containing: 50mM Tris- } \\
\mathrm{HCL}(\mathrm{pH} 7.4), 300 \mathrm{mM} \\
\mathrm{NaCl}, 5 \mathrm{mM} \text { Immidazole }\end{array}$ \\
\hline 5 & & & $\begin{array}{c}\text { Roatating mixer for } 2 \\
\text { hours at } 4^{\circ} \mathrm{C}\end{array}$ \\
\hline 6 & Ni-NTA wash & $2 \mathrm{~mL}$ & W10 \\
\hline 7 & Ni-NTA wash & $2 \mathrm{~mL}$ & W20 \\
\hline $8-22$ & Elution 1 & $1 \mathrm{~mL}$ & E1 (5 minute incubation) \\
\hline 23 & Ni-NTA wash & $2 \mathrm{~mL}$ & W20 \\
\hline 24 & \multirow{3}{*}{ Elution 2} & $2 \mathrm{~mL}$ & E2 \\
\hline 25 & & $2 \mathrm{~mL}$ & E2 \\
\hline 26 & & $2 \mathrm{~mL}$ & E2 \\
\hline 27 & Ni-NTA wash & $2 \mathrm{~mL}$ & W0 \\
\hline 28 & Ni-NTA wash & $2 \mathrm{~mL}$ & W0 \\
\hline 29 & $\begin{array}{c}\text { Prepare Ni-NTA for } \\
\text { Storage }\end{array}$ & $2 \mathrm{~mL}$ & W0 (70\% ethanol, v/v) \\
\hline
\end{tabular}

